\title{
Análise de Perfis com Dados Incompletos
}

\author{
Sarita Papescu
}

\author{
DISSERTAÇÃO APRESENTADA AO \\ INSTITUTO DE MATEMÁTICA E ESTATíSTICA \\ DA UNIVERSIDADE DE SÃO PAULO \\ PARA OBTENÇÃO DO GRAU DE MESTRE \\ EM ESTATÍSTICA \\ Área de Concentraçào: Estatística \\ Orientador: Prof. Dr. Julio da Motta Singer
}

- São Paulo, Janeiro de 1995 - 


\title{
Análise de Perfis com \\ Dados Incompletos
}

\author{
Este exemplar corresponde à redação \\ final da dissertação devidamente corrigida \\ e apresentada por \\ Sarita Papescu \\ e aprovada pela Comissão Julgadora.
}

São Paulo, 19 de Janeiro de 1995.

Banca Examinadora:

Prof. Dr. Julio M. Singer (Orientador) - IME-USP

Prof. Dr. Dalton F. Andrade ～- IME-USP

Prof. Dr. Adolpho Walter P. Canton - FEA-USP 


\title{
Sumário
}

A análise de perfis é uma técnica bastante utilizada na análise de dados longitudinais e implementada em grande parte dos programas estatísticos conhecidos. Entretanto, na presença de dados incompletos surgem problemas computacionais, uma vez que tais programas acabam por eliminar todos os vetores de observações individuais que possuam algum dado não-observado. Neste trabalho são apresentados os procedimentos usuais de análise sob o enfoque de mínimos quadrados e máxima verossimilhança aplicados a dados completos e incompletos. Para essa última situação sugerimos uma análise baseada no método de Bartlett. Os programas estatísticos mais comuns são utilizados para análise de um exemplo numérico.

\begin{abstract}
Profile analysis is a widely used technique in longitudinal data analysis and it is implemented in the majority of statistical packages. In the presence of incomplete data, however, several computational problems arise, since these packages eliminate the entire vector of individual observations that contain any non-observed data. In this work we present analysis procedures using the least squares and maximum likelihood approaches applied to both complete and incomplete data. For this last situation we sugest an analysis based on Bartlett's method. The most common statistical packages are used to analyse a numerical example.
\end{abstract}




\section{Agradecimentos}

Acima de tudo, gostaria de agradecer sinceramente ao Prof. Julio Singer pela sua constante dedicação e presença.

Também devo muito à pessoa que durante todos esses anos de estudos me acompanhou e me ouviu. Obrigada, Cris!

Aos professores Dalton Andrade e Paulo Santana agradeço pela atenção, sugestões e críticas ao meu trabalho.

Como não poderia deixar de ser, agradeço àqueles que sempre fizeram e sempre farăo parte da minha vida, por serem especiais e me apoiarem nas minhas opções. Obrigada a meus pais Rebeca e Jaques, à Irma, ao Michel e à Shê. Obrigada Má pelas dicas.

Um agradecimento afetivo à Rebeca Scherer que deu o ponta-pé inicial.

Por fim, agradeço à CAPES pelo suporte financeiro. 


\section{Conteúdo}

1 Conceitos básicos 1

1.1 Introdução . . . . . . . . . . . . . . . . . . . . 1

1.2 Mecanismos de Não-Resposta . . . . . . . . . . . . . . . . . . 11

1.3 O Modelo Linear Geral . . . . . . . . . . . . . . . . . . . . . . . . 16

2 Análise através do método de Mínimos Quadrados 22

2.1 Dados Completos . . . . . . . . . . . . . . . . . . . . . . 22

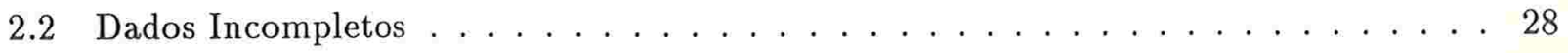

2.3 O Método de Bartlett . . . . . . . . . . . . . . . . . . 35

3 Análise através do método de Máxima Verossimilhança 43

3.1 Modelos para a estrutura de covariância . . . . . . . . . . . . . . . . . 44

3.2 Estimação e Testes de Hipóteses . . . . . . . . . . . . . . . . . . . . . 47

4 Implementação Computacional e Exemplos $\quad 57$

4.1 Comparação entre o método de Bartlett e o procedimento usual que descarta os indivíduos com dados incompletos . . . . . . . . . . . . . . . 58

4.2 Alternativas de implementação computacional para análise utilizando o método de

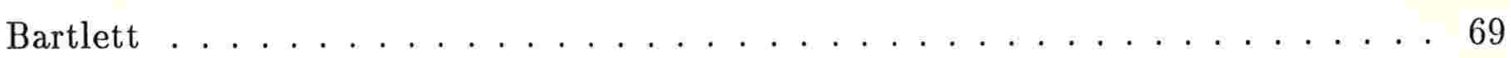




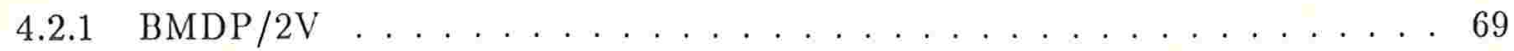

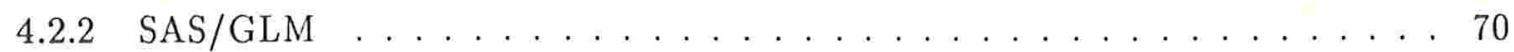

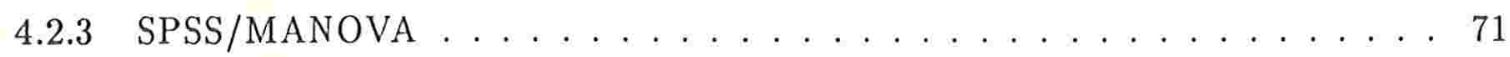

4.3 Implementação computacional para Máxima Verossimilhança - BMDP/5V . . . . . 72

$\begin{array}{lll}\text { A Demonstrações associadas à Seção } 2.3 & 75\end{array}$

$\begin{array}{ll}\text { B Tabelas e programas associados ao Capítulo } 4 & 79\end{array}$ 


\section{Capítulo 1}

\section{Conceitos básicos}

\subsection{Introdução}

O termo medidas repetidas é usado para descrever situações nas quais uma ou mais características (variáveis resposta) são observadas nas mesmas unidades amostrais em várias ocasiões de avaliação. As unidades amostrais (também denotadas aqui por indivíduos) podem ser pessoas, animais, equipamentos, espaços geográficos, etc. De uma forma geral, elas encontram-se classificadas em diferentes tratamentos definidos por um ou mais fatores, como procedência, sexo, idade, tipo de material, etc. As ocasiões de avaliação geralmente correspondem a diferentes tempos, porém, podem estar associadas a outra dimensão; por exemplo, em um experimento onde se pretende estudar a resistência de cabos de aço, medidas de força são tomadas em vários pontos da sua extensão e neste caso, a distância a um determinado ponto do cabo representa a dimensão ao longo da qual são realizadas as observações. Ainda, em um experimento onde as medidas são obtidas sob diferentes dosagens de uma determinada droga, a dimensão de interesse é a dosagem.

Há casos onde várias características são observadas em cada ocasião de avaliação, mas neste trabalho iremos considerar somente situações onde uma única característica é avaliada. Além disso, enfocaremos somente os casos envolvendo medidas contínuas. Agresti (1990, cap.11) discute casos 
onde a variável resposta é discreta.

Com relação à ordem em que as observaçōes são obtidas, os estudos com medidas repetidas envolvem basicamente dois tipos de situaçōes: no primeiro, as várias ocasiōes de avaliação podem ser aleatorizadas, como no caso dos cabos de aço citado há pouco, onde seria possível fazer primeiramente a medida correspondente a $45 \mathrm{~cm}$ e depois aquela correspondente a $20 \mathrm{~cm}$, etc.; o outro tipo de situação é aquele onde as medidas se dão sequencialmente ao longo da dimensão especificada; isto ocorre, por exemplo, sempre que a dimensão em questão é o tempo. A esse segundo tipo de situação dá-se o nome de estudo longitudinal, ao qual daremos maior enfoque nesse trabalho.

Embora teoricamente um número máximo de ocasiões de avaliação em um estudo longitudinal não seja estipulado, na prática, a aplicação das técnicas usuais fica prejudicada devido a aspectos computacionais quando esse número é muito grande (isto é, da ordem de 30 ou mais). Para esses casos, os métodos conhecidos na literatura estatística por análise de séries temporais são mais apropriados (para detalhes consulte, por exemplo, Morettin e Toloi (1985) ou ainda Shumway (1988)).

Uma outra classe de estudos que também envolve um conjunto de observações em cada uma das unidades amostrais é conhecida como estudos de sobrevivência. Nesse caso, apesar de as unidades amostrais serem observadas sequencialmente, o interesse se concentra na avaliação dos tempos para a ocorrência de um certo evento, como por exemplo, falha de um determinado equipamento ou morte de um paciente. Essa classe de estudos não será incluída neste trabalho mas o leitor interessado pode consultar Kalbfleisch e Prentice (1980) ou Elandt-Johnson e Johnson (1980), entre outros.

Estudos longitudinais com planejamento balanceado com relação às ocasiões de avaliação são aqueles planejados de forma que cada um dos $N$ indivíduos seja observado em todas as $T$ ocasiões de avaliação, de modo que o formato básico dos dados pode ser concisamente identificado por uma matriz com $N$ linhas correspondentes aos indivíduos e $T$ colunas correspondentes às ocasiões de avaliação. Em geral, os $N$ indivíduos encontram-se alocados a $G$ tratamentos, sendo que o número de indivíduos pode ser diferente para cada tratamento. 
Exemplo 1.1: (Este é um exemplo artificial que será utilizado no decorrer do trabalho para ilustrar os conceitos.)

Em um experimento hipotético, seis indivíduos alocados a dois tratamentos diferentes foram observados em três tempos consecutivos com relação a uma determinada resposta, gerando o seguinte conjunto de dados $(N=6, T=3, G=2)$ :

Tabela 1.1: Dados hipotéticos

\begin{tabular}{ccrrr}
\hline Tratamento & Indivíduo & $T_{1}$ & $T_{2}$ & $T_{3}$ \\
\hline 1 & 1 & 23 & 20 & 15 \\
1 & 2 & 20 & 17 & 12 \\
1 & 3 & 25 & 19 & 17 \\
2 & 1 & 11 & 11 & 10 \\
2 & 2 & 10 & 12 & 7 \\
2 & 3 & 12 & 7 & 5 \\
\hline
\end{tabular}

Exemplo 1.2: (Crowder e Hand (1990))

Em um estudo nutricional três grupos de ratos foram submetidos a diferentes dietas e seus pesos (em gramas) foram observados em sete ocasiões ao longo de sete semanas. Os dados estão reproduzidos na Tabela 1.2. O mesmo número de medidas foi previsto para todos os animais e todos os dados foram obtidos, o que caracteriza um estudo longitudinal balanceado com relação às ocasiões de avaliação (cuja dimensão é o tempo). Observe que aqui o estudo é desbalanceado quanto ao número de indivíduos por tratamento. 
Tabela 1.2: Pesos de ratos $(\mathrm{g})$

\begin{tabular}{ccccccccc}
\hline & & & \multicolumn{7}{c}{ Dia } \\
Dieta & Rato & 1 & 8 & 15 & 22 & 29 & 36 & 43 \\
\hline 1 & 1 & 240 & 250 & 255 & 260 & 262 & 258 & 266 \\
1 & 2 & 225 & 230 & 230 & 232 & 240 & 240 & 243 \\
1 & 3 & 245 & 250 & 250 & 255 & 262 & 265 & 267 \\
1 & 4 & 260 & 255 & 255 & 265 & 265 & 268 & 270 \\
1 & 5 & 255 & 260 & 255 & 270 & 270 & 273 & 274 \\
1 & 6 & 260 & 265 & 270 & 275 & 275 & 277 & 278 \\
1 & 7 & 275 & 275 & 260 & 270 & 273 & 274 & 276 \\
1 & 8 & 245 & 255 & 260 & 268 & 270 & 265 & 265 \\
2 & 1 & 410 & 415 & 425 & 428 & 438 & 443 & 442 \\
2 & 2 & 405 & 420 & 430 & 440 & 448 & 460 & 458 \\
2 & 3 & 445 & 445 & 450 & 452 & 455 & 455 & 451 \\
2 & 4 & 555 & 560 & 565 & 580 & 590 & 597 & 595 \\
3 & 1 & 470 & 465 & 475 & 485 & 487 & 493 & 493 \\
3 & 2 & 535 & 525 & 530 & 533 & 535 & 540 & 525 \\
3 & 3 & 520 & 525 & 530 & 540 & 543 & 546 & 538 \\
3 & 4 & 510 & 510 & 520 & 515 & 530 & 538 & 535 \\
\hline
\end{tabular}

Podemos distinguir três tipos de desbalanceamento com relação às ocasiões de avaliação em estudos longitudinais:

(i) O primeiro ocorre quando o desbalanceamento se dá devido ao planejamento, onde propositadamente, nem todos os indivíduos são observados em todas as ocasiões de avaliação; é o caso, por exemplo, de um estudo de três anos de duração cujo objetivo é o de estudar uma variável ligada à função pulmonar em crianças na faixa dos 6 aos 12 anos de idade, onde cada criança é medida em quatro idades consecutivas, começando da idade no início do estudo; Nesse caso, as ocasiões de avaliação (idades) variam de criança para criança (veja Goldstein (1979)).

(ii) O segundo ocorre quando não há condições para que os tempos de coleta dos dados sejam 
os mesmos para todos os indivíduos, o que acontece muito em estudos médicos, onde as observações são feitas em pacientes e ocasiões disponíveis.

(iii) O último tipo de desbalanceamento caracteriza-se pelo fato de o estudo ter sido planejado de forma a se obter o conjunto de medidas de cada um dos indivíduos nas mesmas ocasiões de avaliação, mas nem todas as medidas puderam ser feitas. A esse último caso é que se dá o nome de estudo com dados incompletos, e é a ele que daremos maior ênfase nesse trabalho.

\section{Exemplo 1.3: (Coons(1957))}

Um experimento foi planejado para estudar a perda de energia em transformadores, utilizando um planejamento split-plot. As unidades experimentais são oito chapas de aço, divididas em dois grupos de quatro chapas cada. Ao primeiro grupo foi aplicado revestimento em vidro, enquanto que ao segundo, um outro tipo de revestimento conhecido por carlite. De cada chapa foram obtidas medidas de tensão (em $\mathrm{N} / \mathrm{m}$ ) em quatro pontos diferentes ao longo da extensão da chapa (medidas repetidas). Os dados encontram-se reproduzidos na Tabela 1.3. Nesse experimento, planejado de forma a ser balanceado, duas das observações não puderam ser obtidas, originando dados incompletos.

Tabela 1.3: Medidas de tensão $(\mathrm{N} / \mathrm{m})$

\begin{tabular}{cccccc}
\hline Grupo & Chapa & Medida 1 & Medida 2 & Medida 3 & Medida 4 \\
\hline 1 & 1 & 75 & 70 & 122 & 114 \\
1 & 2 & 69 & 51 & 91 & 125 \\
1 & 3 & 66 & 68 & 102 & 84 \\
1 & 4 & 56 & 50 & - & 72 \\
2 & 1 & 42 & 59 & 39 & 82 \\
2 & 2 & 75 & 66 & 50 & 46 \\
2 & 3 & - & 106 & 74 & 77 \\
2 & 4 & 62 & 102 & 34 & 56 \\
\hline
\end{tabular}

(-): dados não-observados 


\section{Exemplo 1.4: (Singer e Mauro (1987))}

Em um estudo na área de fisiologia animal, foram obtidas medidas do potencial de ação composto (PAC) do nervo conectivo cérebro-visceral (em $\mathrm{mV}$ ) de dezoito mexilhões em quatro condições de salinidade da água. O objetivo consistia em avaliar o comportamento médio do PAC em função da variação da salinidade da água medida em relação a salinidade de aclimatação original dos mexilhões. Embora o experimento tenha sido planejado para que todos os animais fossem observados nas quatro salinidades, por motivos técnicos não relacionados ao estudo, $25 \%$ das observações não foram coletadas. Os dados encontram-se na Tabela 1.4 .

Tabela 1.4: Medidas de amplitude do PAC (mV)

\begin{tabular}{ccccc}
\hline \multicolumn{5}{c}{ Variação de salinidade } \\
Mexilhão & $-1.7 \%$ & $-1.0 \%$ & $-0.5 \%$ & $0 \%$ \\
\hline 1 & 6.0 & - & - & 14.0 \\
2 & 8.0 & - & - & 15.0 \\
3 & 5.1 & - & - & 9.6 \\
4 & 1.0 & 11.0 & 12.5 & 15.0 \\
5 & - & 5.4 & 7.5 & 11.0 \\
6 & - & 8.4 & 10.6 & 12.4 \\
7 & - & 6.0 & 13.0 & 17.0 \\
8 & 5.8 & 4.4 & - & 9.2 \\
9 & 6.8 & 6.8 & 8.0 & 18.0 \\
10 & 3.0 & 5.4 & 6.6 & 6.4 \\
11 & - & - & 6.0 & 9.4 \\
12 & 5.8 & 6.0 & 8.0 & 12.0 \\
13 & - & 6.4 & 9.6 & 10.4 \\
14 & 8.8 & 10.4 & 10.8 & 13.0 \\
15 & - & 9.6 & - & 11.2 \\
16 & 7.6 & 11.2 & - & 12.0 \\
17 & 3.2 & 6.0 & 10.4 & 12.0 \\
18 & - & - & 9.6 & 14.0 \\
\hline
\end{tabular}

(-): dados não-observados 
Os principais objetivos em estudos longitudinais são essencialmente:

(i) comparação dos diferentes tratamentos quanto ao padrão de variação das respectivas distribuições médias de respostas ao longo das diferentes ocasiões de avaliação, ou seja, a verificação da existência de interação entre o(s) fator(es) que define $(\mathrm{m})$ os tratamentos e aquele que define as ocasiões de avaliação;

(ii) comparação dos diferentes tratamentos quanto às respectivas distribuições médias de respostas (em relação às diversas ocasiões de avaliação), ou seja, verificação da existência de efeito do(s) fator(es) que define(m) os tratamentos;

(iii) comparação das diferentes ocasiões de avaliação quanto às respectivas distribuições médias de respostas (em relação aos diversos tratamentos), ou seja, verificação da existência de efeito do fator que define as ocasiōes de avaliação;

(iv) ajuste de modelos (geralmente na forma de curvas polinomiais) para explicar a variação das respostas médias (ou de outras características das distribuições de respostas) como função do fator que define as ocasiōes de avaliação.

Considere o gráfico da. Figura 1.1 correspondente aos perfis médios observados de respostas dos dados apresentados no Exemplo 1.2: 
Figura 1.1: Perfis médios dos pesos de ratos submetidos a diferentes dietas

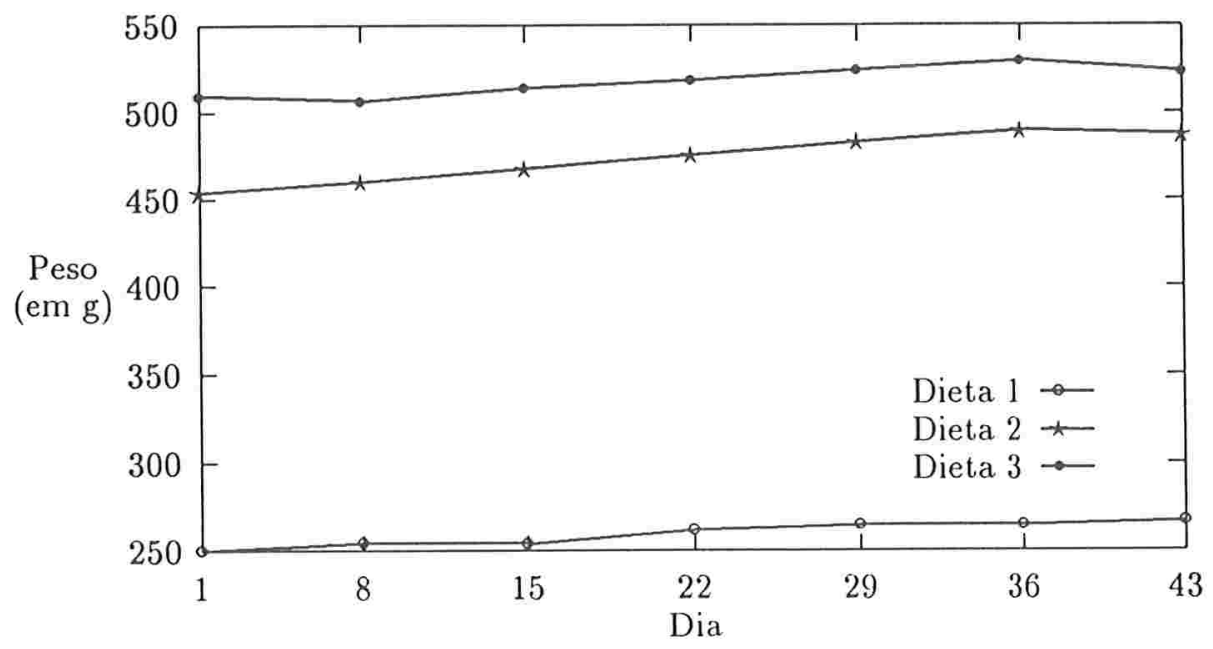

Os objetivos (i)-(iii) podem ser traduzidos nas seguintes hipóteses nulas de interesse, respectivamente:

$H_{01}$ : os perfis médios de respostas correspondentes aos diferentes tratamentos são paralelos, ou seja, não há interação entre os fatores Tratamento e Tempo;

$H_{02}$ : os perfis médios de respostas correspondentes aos diferentes tratamentos são coincidentes, ou seja, não há efeito do fator Tratamento;

$H_{03}$ : os perfis médios de respostas correspondentes aos diferentes tratamentos são paralelos ao eixo das abscissas, ou seja, não há efeito do fator Tempo.

A hipótese $H_{01}$ deve ser sempre a primeira a ser verificada, pois a interpretação dos resultados dos testes associados a $H_{02}$ e $H_{03}$ pode estar comprometida caso $H_{01}$ seja rejeitada.

A característica que distingue estudos longitudinais dos chamados estudos transversais é o fato de nos primeiros haver várias observaçōes sobre um mesmo indivíduo, o que pode induzir 
correlações entre elas. Sendo assim, uma análise apropriada para esse tipo de dados deve levar em conta essas correlações. Algumas das técnicas clássicas para análise de dados longitudinais completos e balanceados com relação às ocasiões de avaliação são:

a) Análise através de medidas resumo: Esse tipo de técnica é apropriado para situações onde o objetivo se restringe à comparação de tratamentos e consiste de análises univariadas de determinadas medidas de interesse obtidas a partir dos perfis individuais de resposta, tais como média, valor final, diferença entre os valores final e inicial, área sob a curva, etc. (para maiores detalhes veja, por exemplo, Domenech (1989)).

b) Análise de perfis: Consiste na comparação dos perfis médios de resposta. Para essa finalidade os dois modelos mais usados são:

- Análise de perfis univariada, que utiliza um modelo split-plot (ver, por exemplo, Winer (1971, cap.5));

- Análise de perfis multivariada, baseada no modelo de manova (ver Morrison (1976, cap.5) ou ainda Singer e Andrade (1986, cap.2));

c) Ajuste de curvas de crescimento: Consiste no ajuste de curvas polinomiais aos perfis médios de resposta (para maiores detalhes ver, por exemplo, Singer (1977)).

Neste trabalho vamos concentrar a atenção em análise de perfis.

Há diversos métodos propostos pela literatura estatística especializada para a análise de dados incompletos (alguns desses métodos estão descritos em Hartley e Hocking (1971), Dempster, Laird e Rubin (1977) e Little (1982), entre outros). Esses métodos podem ser agrupados nas seguintes categorias (que não são mutuamente exclusivas):

a) Análise através de medidas resumo. 
b) Procedimentos que simplesmente descartam as unidades amostrais que tenham pelo menos um dado não-observado e consideram para a análise somente o conjunto de dados completos (veja, por exemplo, Little e Rubin (1987, cap.3)). Esses métodos costumam ser de fácil aplicação e podem proporcinar resultados satisfatórios no caso de haver um número pequeno de dados não-observados. Entretanto, podem implicar perdas significativas de informação e vir a comprometer seriamente os resultados se o número de observações incompletas for grande.

c) Procedimentos baseados na substituição dos dados não-observados por estimativas, seguida da análise dos dados, então completos, a partir da utilização de métodos usuais. Nestes casos, são necessárias algumas modificações nas análises usuais de forma que os dados realmente observados sejam tratados de uma maneira diferenciada dos valores colocados para substituir os dados não-observados.

d) Procedimentos onde se define um modelo para o mecanismo de não-resposta responsável pelos dados incompletos e se estimam os parâmetros correspondentes através de métodos baseados na verossimilhança (ver, por exemplo, Little e Rubin (1987, parte II)).

A terceira categoria de métodos é a que será enfocada neste trabalho. A seguir serão apresentados alguns conceitos relacionados com mecanismos de não-resposta e ainda nesse capítulo será introduzido o modelo linear geral para dados completos e incompletos. No Capítulo 2 apresentaremos alguns métodos de análise de dados longitudinais com dados completos e incompletos sob modelos do tipo split-plot; no Capítulo 3 enfocaremos o método de máxima verossilmilhança e finalmente no Capítulo 4 serão apresentadas alternativas de implementação computacional (utilização de pacotes estatísticos conhecidos, na análise de estudos longitudinais com dados incompletos) ilustradas por um exemplo. 


\subsection{Mecanismos de Não-Resposta}

O aparecimento de dados incompletos é bastante frequente na prática. Rubin (1976) cita um exemplo típico, onde em um experimento, um grande número de famílias foi observado em 1967 com relação a variáveis sócio-econômicas e em 1970 desejou-se prosseguir com o estudo utilizando as mesmas famílias. É provável que, além de observações incompletas na primeira etapa, tenha havido blocos inteiros de dados não-observados na segunda, pois muitas das famílias estudadas em 1967 não devem ter sido localizadas em 1970. Usualmente, a análise de dados como esses é realizada sob a suposição, implícita ou explícita, de que o processo que originou os dados incompletos pode ser ignorado, mas nem sempre isso é verdade; se não for, os resultados obtidos podem estar seriamente comprometidos. Vamos introduzir aqui alguns conceitos associados a mecanismos de não-resposta e definir em quais situações eles podem ser ignorados.

Para simplificar a notação, iremos considerar nesta seção o caso em que as unidades amostrais estão alocadas a um único tratamento. O conjunto de respostas associado à $j$-ésima unidade amostral será representado pelo vetor $(T \times 1)$ de variáveis aleatórias $y_{j}=\left(Y_{j 1}, \ldots, Y_{j T}\right)^{t}, j=$ $1, \ldots, N$, onde $Y_{j k}$ e $Y_{j l}$ podem ser correlacionadas, $k, l=1, \ldots, T$; seja $X_{j}$ a matriz $(T \times p)$ de especificação do modelo associada à $j$-ésima unidade amostral. Admitamos que os vetores $\boldsymbol{y}_{j}$ sejam independentes e obedeçam a uma mesma função densidade de probabilidade $f(\boldsymbol{y} \mid \boldsymbol{X}, \boldsymbol{\theta})$, onde $\boldsymbol{\theta}$ é um vetor $(p \times 1)$ de parâmetros desconhecidos. (Com o objetivo de facilitar a notação, iremos omitir os índices das funções densidade).

Para levar em consideração o mecanismo de não-resposta responsável pelos dados incompletos, vamos introduzir um modelo de não-resposta: seja $m_{j}=\left(M_{j 1}, \ldots, M_{j T}\right)^{t}$ um vetor $(T \times 1)$ de variáveis aleatórias indicadoras dos dados incompletos correspondente à $j$-ésima unidade amostral, $j=1, \ldots, N$, onde $m_{j t}, t=1, \ldots, T$, assume o valor 1 se a resposta $Y_{j t}$ for observada e o valor 0 , caso contrário; seja $Z$ a matriz $(T \times h)$ de covariáveis adicionais que afetam o processo de não-resposta. Sendo $\phi$ o vetor $(q \times 1)$ de parâmetros desconhecidos associado ao modelo de não- 
resposta, a função densidade de probabilidade de $m_{j}$ condicionada a $y, X, Z$ e $\phi$ é denotada por $f(m \mid y, X, Z, \phi)$. É justamente a distribuição condicional $f(m \mid y, X, Z, \phi)$ que corresponde ao mecanismo de não-resposta. O objetivo é fazer inferências sobre $\theta$, enquanto $\phi$ é visto como um vetor de parâmetros auxiliares do modelo.

Dado $m_{j}$, vamos considerar a seguinte partição do vetor de observações associado à $j$-ésima unidade amostral: $y_{j}=\left(y_{j o}^{t}, y_{j m}^{t}\right)^{t}$, onde $y_{j o}$ corresponde ao conjunto de dados observados, enquanto $\boldsymbol{y}_{j m}$ corresponde ao conjunto de dados não-observados. As dimensões de $\boldsymbol{y}_{j o}$ e $\boldsymbol{y}_{j m}$ podem variar de unidade amostral para unidade amostral, uma vez que dependem dos vetores aleatórios $m_{j}$ 's. Para simplificar, utilizaremos a notação $y=\left(\boldsymbol{y}_{o}^{t}, \boldsymbol{y}_{m}^{t}\right)^{t}$ para qualquer unidade amostral.

Podemos definir a densidade conjunta de $y_{0}$ e $m$ como

$$
f\left(y_{o}, m \mid X, Z, \theta, \phi\right)=\int_{S} f(y \mid X, \theta) f(m \mid y, X, Z, \phi) d y_{m}
$$

onde a integração é sobre o espaço amostral $S$ correspondente a $y_{m}$.

Segundo Laird (1988), quando o mecanismo de não-resposta não depende de $\boldsymbol{y}$ (ou seja, $\boldsymbol{y}$ e $m$ são independentes), dizemos que os dados são incompletos completamente ao acaso (MCARmissing completely at random). Quando essa situação é verificada, a maioria dos procedimentos padrões de análise são válidos, de forma que o único problema em se adotar tais procedimentos está na dificuldade de sua implementação para dados incompletos. Procedimentos que descartam indivíduos com dados incompletos também fornecem inferências válidas, porém implicam perda de eficiência.

Observe que para dados MCAR, a densidade de $m$ reduz-se a $f(m \mid X, Z, \phi)$ e (1.1) pode ser escrita como

$$
f\left(y_{\circ}, m \mid X, Z, \theta, \phi\right)=f(m \mid X, Z, \phi) \int_{S} f(y \mid X, \theta) d y_{m},
$$

onde $S$ é o espaço amostral de $y_{m}$. Isso implica que a densidade de $y_{o}$ é simplesmente a densidade 
marginal usual:

$$
f\left(y_{o} \mid X, \theta\right)=\int f\left(y_{o}, m \mid X, Z, \theta, \phi\right) d m=\int_{S} f(y \mid X, \theta) d y_{m}
$$

ou seja, não é preciso considerar o mecanismo de não-resposta para se fazerem inferências sobre $\theta$.

Há casos onde não se pode afirmar que os dados são MCAR e utilizam-se inferências sobre $\boldsymbol{\theta}$ que requerem suposições distribucionais (o que Laird (1988) chama de inferências baseadas na verossimilhança). Para tais situações, o mecanismo de não-resposta é dito ignorável, indicando que não se faz necessária a especificação da densidade $f(m \mid y, X, Z, \phi)$ ou a estimação de seus parâmetros a fim de se obterem inferências válidas sobre $\theta$. Isso ocorre quando a probabilidade de não-resposta depende dos dados observados, $y_{o}$, mas nunca dos dados não-observados, $y_{m}$. Nesse caso, temos

$$
f(y \mid X, \theta)=f\left(y_{m} \mid y_{o}, X, \theta\right) f\left(y_{o} \mid X, \theta\right)
$$

onde

$$
f\left(y_{o} \mid X, \theta\right)=\int_{S} f(y \mid X, \theta) d y_{m}
$$

e podemos escrever (1.1) como

$$
\begin{aligned}
f\left(\boldsymbol{y}_{o}, m \mid X, Z, \theta, \phi\right) & =\int_{S} f\left(y_{m} \mid y_{\circ}, X, \theta\right) f\left(y_{o} \mid X, \theta\right) f\left(m \mid y_{o}, X, Z, \phi\right) d y_{m}= \\
& =f\left(y_{o} \mid X, \theta\right) f\left(m \mid y_{o} X, Z, \phi\right) \int_{S} f\left(y_{m} \mid y_{o}, X, \theta\right) d y_{m}= \\
& =f\left(y_{o} \mid X, \theta\right) f\left(m \mid y_{o}, X, Z, \phi\right) .
\end{aligned}
$$

Portanto, se estivermos interessados somente em inferências sobre $\theta$, a contribuição para a verossimilhança será dada por $f\left(y_{o} \mid X, \theta\right)$ e $f\left(m \mid y_{o}, X, Z, \phi\right)$ pode ser ignorado. Já no caso em que o mecanimo é dito não-ignorável, esta fatoração não seria possível.

Como ilustração, consideremos um caso hipotético onde $y=\left(Y_{1}, \ldots, Y_{N}\right)^{t}$ é uma amostra aleatória de tamanho $N$ de uma distribuição exponencial com média $\theta$. Então,

$$
f(y \mid \theta)=f\left(y_{o}, y_{m} \mid \theta\right)=\theta^{-N} \exp \left(-\sum_{j=1}^{N} Y_{j} / \theta\right)
$$


Se $r<N$ observações estiverem presentes e as restantes $(N-r)$ estiverem faltando, então a função de verossimilhança, ignorando o mecanismo de não-resposta, será dada por

$$
f\left(y_{0} \mid \theta\right)=\theta^{-r} \exp \left(-\sum_{j=1}^{r} Y_{j} / \theta\right) .
$$

Vamos considerar dois modelos diferentes para a distribuição de $m$ dado $y$. Primeiramente, vamos supor que as observações sejam independentes e possam deixar de ser obtidas com uma probabilidade $\phi$ conhecida. Então,

$$
f\left(m \mid y_{o}, \phi\right)=\phi^{r}(1-\phi)^{N-r}
$$

$\mathrm{e}$

$$
f\left(y_{o}, m \mid \theta, \phi\right)=\phi^{r}(1-\phi)^{N-r} \theta^{-r} \exp \left(-\sum_{j=1}^{r} Y_{j} / \theta\right) .
$$

As verossimilhanças baseadas em (1.8) e (1.10) diferem pelo fator $\phi^{r}(1-\phi)^{N-r}$ que não depende de $\theta$, o que significa que o espaço paramétrico conjunto de $\theta$ e $\phi$ se fatoriza em um espaço $\theta$ e um espaço $\phi$ e que portanto, podemos basear inferências em (1.8) ignorando o mecanismo de não-resposta. Considere agora que a amostra seja censurada de tal forma que somente os valores abaixo de um determinado ponto de censura $c$ conhecido sejam observados. Então

$$
f\left(m \mid y_{o}, \phi\right)=\prod_{j=1}^{N} f\left(M_{j} \mid Y_{j}\right)
$$

onde

$$
f\left(M_{j} \mid Y_{j}\right)=\left\{\begin{aligned}
1, & \text { se } M_{j}=1 \text { e } Y_{j}<c \\
& \text { ou } M_{j}=0 \text { e } Y_{j}>c \\
0, & \text { caso contrário }
\end{aligned}\right.
$$

$\mathrm{e}$

$$
\begin{aligned}
f\left(y_{o}, m \mid \theta\right) & =\prod_{j: M_{j}=1} f\left(Y_{j} \mid \theta\right) f\left(M_{j} \mid Y_{j}<c\right) \prod_{j: M_{j}=0} \operatorname{Pr}\left(Y_{j}>c \mid \theta\right)= \\
& =\theta^{-r} \exp \left(-\sum_{j=1}^{r} Y_{j} / \theta\right) \exp (-(N-r) c / \theta) .
\end{aligned}
$$


Neste caso, o mecanismo de não-resposta não é ignorável pois as verossimilhanças baseadas em (1.8) e (1.12) são diferentes. Em particular, o estimador de máxima verossimilhança de $\theta$ baseado em (1.8) é igual a $\sum_{j=1}^{r} Y_{j} / r$, a média dos valores observados, que é menor do que o estimador de máxima verossimilhança baseado em (1.12), igual a $\left(\sum_{j=1}^{r} Y_{j}+(N-r) c\right) / r$.

Em alguns casos a diferença entre dados MCAR e dados com mecanismo de não-resposta ignorável é pouco evidente. Porém, quando se utilizam inferências baseadas na verossimilhança, não é necessário que se faça essa distinção, pois em ambos os casos, o mecanismo de não-resposta pode ser desconsiderado.

Na prática, é comum supor que o mecanismo de não-resposta é ignorável. Embora essa suposição seja bastante forte, ela tem a vantagem de prescindir de um modelo de não-resposta para os dados incompletos. Por exemplo, pacientes podem se recusar a continuar um tratamento por ele não estar dando bons resultados ou mesmo por considerarem suficientes os resultados obtidos até um determinado instante que precede a data estipulada para o fim da coleta de dados. Esse tipo de situação pode gerar dados incompletos e, nesse caso, o mecanismo de não-resposta está diretamente relacionado com o tratamento, o que faz com que ele não possa ser ignorado na análise. Por outro lado, para levá-lo em consideração seria necessário definir uma função densidade de probabilidade para o comportamento desses pacientes, o que na maioria dos casos é praticamente inviável. Em todas essas situações onde os dados incompletos são dependentes do tratamento, as análises que não levam esse fator em consideração tornam-se inválidas.

Neste trabalho serão discutidos somente métodos considerados apropriados para análise de dados incompletos onde o mecanismo de não-resposta é ignorável. Laird (1988) e Little e Rubin (1987) apresentam algumas aplicações em casos onde o mecanismo de não-resposta é não-ignorável. 


\subsection{O Modelo Linear Geral}

Em estudos longitudinais, onde cada indivíduo é observado em cada uma das $T$ ocasiōes de avaliação (aqui consideradas como tempos), costuma-se empregar o modelo linear geral (veja Graybill (1976), por exemplo)

$$
y=X \beta+\varepsilon,
$$

onde $\boldsymbol{y}=\left(\boldsymbol{y}_{11}^{t}, \boldsymbol{y}_{12}^{t}, \ldots, \boldsymbol{y}_{1 n_{1}}^{t}, \boldsymbol{y}_{21}^{t}, \ldots, \boldsymbol{y}_{G n_{G}}^{t}\right)^{t}$ é o vetor $(N T \times 1)$ de todas as observações, $N=$ $\sum_{i=1}^{G} n_{i}, n_{i}$ é o número de indivíduos submetidos ao $i$-ésimo tratamento, $y_{i j}=\left(Y_{i j 1}, Y_{i j 2}, \ldots, Y_{i j T}\right)^{t}$ é o vetor $(T \times 1)$ das observações do $j$-ésimo indivíduo submetido ao $i$-ésimo tratamento, $X=$ $\left(X_{11}^{t}, X_{12}^{t}, \ldots, X_{1 n_{1}}^{t}, X_{21}^{t}, \ldots, X_{G n_{G}}^{t}\right)^{t}$ é uma matriz $(N T \times p)$ de especificação (global) conhecida, onde $\boldsymbol{X}_{i j}$ é a matriz de especificação associada ao $i j$-ésimo indivíduo (que sem perda de generalidade, assume-se ter posto completo), $\beta$ é o vetor $(p \times 1)$ de parâmetros desconhecidos e $\varepsilon=\left(\varepsilon_{11}^{t}, \varepsilon_{12}^{t}, \ldots, \varepsilon_{1 n_{1}}^{t}, \varepsilon_{21}^{t}, \ldots, \varepsilon_{G n_{G}}^{t}\right)^{t}$ é o vetor $(N T \times 1)$ de erros aleatórios. Em geral, assume-se que $\varepsilon_{i j}$ segue uma distribuição Normal com média 0 e matriz de covariância $\Sigma$ para todo $i, j$, onde 0 é um vetor $(T \times 1)$ com todos os elementos iguais a zero e $\Sigma$ é uma matriz $(T \times T)$ simétrica e positiva definida e que os vetores $\varepsilon_{i j}$ são independentes entre si, para todo $i, j$. Assim, $\boldsymbol{y}_{i j}$ segue uma distribuição $N_{T}\left(X_{i j} \beta, \Sigma\right)$ e consequentemente, $y$ segue uma distribuição $N_{N T}\left(X \beta, \Sigma_{\star}\right)$, onde $\boldsymbol{\Sigma}_{\star}=\boldsymbol{I}_{N} \otimes \boldsymbol{\Sigma}$ e $\boldsymbol{I}_{N}$ é a matriz identidade de ordem $N$.

Uma maneira alternativa de se escrever (1.13) seria através de modelos individuais, ou seja

$$
y_{i j}=X_{i j} \beta+\varepsilon_{i j}
$$

que é o modelo associado ao $i j$-ésimo indivíduo, $i=1, \ldots, G, j=1, \ldots, n_{i}$.

Nesse contexto, podemos considerar várias parametrizações, dentre as quais destacamos:

(i) Parametrização através de médias de caselas, onde

$$
Y_{i j k}=\mu_{i k}+\varepsilon_{i j k}
$$


Nesse caso, $\mu_{i k}$ corresponde à média de todas as observações do $i$-ésimo tratamento no $k$ ésimo tempo e $\varepsilon_{i j k}$ corresponde ao efeito aleatório associado à $i j k$-ésima observação. Com essa parametrização é mais conveniente definir os termos em (1.13) na forma matricial, ou seja,

$$
Y=V \mu+E
$$

onde $Y=\left(y_{11}, y_{12}, \ldots, y_{1 n_{1}}, y_{21}, \ldots, y_{G n_{G}}\right)^{t}$ é a matriz $(N \times T)$ das observações, $V=$ $\operatorname{diag}\left(1_{n_{1}}, \ldots, 1_{n_{G}}\right)$, com $1_{n_{i}}$ representando um vetor coluna de ordem $n_{i}$ com todos os elementos iguais a um, é uma matriz $(N \times G)$ de especificação, $\mu=\left(\mu_{1}, \ldots, \mu_{G}\right)^{t}$, com $\mu_{i}=\left(\mu_{i 1}, \ldots, \mu_{i T}\right)$, é a matriz $(G \times T)$ de parâmetros desconhecidos e $E$ é a matriz $(N \times T)$ de erros aleatórios. Em termos dos parâmetros de (1.15), as hipóteses apresentadas na Seção 1.1 podem ser expressas na forma:

$$
\begin{aligned}
& H_{01}:\left(\begin{array}{c}
\mu_{11}-\mu_{12} \\
\mu_{12}-\mu_{13} \\
\vdots \\
\mu_{1(T-1)}-\mu_{1 T}
\end{array}\right)=\left(\begin{array}{c}
\mu_{21}-\mu_{22} \\
\mu_{22}-\mu_{23} \\
\vdots \\
\mu_{2(T-1)}-\mu_{2 T}
\end{array}\right)=\ldots=\left(\begin{array}{c}
\mu_{G 1}-\mu_{G 2} \\
\mu_{G 2}-\mu_{G 3} \\
\vdots \\
\mu_{G(T-1)}-\mu_{G T}
\end{array}\right) \\
& H_{02}: \sum_{k=1}^{T} \mu_{1 k}=\sum_{k=1}^{T} \mu_{2 k}=\ldots=\sum_{k=1}^{T} \mu_{G k} \\
& H_{03}: \sum_{i=1}^{G} \mu_{i 1}=\sum_{i=1}^{G} \mu_{i 2}=\ldots=\sum_{i=1}^{G} \mu_{i T} .
\end{aligned}
$$

Uma outra maneira de escrevê-las é na forma da hipótese linear geral

$$
H_{0}: C^{*} \mu U^{*}=0
$$

onde $C^{*}$ e $U^{*}$ são matrizes $(c \times G)$ e $(T \times u)$ de constantes conhecidas com postos $c$ e $u$, respectivamente. Por exemplo, para $H_{01}$, uma maneira seria: 


$$
C^{*}=C_{1}^{*}=\left(\begin{array}{rrrrr}
1 & -1 & 0 & \ldots & 0 \\
0 & 1 & -1 & \ldots & 0 \\
\vdots & \vdots & \vdots & \ddots & \vdots \\
0 & 0 & 0 & \ldots & -1
\end{array}\right) \text { e } U^{*}=U_{1}^{*}=\left(\begin{array}{rrrr}
1 & 0 & \ldots & 0 \\
-1 & 1 & \ldots & 0 \\
0 & -1 & \ldots & 0 \\
\vdots & \vdots & \ddots & \vdots \\
0 & 0 & \ldots & -1
\end{array}\right) \text {, }
$$

onde $C_{1}^{*}$ e $U_{1}^{*}$ são matrizes $((G-1) \times G)$ e $(T \times(T-1))$, respectivamente. Para $H_{02}$ :

$$
C^{*}=C_{1}^{*} \text { e } \quad U^{*}=1_{T}
$$

e para $H_{03}$ :

$$
C^{*}=1_{G}^{t} \text { e } U^{*}=U_{1}^{*}
$$

Se considerarmos o Exemplo 1.1, onde há 2 tratamentos e 3 tempos, teremos

$$
C^{*}=\left(\begin{array}{ll}
1 & -1
\end{array}\right) \text { e } U^{*}=\left(\begin{array}{rr}
1 & 0 \\
-1 & 1 \\
0 & -1
\end{array}\right) .
$$

(ii) Parametrização através de desvios médios, onde

$$
Y_{i j k}=\mu+\alpha_{i}+\gamma_{k}+\alpha \gamma_{i k}+\varepsilon_{i j k}
$$

com as seguintes restrições de identificabilidade sobre os parâmetros:

$$
\sum_{i=1}^{G} \alpha_{i}=\sum_{k=1}^{T} \gamma_{k}=\sum_{i=1}^{G} \alpha \gamma_{i k}=\sum_{k=1}^{T} \alpha \gamma_{i k}=0 .
$$

Dessa forma, $\mu$ corresponde à média geral, $\alpha_{i}$ e $\gamma_{k}$ correspondem, respectivamente, aos efeitos principais dos fatores Tratamento e Tempo e $\alpha \gamma_{i k}$ à interação entre eles. Todos esses são efeitos fixos e $\varepsilon_{i j k}$ corresponde ao efeito aleatório associado à $i j k$-ésima observação. $O$ número de parâmetros fixos do modelo é $p=(G-1)+(T-1)+(G-1)(T-1)+1=G T$ e o vetor de parâmetros em (1.13) e (1.14) é dado por

$$
\beta=\left(\mu, \alpha_{1}, \ldots, \alpha_{G-1}, \gamma_{1}, \ldots, \gamma_{T-1}, \alpha \gamma_{11}, \ldots, \alpha \gamma_{(G-1)(T-1)}\right)^{t} .
$$


Em termos dos parâmetros do modelo (1.20), as hipóteses apresentadas na Seção 1.1 podem ser expressas da seguinte forma:

$$
\begin{aligned}
& H_{01}: \alpha \gamma_{11}=\alpha \gamma_{12}=\ldots=\alpha \gamma_{21}=\ldots=\alpha \gamma_{G T}=0 \\
& H_{02}: \alpha_{1}=\alpha_{2}=\ldots=\alpha_{G}=0 \\
& H_{03}: \gamma_{1}=\gamma_{2}=\ldots=\gamma_{T}=0
\end{aligned}
$$

Novamente podemos escrevê-las de uma forma unificada, ou seja,

$$
H_{0}: C \beta=0,
$$

onde $C$ é uma matriz $(c \times p)$ de constantes conhecidas e posto $c$. Considerando o Exemplo 1.1, as hipóteses em questão podem ser escritas na forma (1.24) com $C$ dada respectivamente por:

$$
\begin{aligned}
& C_{1}=\left(\begin{array}{llllll}
0 & 0 & 0 & 0 & 1 & 0 \\
0 & 0 & 0 & 0 & 0 & 1
\end{array}\right), \\
& C_{2}=\left(\begin{array}{llllll}
0 & 1 & 0 & 0 & 0 & 0
\end{array}\right)
\end{aligned}
$$

$\mathrm{e}$

$$
C_{3}=\left(\begin{array}{cccccc}
0 & 0 & 1 & 0 & 0 & 0 \\
0 & 0 & 0 & 1 & 0 & 0
\end{array}\right) .
$$

Embora as duas parametrizações apresentadas sejam equivalentes, dependendo do caso, uma delas pode ser mais conveniente do que a outra. Nesse sentido, podemos notar que (1.13) e (1.16) estão relacionadas através da expressão

$$
X=\left(V \otimes I_{T}\right) W
$$


enquanto que (1.19) e (1.24) se relacionam através de

$$
C=\left(C^{*} \otimes U^{*^{t}}\right) W
$$

onde $W$ é uma matriz $(G T \times G T)$ que faz a associação entre os modelos (1.15) e (1.20), de modo que $\boldsymbol{\mu}^{*}=\boldsymbol{W} \boldsymbol{\beta}$, onde $\boldsymbol{\mu}^{*}=\left(\boldsymbol{\mu}_{1}^{t}, \ldots, \boldsymbol{\mu}_{G}^{t}\right)^{t}$. Para o Exemplo 1.1 , teremos

$$
\begin{aligned}
& X=\left(\begin{array}{rrrrrr}
1 & 1 & 1 & 0 & 1 & 0 \\
1 & 1 & 0 & 1 & 0 & 1 \\
1 & 1 & -1 & -1 & -1 & -1 \\
1 & 1 & 1 & 0 & 1 & 0 \\
1 & 1 & 0 & 1 & 0 & 1 \\
1 & 1 & -1 & -1 & -1 & -1 \\
1 & 1 & 1 & 0 & 1 & 0 \\
1 & 1 & 0 & 1 & 0 & 1 \\
1 & 1 & -1 & -1 & -1 & -1 \\
1 & -1 & 1 & 0 & -1 & 0 \\
1 & -1 & 0 & 1 & 0 & -1 \\
1 & -1 & -1 & -1 & 1 & 1 \\
1 & -1 & 1 & 0 & -1 & 0 \\
1 & -1 & 0 & 1 & 0 & -1 \\
1 & -1 & -1 & -1 & 1 & 1 \\
1 & -1 & 1 & 0 & -1 & 0 \\
1 & -1 & 0 & 1 & 0 & -1 \\
1 & -1 & -1 & -1 & 1 & 1
\end{array}\right) \\
& V=\left(\begin{array}{ll}
1 & 0 \\
1 & 0 \\
1 & 0 \\
0 & 1 \\
0 & 1 \\
0 & 1
\end{array}\right) \quad \text { e } \quad W=\left(\begin{array}{rrrrrr}
1 & 1 & 1 & 0 & 1 & 0 \\
1 & 1 & 0 & 1 & 0 & 1 \\
1 & 1 & -1 & -1 & -1 & -1 \\
1 & -1 & 1 & 0 & -1 & 0 \\
1 & -1 & 0 & 1 & 0 & -1 \\
1 & -1 & -1 & -1 & 1 & 1
\end{array}\right)
\end{aligned}
$$

Em análises de dados longitudinais, apesar de um maior interesse estar concentrado no vetor de médias, é necessário levar em consideração a estrutura de covariância, pois é nela que está contida a informação essencial sobre a natureza longitudinal dos dados. Um dos principais problemas 
é encontrar uma estrutura adequada para $\Sigma$, a matriz $(T \times T)$ de covariância das observações realizadas num mesmo indivíduo. No caso em que nenhuma estrutura é imposta a $\Sigma$, há $T(T+1) / 2$ parâmetros de covariância:

$$
\Sigma=\left\langle\operatorname{cov}\left(\varepsilon_{i j k}, \varepsilon_{i j k^{\prime}}\right)\right\rangle=\left(\begin{array}{cccc}
\sigma_{1}^{2} & \sigma_{12} & \ldots & \sigma_{1 T} \\
\sigma_{12} & \sigma_{2}^{2} & \ldots & \sigma_{2 T} \\
\vdots & \vdots & \ddots & \vdots \\
\sigma_{1 T} & \sigma_{2 T} & \ldots & \sigma_{T}^{2}
\end{array}\right)
$$

Neste trabalho serão apresentadas algumas estruturas para $\Sigma$, e dentre elas abordaremos com maior profundidade a chamada estrutura de simetria composta que será introduzida no Capítulo 2. 


\section{Capítulo 2}

\section{Análise através do método de Mínimos Quadrados}

Nesse capítulo trataremos a análise de dados longitudinais através de técnicas que envolvem minimos quadrados e o modelo do tipo split-plot. Esse enfoque é amplamente difundido na literatura e implementado na maioria dos pacotes estatísticos, como o BMDP, o SAS e o SPSS. Na Seção 2.1 será apresentada a análise para o caso de dados completos, enquanto que na Seção 2.2 a mesma análise será adaptada para o caso de dados incompletos. Na Seção 2.3 apresentaremos uma alternativa para análise de dados incompletos proposta por Bartlett (1937).

\subsection{Dados Completos}

A análise de dados longitudinais pode ser fundamentada em um modelo misto do tipo split-splot que em geral é parametrizado através de desvios médios (1.20) com o termo aleatório decomposto em dois efeitos específicos, ou seja,

$$
\varepsilon_{i j k}=\pi_{j(i)}+e_{i j k}
$$


onde $\pi_{j(i)}$ corresponde ao efeito aleatório associado ao $j$-ésimo indivíduo dentro do $i$-ésimo tratamen to e $e_{i j k}$ correponde ao erro alea tório associado à $i j k$-ésima observação. Neste modelo, os fatores Tempo e Tratamento são fixos e cruzados, enquanto o fator Indivíduo é aleatório e hierárquico em relação ao fator Tratamento. Assume-se que $\pi_{j(i)}$ e $e_{i j k}$ seguem distribuições Normais com médias 0 e variâncias $\sigma_{\pi}^{2}$ e $\sigma^{2}$, respectivamente, e que são independentes entre si. Dessa forma, a matriz de covariância associada a cada vetor $y_{i j}$ é

$$
\begin{aligned}
\Sigma & =\left(\begin{array}{cccc}
\sigma_{\pi}^{2}+\sigma^{2} & \sigma_{\pi}^{2} & \ldots & \sigma_{\pi}^{2} \\
\sigma_{\pi}^{2} & \sigma_{\pi}^{2}+\sigma^{2} & \ldots & \sigma_{\pi}^{2} \\
\vdots & \vdots & \ddots & \vdots \\
\sigma_{\pi}^{2} & \sigma_{\pi}^{2} & \ldots & \sigma_{\pi}^{2}+\sigma^{2}
\end{array}\right) \\
& =\sigma_{\pi}^{2} 1_{T} 1_{T}^{t}+\sigma^{2} I_{T} .
\end{aligned}
$$

Esse padrão para a matriz $\Sigma$ é conhecido como simetria composta (ou uniforme). A estrutura (2.2) é um tanto quanto restritiva, uma vez que em estudos longitudinais espera-se que a correlação entre duas observações tomadas em tempos próximos seja maior do que quando tomadas em tempos mais distantes (veja Kenward (1987), por exemplo). Apesar disso, esse tipo de enfoque apresenta algumas vantagens, como o fato de reduzir o número de parâmetros da matriz de covariância de $T(T+1) / 2$, no caso não-estruturado (1.27), para 2 e por permitir que testes $F$ exatos possam ser obtidos para algumas hipóteses mesmo quando $\Sigma$ satisfaz uma condição menos restritiva que a de uniformidade. Além disso, testes $F$ aproximados também podem ser considerados mesmo em situações ainda mais gerais (veja Singer e Andrade (1994)).

Sob o modelo composto por (1.20) e (2.1), as hipóteses nulas $H_{01}, H_{02}$ e $H_{03}$ podem ser testadas através das estatísticas $F_{1}, F_{2}$ e $F_{3}$, respectivamente, apresentadas na Tabela 2.1 de AnOva: 
Tabela 2.1: ANOVA associada ao modelo composto por (1.20) e (2.1)

\begin{tabular}{lccc}
\hline $\begin{array}{l}\text { Fonte de } \\
\text { Variação }\end{array}$ & $\begin{array}{c}\text { Graus de } \\
\text { Liberdade }\end{array}$ & $\begin{array}{c}\text { Somas de } \\
\text { Quadrados }\end{array}$ & $\begin{array}{c}\text { Estatística } \\
\text { Para o teste }\end{array}$ \\
\hline Entre indiv. & $N-1$ & & \\
Tratamento & $G-1$ & $S Q H_{02}$ & $F_{2}=\frac{S Q H_{02} /(G-1)}{S Q E_{1} /(N-G)}$ \\
Indiv. (erro 1) & $N-G$ & $S Q E_{1}$ & \\
\hline Intra-Indiv. & $N(T-1)$ & & \\
Tempo & $T-1$ & $S Q H_{03}$ & $F_{3}=\frac{S Q H_{03} /(T-1)}{S Q E_{2} /((N-G)(T-1))}$ \\
Tratamento $\times$ Tempo & $(G-1)(T-1)$ & $S Q H_{01}$ & $F_{1}=\frac{S Q H_{01} /((G-1)(T-1))}{S Q E_{2} /((N-G)(T-1))}$ \\
Tempo $\times$ Indiv. (erro 2) & $(N-G)(T-1)$ & $S Q E_{2}$ & \\
\hline
\end{tabular}

onde a soma de quadrados relativa à hipótese $H_{0 w}, w=1,2,3$, é igual a

$$
S Q H_{0 w}=\hat{\boldsymbol{\beta}}^{t} C_{w}^{t}\left(C_{w}\left(X^{t} X\right)^{-1} C_{w}^{t}\right)^{-1} C_{w} \hat{\boldsymbol{\beta}}
$$

sendo $\hat{\beta}$ dado por (2.15) e $C_{w}$ é uma matriz que especifica essa hipótese, assim como em (1.24). Além disso,

$$
S Q E_{1}=y^{t}\left[\left(I_{N T}-X\left(X^{t} X\right)^{-1} X^{t}\right)\left(I_{N} \otimes\left(T^{-1} 1_{T} 1_{T}^{t}\right)\right)\right] y
$$

$\mathrm{e}$

$$
S Q E_{2}=y^{t}\left[\left(I_{N T}-X\left(X^{t} X\right)^{-1} X^{t}\right)\left(I_{N} \otimes\left(U^{*}\left(U^{*^{t}} U^{*}\right)^{-1} U^{*^{t}}\right)\right)\right] y,
$$

onde

$$
U^{*}=\left(\begin{array}{rrrr}
1 & 0 & \ldots & 0 \\
-1 & 1 & \ldots & 0 \\
0 & -1 & \ldots & 0 \\
\vdots & \vdots & \ddots & \vdots \\
0 & 0 & \ldots & -1
\end{array}\right),
$$


por exemplo.

A soma de quadrados associada ao erro 1 é utilizada nos testes de hipóteses relacionados a comparações entre indivíduos, enquanto que a soma de quadrados associada ao erro 2 é utilizada nos testes das hipóteses intra-individuos. (As somas de quadrados também podem ser obtidas a partir do modelo (1.16), e para isso basta que se façam as devidas substituições em (2.3), (2.4) e (2.5) através das relações (1.25) e (1.26)).

Sob o modelo composto por (1.20) e (2.1), essa análise de variância univariada fornece testes $F$ exatos para testar as hipóteses de interesse, de forma que, $F_{1} \sim F_{[(G-1)(T-1),(N-G)(T-1)]}, F_{2} \sim$ $F_{[(G-1),(N-G)]}$ e $F_{3} \sim F_{[(T-1),(N-G)(T-1)]}$.

Convém notar que simetria composta é um caso particular de uma situação mais ampla sob a qual os mesmos testes $F$ são válidos. Dada uma matriz $P(T \times(T-1))$ de contrastes ortonormais, dizemos que $\Sigma$ satisfaz a condição de esfericidade se $P^{t} \Sigma P$ for um múltiplo escalar da matriz identidade. Em outras palavras, $\Sigma$ obedece ao padrão de esfericidade se ela puder ser escrita na forma

$$
\Sigma=\sigma^{2}\left(\boldsymbol{I}_{T}+d 1_{T} 1_{T}^{t}+\alpha 1_{T}^{t}+1_{T} \boldsymbol{\alpha}^{t}\right),
$$

onde $\sigma^{2}$ e $d$ são constantes e $\alpha$ é um vetor $(T \times 1)$ de constantes tal que $\boldsymbol{\alpha}^{t} 1_{T}=0$. Quando $\boldsymbol{\alpha}=\mathbf{0}$, $\boldsymbol{\Sigma}$ segue o padrão de simetria composta. Huynh e Feldt (1976) mostraram que a simetria composta para $\Sigma$ é uma condição suficiente para que os testes apresentados sejam válidos, enquanto que a esfericidade de $\Sigma$ é uma condição necessária e suficiente.

Mauchly (1940) propôs um teste de esfericidade para verificar se $\Sigma$ satisfaz a condição (2.6), cuja estatística é

$$
W=\frac{\operatorname{det}\left(\boldsymbol{P}^{t} S P\right)}{\left\{(T-1)^{-1} \operatorname{tr}\left(\boldsymbol{P}^{t} S P\right)\right\}^{(T-1)}},
$$

onde $S$ é a matriz de covariância amostral:

$$
S=\frac{1}{N-T} Y^{t}\left(I_{N}-V\left(V^{t} V\right)^{-1} V^{t}\right) Y,
$$


com $V$ e $Y$ definidos em (1.16).

Tabelas para a distribuição exata de $W$ podem ser encontradas em Nagarsenker e Pillai (1972) ou Kres (1983). Davis (1971) mostra que a estatística

$$
\Upsilon=-\left[(N-G)-\frac{2 T^{2}-3 T+3}{6(T-1)}\right] \ln (W)
$$

segue uma distribuição assintótica qui-quadrado com $\nu=(T-2)(T+1) / 2$ graus de liberdade $\left(\chi_{\nu}^{2}\right)$, sob a hipótese de que $\Sigma$ satisfaz a condição de esfericidade. Anderson (1984, cap.10) apresenta uma outra aproximação assintótica para o teste de esfericidade, onde

$$
\operatorname{Pr}\{\Upsilon \leq z\}=\operatorname{Pr}\left\{\chi_{(\nu)}^{2} \leq z\right\}+w\left(\operatorname{Pr}\left\{\chi_{(\nu+4)}^{2} \leq z\right\}-\operatorname{Pr}\left\{\chi_{(\nu)}^{2} \leq z\right\}\right)+o\left(n^{-3}\right)
$$

com

$$
w=\frac{(T+1)(T-2)(T-3)\left(2 T^{3}-3 T+3\right)}{288(T-1)^{2} n^{2} \rho^{2}},
$$

onde $\rho=1-\left[\left(2 T^{2}-3 T+3\right) /(6 n(T-1))\right]$ e $n=(N-G)$. Huynh e Mandeville (1979) discutem a robustez desse teste diante de desvios com relação à normalidade.

Se $\Sigma$ não obedecer à condição de esfericidade, então os níveis reais de significância dos testes $F$ univariados serão maiores do que os níveis nominais, fazendo com que hipóteses nulas verdadeiras possam ser rejeitadas. Nesses casos, é possível construir testes $F$ aproximados para as hipóteses de interesse a partir da multiplicação dos graus de liberdade originais por uma constante que assume valores entre $1 /(T-1)$ e 1 e que é uma medida de desvio de $\Sigma$ com relação à esfericidade; sugerida por Box (1954), essa constante é dada por

$$
\epsilon=\frac{\left[\operatorname{tr}\left(\boldsymbol{P}^{t} \boldsymbol{\Sigma} \boldsymbol{P}\right)\right]^{2}}{(T-1) \operatorname{tr}\left(\boldsymbol{P}^{t} \boldsymbol{\Sigma} \boldsymbol{P}\right)^{2}}
$$

Geisser e Greenhouse (1958) propuseram o seguinte estimador para $\epsilon$ :

$$
\hat{\epsilon}=\frac{\left[\operatorname{tr}\left(P^{t} S P\right)\right]^{2}}{(T-1) \operatorname{tr}\left(P^{t} S P\right)^{2}} .
$$


O estimador (2.12) possui um pequeno vício, especialmente quando $N$ é pequeno. Huynh e Feldt (1976) sugerem alterações que reduzem o seu vício quando $\epsilon \geq 0.75$, obtendo

$$
\tilde{\epsilon}=\frac{N(T-1) \hat{\epsilon}-2}{(T-1)[N-G-(T-1) \hat{\epsilon}]} .
$$

Note que $\tilde{\epsilon}$ pode assumir valores maiores do que um e nesse caso deve-se tomar $\tilde{\epsilon}=1$.

Greenhouse e Geisser (1959) propuseram o seguinte procedimento para a realização dos testes $F$, que em grande parte das situações evita a estimação de $\epsilon$ :

(i) inicialmente realiza-se um teste $F$ liberal, ou seja, com os graus de liberdade originais $(\epsilon=1)$;

(ii) se o resultado for não-significativo, dá-se por concluído o processo, aceitando-se a hipótese nula; se for significativo, prossegue-se com um teste conservativo, ou seja, com os graus de liberdade multiplicados por $\epsilon=1 /(T-1)$;

(iii) se o resultado for significativo, o teste está terminado e a hipótese nula é rejeitada, caso contrário, é necessário que se estime $\epsilon$ para obter um teste $F$ aproximado.

Vale a pena ressaltar que nenhuma correção precisa ser feita com relação aos testes associados a comparações entre indivíduos, pois elas não são influenciadas pela estrutura de $\Sigma$. Qualquer que seja essa estrutura, $F_{2}$ terá sempre distribuição $F$ exata com $(G-1)$ e $(N-G)$ graus de liberdade, sob a hipótese nula.

Uma maneira de se obter um estimador não-viciado para $\beta$ é através do método de minimos quadrados generalizados; utilizando a notação matricial (1.13), esse estimador é

$$
\hat{\beta}=\left(X^{t} \hat{\Sigma}_{\star}^{-1} X\right)^{-1} X^{t} \hat{\Sigma}_{\star}^{-1} y
$$

onde $\hat{\boldsymbol{\Sigma}}_{\star}$ é um estimador não-viciado para $\boldsymbol{\Sigma}_{\star}$. Por exemplo, $\hat{\boldsymbol{\Sigma}}_{\star}=\boldsymbol{I}_{N} \otimes \hat{\boldsymbol{\Sigma}}$, com $\hat{\boldsymbol{\Sigma}}=\hat{\sigma}_{\pi}^{2} \mathbf{1}_{T} \mathbf{1}_{T}^{t}+$ $\hat{\sigma}^{2} I_{T}$, onde $\hat{\sigma}_{\pi}^{2}$ e $\hat{\sigma}^{2}$ são estimadores de $\sigma_{\pi}^{2}$ e $\sigma^{2}$, respectivamente, obtidos a partir da correspondente Anova. Como o estimador (2.14) possui uma representação S-explícita (veja Andrade e Helms 
(1984) ou Szatrowski (1980), por exemplo), ele pode ser reduzido à forma do estimador de mínimos quadrados ordinários, ou seja

$$
\hat{\beta}=\left(X^{t} X\right)^{-1} X^{t} y
$$

Nesse caso, $\hat{\beta}$ é o estimador não-viciado de $\beta$ de variância mínima e coincide com o estimador de máxima verossimilhança. Note que os efeitos aleatórios não interferem na estimação dos parâmetros associados aos efeitos fixos.

Um estimador não-viciado para a matriz de covariância de $\hat{\beta}$ é dado por

$$
\widehat{\operatorname{Var}}(\hat{\beta})=\left(X^{t} \hat{\Sigma}_{\star}^{-1} X\right)^{-1}
$$

A partir da ANOVA podem-se obter, através do método dos momentos, os seguintes estimadores não-viciados para $\sigma^{2}$ e $\sigma_{\pi}^{2}$ :

$$
\hat{\sigma^{2}}=Q M E_{2}=\frac{S Q E_{2}}{(N-G)(T-1)}
$$

e

$$
\hat{\sigma_{\pi}^{2}}=\frac{Q M E_{1}-Q M E_{2}}{T}=\frac{1}{T}\left[\frac{S Q E_{1}}{(N-G)}-\frac{S Q E_{2}}{(N-G)(T-1)}\right] .
$$

Esse tipo de análise para dados longitudinais completos, baseado em um modelo do tipo splitplot, pode facilmente ser efetuado com o auxílio de muitos pacotes computacionais, como BM DP $/ 2 \mathrm{~V}$, BMDP/4V (Dixon (1990)), SAS/GLM/REPEATED (SAS Institute,Inc.(1987)), sPSS/MANOVA (SPSS, Inc.(1988)).

\subsection{Dados Incompletos}

Seja o modelo linear $y=X \beta+\varepsilon$ parametrizado através de desvios médios conforme (1.20) e (2.1). Considere, então, o seguinte modelo linear, que denominaremos modelo para dados incompletos:

$$
y_{o}=X_{o} \beta+\varepsilon_{o}
$$


onde $y_{o}$ é o subvetor $(T . \times 1)$ de $y$ que contém somente os dados observados, $T .=\sum_{i=1}^{G} \sum_{j=1}^{n_{i}} T_{i j}$, onde $T_{i j}$ é o número de dados observados do $i j$-ésimo indivíduo $\left(T_{i j} \leq T\right), X_{o}$ é a submatriz $(T . \times p)$ de $X$ associada a $y_{o}$ e $\varepsilon_{o}$ é o correspondente subvetor de $\varepsilon$. Assumimos que $\varepsilon_{o}$ obedece a uma distribuição $N\left(0, \Sigma_{o}\right)$, onde $\Sigma_{o}=\operatorname{diag}\left[\Sigma_{11}, \Sigma_{12}, \ldots, \Sigma_{G n_{G}}\right]$ sendo que $\Sigma_{i j}$ é a submatriz $\left(T_{i j} \times T_{i j}\right)$ de $\Sigma$ associada ao $i j$-ésimo indivíduo. $\boldsymbol{\Sigma}_{i j}$ segue sempre o padrão uniforme, uma vez que a estrutura de $\Sigma$ se mantém quando são eliminadas linhas e colunas com o mesmo índice (por exemplo, linha $i$ e coluna $i$ ).

Schwertman (1978) mostrou que os testes relacionados com comparações intra-indivíduos continuam válidos mesmo quando os $\varepsilon_{o i j}$ 's têm variância com a estrutura (2.6), o que é ainda mais abrangente do que o caso onde $\Sigma=\operatorname{Var}\left(y_{i j}\right)$ tem essa estrutura. Uma condição que deve ser satisfeita para que as demonstrações de Schwertman (1978) sejam válidas é que cada tratamento tenha pelo menos uma observação em cada um dos $T$ tempos.

Na presença de dados incompletos, a estimação dos parâmetros fixos do modelo é afetada pela presença de efeitos aleatórios, pois não mais se verifica a ortogonalidade entre as componentes fixas e aleatórias do modelo. Neste caso, para a obtenção de estimativas e somas de quadrados, convém realizar uma análise condicional, tratando os efeitos aleatórios como se fossem fixos e ampliando a matriz de especificação convenientemente. Sejam $X_{o}^{*}$ a matriz de especificação associada aos efeitos fixos e aleatórios (considerados fixos) do modelo e $\beta^{*}=\left(\beta^{t}, \pi^{t}\right)^{t}$, onde $\pi$ é o vetor $((N-G) \times 1)$ dos parâmetros individuais $\pi_{j(i)}$. Uma vez que esses últimos são tratados aqui como efeitos fixos, podemos impor a restrição $\sum_{j=1}^{n_{i}} \pi_{j(i)}=0, i=1, \ldots, G$, para que $\left(X_{o}^{* t} X_{o}^{*}\right)$ seja não-singular. Nesse caso, $\beta^{*}$ tem dimensão $(q \times 1)$, onde $q=p+N-G=G T+N-G$.

Como ilustração, consideremos o Exemplo 1.1 e suponhamos que a observação do primeiro indivíduo do primeiro tratamento correspondente ao tempo $T_{1}$ não tenha sido coletada; então o vetor de parâmetros é

$$
\beta^{*}=\left(\mu, \alpha_{1}, \gamma_{1}, \gamma_{2}, \alpha \gamma_{11}, \alpha \gamma_{12}, \pi_{1(1)}, \pi_{2(1)}, \pi_{1(2)}, \pi_{2(2)}\right)^{t}
$$


e a matriz de especificação é

$$
\boldsymbol{X}_{0}^{*}=\left(\begin{array}{rrrrrrrrrr}
1 & 1 & 0 & 1 & 0 & 1 & 1 & 0 & 0 & 0 \\
1 & 1 & -1 & -1 & -1 & -1 & 1 & 0 & 0 & 0 \\
1 & 1 & 1 & 0 & 1 & 0 & 0 & 1 & 0 & 0 \\
1 & 1 & 0 & 1 & 0 & 1 & 0 & 1 & 0 & 0 \\
1 & 1 & -1 & -1 & -1 & -1 & 0 & 1 & 0 & 0 \\
1 & 1 & 1 & 0 & 1 & 0 & -1 & -1 & 0 & 0 \\
1 & 1 & 0 & 1 & 0 & 1 & -1 & -1 & 0 & 0 \\
1 & 1 & -1 & -1 & -1 & -1 & -1 & -1 & 0 & 0 \\
1 & -1 & 1 & 0 & -1 & 0 & 0 & 0 & 1 & 0 \\
1 & -1 & 0 & 1 & 0 & -1 & 0 & 0 & 1 & 0 \\
1 & -1 & -1 & -1 & 1 & 1 & 0 & 0 & 1 & 0 \\
1 & -1 & 1 & 0 & -1 & 0 & 0 & 0 & 0 & 1 \\
1 & -1 & 0 & 1 & 0 & -1 & 0 & 0 & 0 & 1 \\
1 & -1 & -1 & -1 & 1 & 1 & 0 & 0 & 0 & 1 \\
1 & -1 & 1 & 0 & -1 & 0 & 0 & 0 & -1 & -1 \\
1 & -1 & 0 & 1 & 0 & -1 & 0 & 0 & -1 & -1 \\
1 & -1 & -1 & -1 & 1 & 1 & 0 & 0 & -1 & -1
\end{array}\right)
$$

Com a estrutura uniforme para $\Sigma$ e considerando uma análise condicional, o modelo é

$$
y_{o}=X_{o}^{*} \beta^{*}+e_{o}
$$

onde $e_{o}$ é o subvetor do vetor de erros aleatórios $e=\left(e_{11}^{t}, \ldots, e_{G n_{G}}^{t}\right)^{t}$ correspondente aos dados observados, com $\operatorname{Var}\left(\boldsymbol{e}_{o}\right)=\sigma^{2} \boldsymbol{I}_{T}$.

As somas de quadrados devidas a hipóteses que envolvem comparações intra-indivíduos (como $H_{01}$ e $\left.H_{03}\right)$ podem ser escritas como

$$
S Q H=S Q E_{2}\left(X_{o r}^{*}\right)-S Q E_{2}\left(X_{o}^{*}\right)
$$

onde $X_{o r}^{*}$ é a matriz de especificação restrita (que inclui as restrições impostas pela hipótese nula),

$$
S Q E_{2}\left(X_{o}^{*}\right)=y_{o}^{t}\left(I_{T .}-X_{o}^{*}\left(X_{o}^{* t} X_{o}^{*}\right)^{-1} X_{o}^{* t}\right) y_{o}
$$

e

$$
S Q E_{2}\left(X_{o r}^{*}\right)=y_{o}^{t}\left(I_{T .}-X_{o r}^{*}\left(X_{o r}^{* t} X_{o r}^{*}\right)^{-1} X_{o r}^{* t}\right) y_{o} .
$$


Schwertman (1978) mostrou que

$$
\begin{aligned}
E\left\{S Q E_{2}\left(X_{o}^{*}\right)\right\} & =\sigma^{2} \operatorname{posto}\left(I_{T .}-X_{o}^{*}\left(X_{o}^{* t} X_{o}^{*}\right)^{-1} X_{o}^{* t}\right)= \\
& =\sigma^{2}\left(t r\left(I_{T .}\right)-\operatorname{posto}\left(X_{o}^{*}\right)\right)= \\
& =\sigma^{2}(T .-q)
\end{aligned}
$$

pois $\left(\boldsymbol{I}_{T}-\boldsymbol{X}_{o}^{*}\left(\boldsymbol{X}_{o}^{* t} \boldsymbol{X}_{o}^{*}\right)^{-1} \boldsymbol{X}_{o}^{* t}\right)$ é idempotente e posto $\left(\boldsymbol{X}_{o}^{*}\right)=q$. De maneira análoga temos

$$
\begin{aligned}
E\left\{S Q E_{2}\left(X_{o r}^{*}\right)\right\} & =\sigma^{2}\left(t r\left(\boldsymbol{I}_{T .}\right)-\operatorname{posto}\left(X_{o r}^{*}\right)\right)= \\
& =\sigma^{2}\left(T .-\operatorname{posto}\left(\boldsymbol{X}_{o r}^{*}\right)\right)
\end{aligned}
$$

onde posto $\left(X_{o r}^{*}\right)$ é sempre dado por $q$ menos o número de parâmetros envolvidos na hipótese em questão. De (2.22), (2.25) e (2.26) obtém-se também

$$
\begin{aligned}
E(S Q H) & =E\left\{S Q E_{2}\left(X_{o r}^{*}\right)\right\}-E\left\{S Q E_{2}\left(X_{o}^{*}\right)\right\}= \\
& =\sigma^{2}\left(q-\operatorname{posto}\left(X_{o r}^{*}\right)\right) .
\end{aligned}
$$

Além disso, Schwertman (1978) demonstrou que, sob a hipótese nula,

$$
\frac{S Q E_{2}\left(X_{o}^{*}\right)}{\sigma^{2}} \sim \chi_{(T-q)}^{2}
$$

e

$$
\frac{S Q E_{2}\left(X_{o r}^{*}\right)}{\sigma^{2}} \sim \chi_{\left(T,-p o s t o\left(X_{o r}^{*}\right)\right)}^{2}
$$

Consequentemente,

$$
\frac{S Q H}{\sigma^{2}} \sim \chi_{\left(q-p o s t o\left(X_{o r}\right)\right)}^{2} .
$$

Segundo o Teorema 4.22 de Graybill (1961), (2.29) e (2.30) são independentes, de forma que

$$
\frac{S Q H /\left(q-\operatorname{posto}\left(X_{o r}^{*}\right)\right)}{S Q E_{2}\left(X_{o}^{*}\right) /(T .-q)}=\frac{Q M H}{Q M E_{2}} \sim F_{\left[\left(q-p o s t o\left(X_{o r}^{*}\right)\right) ;(T .-q)\right]}
$$


Para $H_{01}, q-\operatorname{posto}\left(X_{o r}^{*}\right)=(T-1)(G-1)$ e no caso de $H_{03}, q-\operatorname{posto}\left(X_{o r}^{*}\right)=(T-1)$. Se os dados forem completos, $(T-q)=(T-1)(N-G)$, o que corresponde exatamente aos graus de liberdade apresentados na ANOVA na Seção 2.1.

Portanto, qualquer hipótese que envolva comparações intra-indivíduos pode ser testada através de uma análise split-plot, independentemente de os dados serem completos ou incompletos, desde que haja graus de liberdade suficientes para o erro 2 e que a hipótese seja estimável (veja Graybill (1961, Seção 11.4.2)). Entretanto, através de estudos de simulação, Schwertman et al. (1981) mostraram que na presença de dados incompletos, os níveis descritivos dos testes são bem mais sensíveis à condição de esfericidade de $\Sigma$.

Como ilustração, considere os dados do Exemplo $1.1 \mathrm{sem}$ a primeira observação; nesse caso, $N=6, G=2$ e $T=3$, de forma que $q=10$, e $T .=17$. A matriz de especificação $X_{\circ}^{*}$ para esse conjunto de dados é dada por $(2.20)$ e $\operatorname{posto}\left(X_{o}^{*}\right)=10$. Para testar $H_{01}$ (inexistência da interação TempoxTratamento), a matriz de especificação restrita sob a hipótese, $X_{o r}^{*}$, é dada por (2.20) sem as colunas 5 e 6 e posto $\left(X_{o r}^{*}\right)=8$. Assim, de acordo com $(2.28)$ e $(2.30), S Q E_{2}\left(X_{o}^{*}\right) / \sigma^{2}$ e $S Q H / \sigma^{2}$ são independentes com distribuições $\chi_{(7)}^{2}$ e $\chi_{(2)}^{2}$, respectivamente, sob $H_{01}$. Portanto, $Q M H / Q M E_{2} \sim F_{[2 ; 7]}$. De forma análoga podemos testar $H_{03}$ (efeito do Tempo), onde $X_{o r}^{*}$ corresponde a $(2.20)$ sem as colunas 3 e 4 e $\operatorname{posto}\left(X_{o r}^{*}\right)=8$. Nesse caso, considerando apenas os 5 indivíduos que possuem dados completos, o nível descritivo para a aproximação assintótica do teste de Mauchly é igual a 0.76 , indicando que não há evidências contrárias ao padrão de esfericidade para $\boldsymbol{\Sigma}$ (esse teste deve ser considerado com cautela pois o tamanho amostral nesse caso é muito pequeno) e que, portanto, os testes para os efeitos de Tempo e TempoxTratamento podem ser baseados em distribuições $F$ exatas.

Com relação às hipóteses associadas a comparações entre indivíduos, como a hipótese $H_{02}$, não há testes exatos conhecidos. Algumas alternativas para obtenção de testes $F$ aproximados serão apresentadas no final desse capítulo. 
$\mathrm{O}$ vetor de parâmetros $\beta$ pode ser escrito como $\beta=\left(\beta_{1}^{t}, \beta_{2}^{t}\right)^{t}$, onde $\beta_{1}\left(p_{1} \times 1\right)$ contém os $p_{1}$ parâmetros associados aos efeitos de Tratamento e $\beta_{2}\left(p_{2} \times 1\right)$ contém aqueles associados aos efeitos de Tempo e da interação Tratamento $\times$ Tempo $\left(p_{1}+p_{2}=p\right.$ e $\left.\beta^{*}=\left(\beta_{1}^{t}, \boldsymbol{\beta}_{2}^{t}, \pi^{t}\right)^{t}\right)$. Sob o modelo condicional (2.21), o estimador de mínimos quadrados (não-viciado) para $\boldsymbol{\beta}_{2}, \hat{\boldsymbol{\beta}}_{2}$, é dado pelos correspondentes $p_{2}$ elementos de

$$
\hat{\beta}^{*}=\left(X_{o}^{* t} X_{o}^{*}\right)^{-1} X_{o}^{* t} y_{o}
$$

Um estimador para $\boldsymbol{\beta}_{1}, \hat{\boldsymbol{\beta}}_{1}$, sob o modelo (2.19), pode ser dado pelos primeiros $p_{1}$ elementos de

$$
\hat{\beta}=\left(X_{o}^{t} \hat{\Sigma}_{o}^{-1} X_{o}\right)^{-1} X_{o}^{t} \hat{\Sigma}_{o}^{-1} y_{o}
$$

$\operatorname{com} \hat{\Sigma}_{o}=\operatorname{diag}\left[\hat{\Sigma}_{11}, \hat{\Sigma}_{12}, \ldots, \hat{\Sigma}_{G n_{G}}\right]$ e $\hat{\Sigma}_{i j}=\hat{\sigma}_{\pi o}^{2} 1_{T_{i j}} 1_{T_{i j}}^{t}+\hat{\sigma}_{o}^{2} I_{T_{i j}}$, onde $\hat{\sigma}_{\pi o}^{2}$ e $\hat{\sigma}_{o}^{2}$ são estimadores de $\sigma_{\pi}^{2}$ e $\sigma^{2}$, respectivamente. Henderson (1953) apresenta três métodos para a estimação dos componentes de variância no caso de dados desbalanceados, o último dos quais é aplicado a modelos mistos e é equivalente ao método usado no caso de dados completos, podendo ser aqui utilizado para a obtenção de $\hat{\sigma}_{\pi o}^{2}$ e $\hat{\sigma}_{o}^{2}$. As esperanças das somas de quadrados associadas aos erros 1 e 2 (da ANOVA para dados incompletos) são dadas, respectivamente, por

$$
\begin{aligned}
& E\left(S Q E_{1}\right)=(T .-k) \sigma_{\pi}^{2}+(N-G) \sigma^{2} \\
& E\left(S Q E_{2}\right)=(T .-q) \sigma^{2}
\end{aligned}
$$

com

$$
k=\sum_{u=1}^{N}\left[\sum_{i=1}^{p} \sum_{j=1}^{p}\left\langle\left(X_{o}^{t} X_{o}\right)^{-1}\right\rangle_{i j}\left\langle X_{o}^{t} X_{\pi}\right\rangle_{i u}\left\langle X_{\pi}^{t} X_{o}\right\rangle_{u j}\right],
$$

onde $X_{0}$ é tal qual definida em (2.19), $X_{\pi}$ é a matriz de especificação $(T \times N)$ associada aos $N$ parâmetros individuais $\pi_{i(j)}$ (sem restrições sobre esses parâmetros), $p=G T$ e $q=p+N-G$; $\langle A\rangle_{a b}$ denota o $a b$-ésimo elemento da matriz $A$. 
A partir de (2.34) obtêm-se

$$
\begin{aligned}
& S Q E_{1}=(T .-k) \hat{\sigma}_{\pi \circ}^{2}+(N-G) \hat{\sigma}_{o}^{2} \\
& S Q E_{2}=(T .-q) \hat{\sigma}_{o}^{2} .
\end{aligned}
$$

Resolvendo o sistema de equações acima, chega-se aos estimadores

$$
\hat{\sigma}_{o}^{2}=\frac{S Q E_{2}}{(T .-q)}
$$

$$
\hat{\sigma}_{\pi o}^{2}=\frac{1}{(T .-k)}\left[S Q E_{1}-\frac{(N-G)}{(T .-q)} S Q E_{2}\right],
$$

sendo que $\hat{\sigma}_{o}^{2}$ é um estimador não-viciado para $\sigma^{2}$ (ver Henderson (1953)), enquanto que $\hat{\sigma}_{\pi o}^{2}$ é um estimador para $\sigma_{\pi}^{2}$.

Um estimador não-viciado para a variância de $\hat{\boldsymbol{\beta}}_{2}$ é dado pelas $p_{2}$ correspondentes linhas e colunas de

$$
\widehat{\operatorname{Var}}\left(\hat{\boldsymbol{\beta}}^{*}\right)=\left(X_{o}^{* t} \boldsymbol{X}_{o}^{*}\right)^{-1} \hat{\sigma}_{o}^{2}
$$

enquanto que um estimador para a variância de $\hat{\boldsymbol{\beta}}_{1}$ pode ser dado pelas $p_{1}$ correspondentes linhas e colunas de

$$
\widehat{\operatorname{Var}}(\hat{\boldsymbol{\beta}})=\left(X_{o}^{t} \hat{\Sigma}_{* o}^{-1} X_{o}\right)^{-1}
$$

Apesar da maneira simples com que os testes para hipóteses que envolvem comparações intraindivíduos podem ser obtidos, na prática depara-se com complicações computacionais. Muitos pacotes estatísticos lidam com os dados longitudinais dispostos na forma de uma matriz $(N \times$ $T$ ) e, na presença de dados incompletos, eles acabam por eliminar todos os vetores individuais de observações que possuam algum dado não-observado. Esse tipo de procedimento pode vir a desperdiçar muita informação e por isso não é muito adequado na maioria das situações. Nesse contexto, uma maneira de contornar esses problemas computacionais decorrentes da existência de dados incompletos é dada pelo método de Bartlett (1937) que descreveremos a seguir. 


\subsection{O Método de Bartlett}

Bartlett (1937) desenvolveu um procedimento para ANOVA com dados incompletos cuja aplicação para ANOVA com medidas repetidas foi sugerida por Berk (1987). Esse procedimento apresenta as seguintes propriedades:

(i) utiliza um procedimento de ANCOVA padrão que pode ser encontrado em grande parte dos pacotes estatísticos usuais;

(ii) é não-iterativo e portanto, evita questões de convergência;

(iii) a existência de um padrão singular de dados incompletos (ou seja, um padrão onde os parâmetros não possam ser estimados) é acusada pelo método, enquanto que métodos iterativos provavelmente produziriam um resultado inapropriado;

(iv) fornece estimadores não-viciados para os parâmetros e testes $F$ exatos para hipóteses associadas a comparações intra-indivíduos;

$(v)$ os coeficientes das covariáveis fornecem estimativas para os dados não-observados.

Para sua implementação, primeiramente, os $m$ dados não-observados são substituídos por valores quaisquer, de forma a completar o conjunto de dados (esses valores não influenciam os resultados). A seguir, usa-se um modelo de ANCOVA do tipo

$$
y=X \beta+Z \Psi+\varepsilon
$$

onde $\boldsymbol{y}$ é o vetor $(N T \times 1)$ de todas as observações (incluindo aquelas utilizadas para substituir os dados não-observados), com $N=\sum_{i=1}^{G} n_{i}, X$ é a matriz de especificação associada ao vetor $(p \times 1)$ $\beta$ de parâmetros desconhecidos, $Z$ é uma matriz $(N T \times m)$ com os valores de $m$ covariáveis do tipo 0 ou 1 (as $m$ linhas correspondentes aos dados não-observados são vetores $(1 \times m)$ com $m-1$ elementos iguais a zero e um elemento igual a 1, e as $N T-m$ linhas restantes são compostas por 
zeros), $\Psi$ é o vetor $(m \times 1)$ de parâmetros (coeficientes de regressão) desconhecidos associados às covariáveis e $\varepsilon$ é o vetor $(N T \times 1)$ de erros aleatórios; supomos ainda que $\varepsilon \sim N_{N T}\left(0, \Sigma_{\star}\right)$, com $\Sigma_{\star}=I_{N} \otimes \Sigma$ e que $\Sigma$ obedece ao padrão de simetria composta.

Com a parametrização de desvios médios dada por (1.20) e (2.1), o modelo para cada observação pode ser escrito como

$$
Y_{i j k}=\mu+\alpha_{i}+\gamma_{k}+\alpha \gamma_{i k}+\sum_{l=1}^{m} \psi_{l} z_{i j k l}+\pi_{j(i)}+e_{i j k},
$$

onde os termos $\mu, \alpha_{i}, \gamma_{k}, \alpha \gamma_{i k}, \pi_{j(i)}$ e $e_{i j k}$ são tais como aqueles descritos em (1.20) e (2.1), e $\psi_{l}$ é o coeficiente associado ao $l$-ésimo dado não-observado, $l=1, \ldots, m$, sendo que $z_{i j k l}=1$ se o $l$-ésimo dado não-observado corresponder à observação realizada no $k$-ésimo tempo para o $j$-ésimo indivíduo do $i$-ésimo tratamento e $z_{i j k l}=0$ caso contrário.

O modelo (2.40) também pode ser escrito na forma do modelo linear geral

$$
y=A \eta+\varepsilon,
$$

onde $\boldsymbol{A}=(\boldsymbol{X}, Z)$ e $\boldsymbol{\eta}=\left(\boldsymbol{\beta}^{t}, \Psi^{t}\right)^{t}$. Nesse caso, $\boldsymbol{A}$ é uma matriz $(N T \times(p+m))$ e $\boldsymbol{\eta}$ é um vetor $((p+m) \times 1)$.

Assim como foi feito na Seção 2.2, para efeito de obtenção das somas de quadrados e estimação dos parâmetros do modelo associados aos efeitos intra-indivíduos, vamos tratar os efeitos aleatórios $\pi_{j(i)}$ como fixos (fazendo uma análise condicional) e incluir em $\boldsymbol{A}$ as $(N-G)$ colunas associadas a eles (sob a suposição $\sum_{j=1}^{n_{i}} \pi_{j(i)}=0, i=1, \ldots, G$ ). Assim, sob esse aspecto, o modelo é

$$
y=X^{*} \beta^{*}+Z \Psi+e=A^{*} \eta^{*}+e,
$$

onde $\boldsymbol{A}^{*}=\left(\boldsymbol{X}^{*}, Z\right)$ tem dimensão $(N T \times(q+m)), \eta^{*}=\left(\beta_{(q \times 1)}^{* t}, \Psi_{(m \times 1)}^{t}\right)^{t}$ e $\operatorname{Var}(e)=\sigma^{2} \boldsymbol{I}_{N T}$.

Por exemplo, considerando os dados do Exemplo 1.1 e supondo que o primeiro valor não tenha sido observado, teremos 


$$
A^{*}=\left(\begin{array}{rrrrrrrrrrr}
1 & 1 & 0 & 1 & 0 & 1 & 1 & 1 & 0 & 0 & 1 \\
1 & 1 & 0 & 1 & 0 & 1 & 1 & 0 & 0 & 0 & 0 \\
1 & 1 & -1 & -1 & -1 & -1 & 1 & 0 & 0 & 0 & 0 \\
1 & 1 & 1 & 0 & 1 & 0 & 0 & 1 & 0 & 0 & 0 \\
1 & 1 & 0 & 1 & 0 & 1 & 0 & 1 & 0 & 0 & 0 \\
1 & 1 & -1 & -1 & -1 & -1 & 0 & 1 & 0 & 0 & 0 \\
1 & 1 & 1 & 0 & 1 & 0 & -1 & -1 & 0 & 0 & 0 \\
1 & 1 & 0 & 1 & 0 & 1 & -1 & -1 & 0 & 0 & 0 \\
1 & 1 & -1 & -1 & -1 & -1 & -1 & -1 & 0 & 0 & 0 \\
1 & -1 & 1 & 0 & -1 & 0 & 0 & 0 & 1 & 0 & 0 \\
1 & -1 & 0 & 1 & 0 & -1 & 0 & 0 & 1 & 0 & 0 \\
1 & -1 & -1 & -1 & 1 & 1 & 0 & 0 & 1 & 0 & 0 \\
1 & -1 & 1 & 0 & -1 & 0 & 0 & 0 & 0 & 1 & 0 \\
1 & -1 & 0 & 1 & 0 & -1 & 0 & 0 & 0 & 1 & 0 \\
1 & -1 & -1 & -1 & 1 & 1 & 0 & 0 & 0 & 1 & 0 \\
1 & -1 & 1 & 0 & -1 & 0 & 0 & 0 & -1 & -1 & 0 \\
1 & -1 & 0 & 1 & 0 & -1 & 0 & 0 & -1 & -1 & 0 \\
1 & -1 & -1 & -1 & 1 & 1 & 0 & 0 & -1 & -1 & 0
\end{array}\right),
$$

onde a última coluna corresponde à covariável associada à observação não coletada.

Sob o modelo (2.40), a hipótese $H_{0}: C \boldsymbol{\beta}=0$, onde $C$ é uma matriz $(c \times q)$ de posto $c$, pode ser escrita como

$$
H_{0}: D \eta^{*}=0
$$

onde $D=\left(\begin{array}{ll}C & 0\end{array}\right)$. Para testar uma hipótese que envolva comparações intra-indivíduos, a correspondente soma de quadrados devida a hipótese é dada por

$$
\begin{aligned}
S Q H_{A N C} & =\hat{\eta}^{* t} D^{t}\left(D\left(A^{* t} A^{*}\right)^{-1} D^{t}\right)^{-1} D \hat{\eta}^{*}= \\
& =\hat{\boldsymbol{\beta}}^{*} C^{t}\left(C\left(X_{o}^{* t} X_{o}^{*}\right)^{-1} C^{t}\right)^{-1} C \hat{\boldsymbol{\beta}}^{*}
\end{aligned}
$$

onde $\hat{\eta}^{*}$ é dado por (2.52). (2.45) é uma outra maneira de se escrever (2.22) e sua demonstração encontra-se no Apêndice A. Analogamente, mostramos no Apêndice A que a soma de quadrados devida ao erro intra-indivíduos (sob o modelo irrestrito) é dada por 


$$
\begin{aligned}
S Q E_{2 A N C} & =y^{t}\left(I_{N T}-A^{*}\left(A^{* t} A^{*}\right)^{-1} A^{t}\right) y= \\
& =y_{o}^{t}\left(I_{T}-X_{o}^{*}\left(X_{o}^{* t} X_{o}^{*}\right)^{-1} X_{o}^{* t}\right) y_{o}
\end{aligned}
$$

que por sua vez, é idêntica à (2.23).

Como as somas de quadrados (2.45) e (2.46) são iguais às obtidas para o modelo de dados incompletos e os testes $F$ correspondentes são exatos para testar hipóteses associadas a comparações intra-indivíduos (veja Seção 2.2), conclui-se que o método de Bartlett produz testes $F$ exatos para testar essas hipóteses, o que está representado na seguinte tabela de ANCOVA:

Tabela 2.2: ANCOVA associada aos fatores intra-individuos sob o modelo (2.40)

\begin{tabular}{lccc}
\hline Fonte de & Graus de & Somas de & Estatística \\
Variação & Liberdade & Quadrados & Para o Teste \\
\hline Intra-indiv. & $N(T-1)$ & & \\
Tempo & $T-1$ & $S Q H_{03 A N C}$ & $F_{3 A N C}=\frac{S Q H_{03 A N C} /(T-1)}{\left.S Q E_{2 A N C} /(N-G)(T-1)-m\right)}$ \\
Tratamento $\times$ Tempo & $(G-1)(T-1)$ & $S Q H_{01 A N C}$ & $F_{1 A N C}=\frac{S Q H_{01 A N C} /((G-1)(T-1))}{S Q E_{2 A N C} /((N-G)(T-1)-m)}$ \\
Covariáveis & $\mathrm{m}$ & $S Q C o v$ & \\
Tempo $\times$ Indiv. (erro 2) & $(N-G)(T-1)-m$ & $S Q E_{2 A N C}$ & \\
\hline
\end{tabular}

onde SQCov é a soma de quadrados devida às covariáveis.

Sob o método de Bartlett, assim como acontece quando os dados são completos, as estatísticas $F$ obtidas para testar as hipóteses associadas a comparações intra-indivíduos somente obedecem a distribuições $F$ exatas se $\Sigma$ for esférica. Caso contrário, é possível obter uma estimativa para o fator de correção dos graus de liberdade, $\epsilon$, de forma a se conseguirem testes aproximados.

Para verificar se $\boldsymbol{\Sigma}$ segue o padrão de esfericidade pode-se fazer uso do teste de esfericidade de Mauchly apresentado em (2.7)-(2.10), onde $S$ deve ser substituida pela matriz de covariância amostral para o modelo de AnCova. Mais especificamente 


$$
W=\frac{\operatorname{det}\left(P^{t} \tilde{S} P\right)}{\left\{(T-1)^{-1} \operatorname{tr}\left(P^{t} \tilde{S} P\right)\right\}^{(T-1)}},
$$

com

$$
\tilde{S}=\frac{1}{N-T} \tilde{Y}^{t}\left(I_{N}-V\left(V^{t} V\right)^{-1} V^{t}\right) \tilde{Y}
$$

onde $\tilde{Y}$ é o vetor de observações completado com as estimativas dos dados não-observados e $V$ é definido por (1.16), e

$$
\Upsilon=-\left[(N-G-m)-\frac{2 T^{2}-3 T+3}{6(T-1)}\right] \ln (W) .
$$

Sob a hipótese de que $\Sigma$ é esférica, $\Upsilon$ tem uma distribuição assintótica $\chi_{(\nu)}^{2}, \nu=(T-2)(T+1) / 2$. A aproximação de Anderson (1984) é equivalente a (2.10), com $n=(N-G-m)$.

Caso $\boldsymbol{\Sigma}$ não seja esférica, pode-se usar o procedimento de Greenhouse e Geisser (1959), descrito no final da Seção 2.1, para a realização dos testes $F$ aproximados. Assim, se necessário, estimativas de $\epsilon$ podem ser obtidas pelo estimador de Geisser e Greenhouse (1958):

$$
\hat{\epsilon}=\frac{\left[\operatorname{tr}\left(P^{t} \tilde{S} P\right)\right]^{2}}{(T-1) \operatorname{tr}\left(\boldsymbol{P}^{t} \tilde{S} \boldsymbol{P}\right)^{2}}
$$

ou ainda através do estimador de Huynh e Feldt (1976), que no caso de haver $m$ dados nãoobservados é igual a

$$
\tilde{\epsilon}=\frac{N(T-1) \hat{\epsilon}-2}{(T-1)[N-G-(T-1) \hat{\epsilon}]-m} .
$$

Sob o modelo (2.43), o estimador de mínimos quadrados para $\eta^{*}$ é dado por

$$
\hat{\eta}^{*}=\left(\begin{array}{c}
\hat{\beta}^{*} \\
\hat{\Psi}
\end{array}\right)=\left(A^{* t} A^{*}\right)^{-1} A^{* t} y .
$$

Utilizando a fórmula para inversão de uma matriz particionada, temos (ver Apêndice A):

$$
\hat{\boldsymbol{\beta}}^{*}=\left(X_{o}^{* t} X_{o}^{*}\right)^{-1} X_{o}^{* t} y_{o}
$$


que é igual ao estimador obtido em (2.32), onde $X_{o}^{*}$ e $y_{o}$ são componentes do modelo (2.21). Portanto, com $\beta^{*}=\left(\beta_{1}^{t}, \beta_{2}^{t}, \pi^{t}\right)^{t}$, um estimador não-viciado para $\beta_{2}$ (parâmetros associados aos efeitos fixos intra-indivíduos) é dado pelos correspondentes $p_{2}$ elementos de $\hat{\eta}^{*}$.

Além disso, um estimador para a variância de $\hat{\eta}^{*}$ é dado por

$$
\widehat{\operatorname{Var}}\left(\hat{\eta}^{*}\right)=\left(\begin{array}{cc}
\widehat{\operatorname{Var}}\left(\hat{\boldsymbol{\beta}}^{*}\right) & \widehat{\operatorname{Cov}}\left(\hat{\boldsymbol{\beta}}^{*}, \hat{\Psi}\right) \\
\widehat{\operatorname{Cov}}\left(\hat{\boldsymbol{\beta}}^{*}, \hat{\Psi}\right) & \widehat{\operatorname{Var}}(\hat{\Psi})
\end{array}\right)=\left(A^{* t} A^{*}\right)^{-1} \hat{\sigma}_{A N C}^{2},
$$

onde $\hat{\sigma}_{A N C}^{2}$ é obtido a partir da ANCOVA por $S Q E_{2 A N C} /[(N-G)(T-1)-m]$ que é idêntico à $\hat{\sigma}_{o}^{2}$ obtido em (2.36). Assim, sob o modelo condicional (2.43), e utilizando (A.3) (do Apêndice A),

$$
\widehat{\operatorname{Var}}\left(\hat{\beta}^{*}\right)=\left(X_{\dot{v}}^{* t} X_{\dot{v}}^{*}\right)^{-1} \hat{\sigma}_{\dot{v}}^{2},
$$

que é igual a (2.38), o que significa que um estimador não-viciado para $\widehat{\operatorname{Var}}\left(\hat{\boldsymbol{\beta}}_{2}\right)$ é dado pelas correspondentes $p_{2}$ linhas e colunas de $\widehat{\operatorname{Var}}\left(\hat{\eta}^{*}\right)$.

Portanto, através de uma ANCOVA para dados artificialmente completos, obtêm-se estimadores não-viciados para os parâmetros fixos associados a comparações intra-indivíduos.

Estimadores para $\beta_{1}$ e $\operatorname{Var}\left(\hat{\boldsymbol{\beta}}_{1}\right)$ foram sugeridos em (2.33) e (2.39) da Seção 2.2. Uma outra opção seria completar o conjunto de dados com estimativas obtidas a partir de (2.57) e obter $\hat{\boldsymbol{\beta}}_{1} \mathrm{e}$ $\widehat{\operatorname{Var}}\left(\hat{\boldsymbol{\beta}}_{1}\right)$ da maneira usual (veja Seção 2.1 ).

A partir dos coeficientes das covariáveis obtidos com a AnCOVA é possível obter estimativas de mínimos quadrados para os dados não-observados. De (2.52) obtemos um estimador de mínimos quadrados para $\Psi$, dado por

$$
\hat{\Psi}=y_{m}-X_{m}^{*} \hat{\beta}^{*}
$$

onde $y_{m}$ é o vetor $(m \times 1)$ dos dados não-observados previamente substituídos por valores quaisquer e $X_{m}^{*}(m \times p)$ é a correspondente matriz de especificação. Um estimador de mínimos quadrados 
para $\boldsymbol{y}_{m}$ é dado por

$$
\hat{y}_{m}=X_{m}^{*} \hat{\beta}^{*}
$$

Logo, substituindo (2.56) em (2.57), obtemos

$$
\hat{y}_{m}=y_{m}-\hat{\Psi} .
$$

Particularmente, se os valores não-observados forem substituídos por zeros $\left(y_{m}=0\right)$, então cada um desses valores não-observados pode ser estimado pelo coeficiente da covariável associada a ele com sinal trocado.

Rubin $(1972,1976)$ apresenta um outro procedimento para análise de dados incompletos em geral, que fornece resultados equivalentes aos obtidos pelo método de Bartlett. Berk (1987) sugere a aplicação desse procedimento na análise de dados longitudinais. Esse método utiliza somente rotinas de ANOVA para dados completos e balanceados seguidas da inversão de uma matriz simétrica $(m \times m)$. Pelo fato de requerer uma quantidade bem maior de cálculos, o procedimento de Rubin parece ser mais interessante somente no caso de não haver disponibilidade de recursos para se efetuar uma ANcova. Detalhes sobre essa técnica podem ser encontradas em Rubin $(1972,1976)$ ou ainda em Little e Rubin (1987).

Nenhum dos três métodos para análise de dados incompletos mencionados neste capítulo modelo linear geral, método de Bartlett e procedimento de Rubin - fornece testes exatos para testar hipóteses associadas a comparaçōes entre indivíduos, como $H_{02}$. No caso de haver poucas observações incompletas, existem algumas maneiras de se obter um teste $F$ aproximado:

(i) Efetua-se a análise dos dados incompletos utilizando alguma das técnicas descritas aqui e a partir da estimação de $\beta$ obtêm-se estimativas para os dados não-observados através de $\hat{\boldsymbol{y}}_{m}=X_{m} \hat{\boldsymbol{\beta}}^{*}$ (que no caso do método de Bartlett é igual a (2.58)). Substituem-se os valores que faltavam pelas suas estimativas e, agora na presença de dados completos, prossegue-se com uma análise usual. 
(ii) Calcula-se a média de todas as observações para cada indivíduo, e efetua-se uma análise de variância usual com um fator fixo (que é exatamente o procedimento realizado pela ANOVA no caso de dados completos).

Vantagens e desvantagens decorrentes dessas duas sugestōes de testes aproximados para comparações entre indivíduos não são aqui abordadas, e podem sugerir futuras pesquisas. 


\section{Capítulo 3}

\section{Análise através do método de}

\section{Máxima Verossimilhança}

Um enfoque alternativo para análise de dados incompletos em estudos longitudinais consiste na utilização do modelo linear geral (introduzido na Seção 1.3) e na estimação de seus parâmetros através dos métodos de máxima verossimilhança (MV) ou máxima verossimilhança restrita (MVR). Uma das grandes vantagens desse enfoque está na possibilidade de acomodação de diferentes estruturas para a matriz de covariância $\Sigma$.

Consideremos o modelo para dados incompletos (2.19). Para simplificar a notação, vamos ignorar, sem perda de generalidade, a alocação dos indivíduos a vários tratamentos e eliminar o índice $i$ dos componentes do modelo. Assim, o modelo associado ao $j$-ésimo indivíduo, $j=1, \ldots, N$, é dado por

$$
y_{o j}=X_{o j} \beta+\varepsilon_{o j}
$$

onde $y_{o j}, X_{o j}$ e $\varepsilon_{o j}$ são, respectivamente, o vetor dos dados observados, a correspondente matriz de especificação e o correspondente vetor de erros aleatórios, $j=1, \ldots, N$. Na notação do modelo (2.19), $y_{o}=\left(y_{o 1}^{t}, y_{o 2}^{t}, \ldots, y_{o N}^{t}\right)^{t}, X_{o}=\left(X_{o 1}^{t}, X_{o 2}^{t}, \ldots, X_{o N}^{t}\right)^{t}$ e $\varepsilon_{o}=\left(\varepsilon_{o 1}^{t}, \varepsilon_{o 2}^{t}, \ldots, \varepsilon_{o N}^{t}\right)^{t}$. 
Assumimos que $\varepsilon_{o 1}, \ldots, \varepsilon_{o N}$ são independentes com $\varepsilon_{o j} \sim N\left(0, \Sigma_{j}\right)$, onde cada $\boldsymbol{\Sigma}_{j}$ é uma matriz simétrica positiva definida (em (2.19) $\Sigma_{j}$ era necessariamente uniforme). Consequentemente, $y_{o j} \sim N\left(X_{o j} \beta, \Sigma_{j}\right)$ e $y_{o 1}, \ldots, y_{o N}$ são independentes. Além disso, assumimos que $X_{o}$ tem posto $p \leq T$. e que os elementos de $\Sigma_{j}$ são funções conhecidas de um vetor $\theta(h \times 1)$ de parâmetros desconhecidos não-redundantes, cujos elementos não dependem de $\beta$, ou seja, $\Sigma_{j}=\Sigma_{j}(\theta)$. Então, $\operatorname{Var}\left(y_{o}\right)=\Sigma_{o}=\operatorname{diag}\left[\Sigma_{1}(\theta), \ldots, \Sigma_{N}(\theta)\right]$

No caso de dados completos, supomos que uma mesma estrutura de covariância esteja associada a todos os indivíduos, ou seja, $\boldsymbol{\Sigma}_{j}(\theta)=\Sigma(\theta)=\Sigma, j=1, \ldots, N$. Na presença de dados incompletos, $\Sigma_{j}\left(T_{j} \times T_{j}\right)$ é obtida de $\Sigma(T \times T)$ selecionando-se as linhas e colunas correspondentes às $T_{j}$ ocasiões de avaliação efetivas do $j$-ésimo indivíduo.

\subsection{Modelos para a estrutura de covariância}

A escolha de um modelo para a estrutura de $\Sigma$ depende do conhecimento do pesquisador a respeito do processo de geração dos dados, bem como da maneira como eles foram coletados no decorrer das ocasiões de avaliação. Por exemplo, em muitos estudos envolvendo a comparação de dietas para frangos de corte, espera-se que a variabilidade dos dados seja maior na fase inicial de engorda e diminua com o crescimento dos animais. Jennrich e Schluchter (1986) entre outros, apresentam alguns modelos para $\Sigma$ :

(i) $\Sigma$ não-estruturada (como em (1.27)).

Geralmente essa estrutura é aplicada quando não há bases empíricas ou teóricas para se estabelecer algum padrão para a matriz de covariância. Como o número de ocasiões de avaliação é $T, \boldsymbol{\theta}=\left(\sigma_{1}^{2}, \sigma_{12}, \ldots, \sigma_{1 T}, \sigma_{2}^{2}, \ldots, \sigma_{T}^{2}\right)^{t}$ tem $T(T+1) / 2$ parâmetros. Quando $N$ é pequeno em relação a $T$, pode ser impossível estimar todos os $T(T+1) / 2$ parâmetros de $\Sigma$, especialmente se houver muitos dados incompletos. Além disso, o excessivo número de parâmetros pode ocasionar ineficiência na estimação da variância do estimador de $\beta$. Nesses 
casos, estruturas mais restritivas (e com menos parâmetros) como as apresentadas a seguir, devem ser consideradas.

(ii) Estruturas associadas a modelos de séries temporais.

Nesse caso supõe-se que os vetores de erros aleatórios $\varepsilon_{j}$ obedecem a processos autorregressivos estacionários ou de médias móveis (veja Shumway (1988), por exemplo). Esse tipo de estrutura é especialmente conveniente quando há poucas unidades amostrais ( $N$ pequeno) e um grande número de ocasiões de avaliação ( $T$ grande), mesmo na presença de dados incompletos. Podemos destacar alguns casos particulares:

(ii.1) Estrutura autorregressiva de primeira ordem (AR(1)).

Aqui,

$$
\Sigma=\sigma^{2}\left(\begin{array}{ccccc}
1 & \rho & \rho^{2} & \ldots & \rho^{T-1} \\
\rho & 1 & \rho & \ldots & \rho^{T-2} \\
\rho^{2} & \rho & 1 & \ldots & \rho^{T-3} \\
\vdots & \vdots & \vdots & \ddots & \vdots \\
\rho^{T-1} & \rho^{T-2} & \rho^{T-3} & \ldots & 1
\end{array}\right)
$$

onde $|\rho|<1$ e $\sigma^{2}>0$. Esse modelo está associado a uma situação bastante encontrada na prática, onde as correlações entre as observações decrescem à medida que aumenta a distância entre elas. Nesse caso, $\theta=\left(\sigma^{2}, \rho\right)^{t}$ e para $T>3$, o número de parâmetros (igual a 2) é muito menor do que em (i).

(ii.2) Estrutura de médias móveis de primeira ordem (MA(1)). 
Nesse caso,

$$
\Sigma=\sigma^{2}\left(\begin{array}{ccccc}
1 & \rho & 0 & \ldots & 0 \\
\rho & 1 & \rho & \ldots & 0 \\
0 & \rho & 1 & \ldots & 0 \\
\vdots & \vdots & \vdots & \ddots & \vdots \\
0 & 0 & 0 & \ldots & 1
\end{array}\right)
$$

onde $|\rho|<1$ e $\sigma^{2}>0$. Com a estrutura acima, supomos que somente as observações realizadas em ocasiões adjacentes são correlacionadas e $\boldsymbol{\theta}=\left(\sigma^{2}, \rho\right)^{t}$.

(ii.1) e (ii.2) são casos especiais da seguinte estrutura de covariância:

(ii.3) Estrutura autorregressiva geral (banded).

Nesse caso,

$$
\Sigma=\sigma^{2}\left(\begin{array}{ccccc}
1 & \rho_{1} & \rho_{2} & \ldots & \rho_{T-1} \\
\rho_{1} & 1 & \rho_{1} & \ldots & \rho_{T-2} \\
\rho_{2} & \rho_{1} & 1 & \ldots & \rho_{T-3} \\
\vdots & \vdots & \vdots & \ddots & \vdots \\
\rho_{T-1} & \rho_{T-2} & \rho_{T-3} & \ldots & 1
\end{array}\right)
$$

de forma que $\boldsymbol{\theta}=\left(\sigma^{2}, \rho_{1}, \rho_{2}, \ldots, \rho_{T-1}\right)^{t}$ é composto por $T$ parâmetros. O modelo (3.4) representa uma estrutura de correlação serial onde a correlação entre duas observações depende unicamente da diferença de tempo entre elas, e que por isso é chamada de estacionária.

(ii.4) Muñoz et al. (1992) propoem uma estrutura chamada estrutura de correlação exponencial amortecida, onde a correlação entre duas observações separadas por $s$ unidades de tempo é modelada por $\rho^{s^{\gamma}}$, e consequentemente, a covariância é modelada por $\sigma^{2} \rho^{s^{\gamma}}$ onde $\rho$ é a correlação entre elementos separados por uma unidade de tempo e $\gamma$ é o parâmetro de amortecimento. Assim, quando $\gamma=0, \gamma=1$ e $\gamma \rightarrow \infty$, obtém-se, respec- 
tivamente, as estruturas de simetria composta, $\mathrm{AR}(1)$ e $\mathrm{MA}(1)$, dadas respectivamente por (2.2), (3.2) e (3.3). Sob esse enfoque, $\theta=\left(\sigma^{2}, \rho, \gamma\right)$.

(iii) Estruturas associadas ao modelo de efeitos aleatórios.

Um outro caso especial importante provém do modelo de efeitos aleatórios. O modelo para o $j$-ésimo indivíduo com dados completos é

$$
y_{j}=X_{j} \beta+Z b_{j}+u_{j},
$$

onde $Z(T \times k)$ é uma matriz conhecida e $b_{j}(k \times 1)$ e $u_{j}(T \times 1)$ são vetores aleatórios independentes com $\left.\boldsymbol{b}_{j} \sim N(\mathbf{0}, \boldsymbol{\Phi})\right)$ e $u_{j} \sim N\left(\mathbf{0}, \sigma^{2} \boldsymbol{I}_{T}\right)$. Então,

$$
\Sigma=Z \Phi Z^{t}+\sigma^{2} I_{T}
$$

Consequentemente, no caso de dados incompletos temos

$$
y_{o j}=X_{o j} \beta+Z_{j} b_{j}+u_{o j}
$$

onde $X_{o j}, Z_{j}$, e $u_{o j}$ contém as linhas de $X_{j}, Z$ e $\boldsymbol{u}_{j}$, respectivamente, correspondentes aos elementos de $\boldsymbol{y}_{j}$ efetivamente observados. Nesse caso,

$$
\Sigma_{j}=Z_{j} \Phi Z_{j}^{t}+\sigma^{2} I_{T_{j}}
$$

O modelo de efeitos aleatórios é estudado por Laird e Ware (1982) e Andreoni (1989) entre outros. Um caso particular é o da estrutura de simetria composta, onde $Z=\mathbf{1}_{T}$ e $\boldsymbol{\Phi}=\sigma_{\pi}^{2}$ em (3.8), de forma que $\boldsymbol{\Sigma}$ é dada por (2.2) e $\boldsymbol{\theta}=\left(\sigma^{2}, \sigma_{\pi}^{2}\right)^{t}$.

\subsection{Estimação e Testes de Hipóteses}

O processo de obtenção dos estimadores de máxima verossimilhança de $\beta$ e $\theta$ consiste em se encontrar $\hat{\boldsymbol{\beta}}$ e $\hat{\boldsymbol{\theta}}$ que maximizam a função de verossimilhança dos dados

$$
L\left(\boldsymbol{y}_{o} ; \boldsymbol{\beta}, \boldsymbol{\theta}\right)=(2 \pi)^{-\frac{T}{2}} \prod_{j=1}^{N}\left|\Sigma_{j}\right|^{-1 / 2} \exp \left\{-\frac{1}{2} \sum_{j=1}^{N}\left(y_{o j}-X_{o j} \beta\right)^{t} \Sigma_{j}^{-1}\left(\boldsymbol{y}_{o j}-X_{o j} \beta\right)\right\},
$$


onde $\boldsymbol{\Sigma}_{j}=\boldsymbol{\Sigma}_{j}(\boldsymbol{\theta})$. Maximizar (3.9) é equivalente a maximizar o logaritmo da função de verossimilhança, ou seja,

$$
l\left(y_{o} ; \beta, \theta\right)=K-\frac{1}{2} \sum_{j=1}^{N} \ln \left|\Sigma_{j}\right|-\frac{1}{2} \sum_{j=1}^{N}\left(y_{o j}-X_{o j} \beta\right)^{t} \Sigma_{j}^{-1}\left(y_{o j}-X_{o j} \beta\right),
$$

onde $K$ é uma constante que não depende de $\beta$ e $\theta$.

Convém, então, definir a função escore

$$
s=\left(\begin{array}{c}
s_{\beta} \\
s_{\theta}
\end{array}\right)=\left(\begin{array}{c}
\partial l / \partial \beta \\
\partial l / \partial \theta
\end{array}\right)
$$

e a matriz Hessiana

$$
\boldsymbol{H}=\left(\begin{array}{ll}
H_{\beta \beta} & H_{\beta \theta} \\
H_{\theta \beta} & H_{\theta \theta}
\end{array}\right)=\left(\begin{array}{ll}
\partial^{2} l / \partial \beta^{t} \partial \beta & \partial^{2} l / \partial \beta^{t} \partial \theta \\
\partial^{2} l / \partial \boldsymbol{\theta}^{t} \partial \beta & \partial^{2} l / \partial \theta^{t} \partial \boldsymbol{\theta}
\end{array}\right)
$$

cujos elementos são dados por

$$
\begin{aligned}
& \underset{(p \times 1)}{s_{\beta}}=\sum_{j=1}^{N} X_{o j}^{t} \Sigma_{j}^{-1} \varepsilon_{o j} \\
& \underset{(h \times 1)}{s_{\theta}}=\left[\left\langle\frac{1}{2} \sum_{j=1}^{N} \operatorname{tr}\left(\Sigma_{j}^{-1}\left(\varepsilon_{o j} \varepsilon_{o j}^{t}-\Sigma_{j}\right) \Sigma_{j}^{-1} \dot{\Sigma}_{j k}\right)\right\rangle_{k}\right], \\
& \underset{(p \times p)}{H_{\beta \beta}}=-\sum_{j=1}^{N} X_{o j}^{t} \Sigma_{j}^{-1} X_{o j}, \\
& \underset{(p \times h)}{H_{\beta \theta}}=H_{\theta \beta}^{t}=\left[\left\langle-\sum_{j=1}^{N} \mathrm{x}_{j l}^{t} \Sigma_{j}^{-1} \dot{\Sigma}_{j k} \Sigma_{j}^{-1} \varepsilon_{o j}\right\rangle_{l k}\right] \mathrm{e} \\
& \underset{(h \times h)}{H_{\theta \theta}}=\left[\left\langle-\frac{1}{2} \sum_{j=1}^{N} \operatorname{tr}\left(\Sigma_{j}^{-1} \dot{\Sigma}_{j m} \Sigma_{j}^{-1}\left(2 \varepsilon_{o j} \varepsilon_{o j}^{t}-\Sigma_{j}\right) \Sigma_{j}^{-1} \dot{\Sigma}_{j k}\right)+\right.\right. \\
& \left.\left.+\frac{1}{2} \sum_{j=1}^{N} \operatorname{tr}\left(\Sigma_{j}^{-1}\left(\varepsilon_{o j} \varepsilon_{o j}^{t}-\Sigma_{j}\right) \Sigma_{j}^{-1} \ddot{\Sigma}_{j m k}\right)\right\rangle_{m k}\right]
\end{aligned}
$$


onde $\boldsymbol{\Sigma}_{j}=\boldsymbol{\Sigma}_{j}(\theta), \varepsilon_{o j}=y_{o j}-X_{o j} \beta, \mathrm{x}_{j l}$ é a $l$ - ésima coluna de $X_{o j}, l=1, \ldots, p, \dot{\Sigma}_{j k}=\partial \boldsymbol{\Sigma}_{j} / \partial \theta_{k} \mathrm{e}$ $\ddot{\Sigma}_{j m k}=\partial^{2} \Sigma_{j} / \partial \theta_{m} \partial \theta_{k}, m, k=1, \ldots, h$. Expressões do tipo $\left[\langle\rangle_{a b}\right]$ denotam matrizes cujo elemento de ordem $(a, b)$ é dado pela expressão entre \langle\rangle e expressões do tipo $\left[\langle\rangle_{a}\right]$ denotam vetores cujo $a$-ésimo elemento é dado pela expressão entre \langle\rangle . As demonstrações das expressões acima podem ser encontradas em Andreoni (1989, Apêndice A).

Os estimadores de máxima verossimilhança de $\beta$ e $\theta$ são dados pela solução das seguintes $p+k$ equações normais:

$$
s=0_{p+k}
$$

mais especificamente, eles são as soluções $\hat{\boldsymbol{\beta}}_{M V}$ e $\hat{\boldsymbol{\theta}}_{M V}$ de

$$
\sum_{j=1}^{N} X_{o j}^{t} \hat{\Sigma}_{j}^{-1} \hat{\varepsilon}_{o j}=0_{p}
$$

onde $\hat{\varepsilon}_{o j}=y_{o j}-X_{o j} \hat{\boldsymbol{\beta}}_{M V}$ e $\hat{\boldsymbol{\Sigma}}_{j}=\hat{\boldsymbol{\Sigma}}_{j}\left(\hat{\boldsymbol{\theta}}_{M V}\right)$; e

$$
\sum_{j=1}^{N} \operatorname{tr}\left(\hat{\Sigma}_{j}^{-1}\left(\hat{\varepsilon}_{o j} \hat{\varepsilon}_{o j}^{t}-\hat{\Sigma}_{j}\right) \hat{\Sigma}_{j}^{-1} \dot{\Sigma}_{j k}\right)=0
$$

$k=1, \ldots, h$, se $\hat{\boldsymbol{\Sigma}}_{j}$ for positiva definida para $j=1, \ldots, N$ e $\boldsymbol{H}\left(\hat{\boldsymbol{\beta}}_{M V}, \hat{\boldsymbol{\theta}}_{M V}\right)$ for negativa definida (de modo a garantir que $\hat{\beta}_{M V}$ e $\hat{\theta}_{M V}$ sejam pontos de máximo).

De (3.14) e (3.15) obtemos

$$
\hat{\boldsymbol{\beta}}_{M V}=\left(\sum_{j=1}^{N} X_{o j}^{t} \hat{\Sigma}_{j}^{-1} X_{o j}\right)^{-1}\left(\sum_{j=1}^{N} X_{o j}^{t} \hat{\Sigma}_{j}^{-1} y_{o j}\right)
$$

e

$$
\sum_{j=1}^{N} \operatorname{tr}\left(\hat{\Sigma}_{j}^{-1} \dot{\Sigma}_{j k}\right)=\sum_{j=1}^{N} \operatorname{tr}\left(\hat{\Sigma}_{j}^{-1} \dot{\Sigma}_{j k} \hat{\Sigma}_{j}^{-1} \hat{\varepsilon}_{o j} \hat{\varepsilon}_{o j}^{t}\right)
$$

$k=1, \ldots, h$. Assim, quando os $\Sigma_{j}$ 's (ou $\theta$ ) são conhecidos, o estimador (3.16) é dado por

$$
\hat{\boldsymbol{\beta}}_{M V}=\left(\sum_{j=1}^{N} X_{o j}^{t} \Sigma_{j}^{-1} X_{o j}\right)^{-1}\left(\sum_{j=1}^{N} X_{o j}^{t} \Sigma_{j}^{-1} \boldsymbol{y}_{o j}\right)
$$


Quando os $\boldsymbol{\Sigma}_{j}$ 's (ou $\theta$ ) são desconhecidos, nem sempre é possível obter soluções explícitas para $\hat{\beta}_{M V}$ e $\hat{\boldsymbol{\theta}}_{M V}$ a partir de (3.16) e (3.17), o que sugere a utilização de processos iterativos. A seguir descreveremos brevemente três desses algoritmos iterativos.

\section{Algoritmos iterativos para maximização da verossimilhança:}

Os valores de $\beta$ e $\theta$ na $w$-ésima iteração serão denotados por $\beta^{(w)}$ e $\theta^{(w)}$, respectivamente, $w=$ $0,1, \ldots$ Qualquer que seja o algoritmo, é sempre necessário que se definam valores iniciais $\beta^{(0)} \mathrm{e} / \mathrm{ou}$ $\theta^{(0)}$ e ainda algum critério de parada das iterações (algumas sugestões são dadas por Andreoni (1989)).

\section{Algoritmo de Newton-Raphson}

Nesse algoritmo a $(w+1)$-ésima iteração é definida por

$$
\left(\begin{array}{l}
\beta^{(w+1)} \\
\theta^{(w+1)}
\end{array}\right)=\left(\begin{array}{l}
\beta^{(w)} \\
\theta^{(w)}
\end{array}\right)-\left(\begin{array}{cc}
H_{\beta \beta} & H_{\beta \theta} \\
H_{\theta \beta} & H_{\theta \theta}
\end{array}\right)^{-1}\left(\begin{array}{c}
s_{\beta} \\
s_{\theta}
\end{array}\right),
$$

onde a matriz Hessiana e a função escore (apresentados em (3.12) e (3.11), respectivamente) são calculadas utilizando $\beta^{(w)}$ e $\theta^{(w)}$. (Para maiores detalhes, veja Harville (1977), por exemplo.)

2. Algoritmo Scoring de Fisher

$\mathrm{O}$ algoritmo Scoring de Fisher substitui a matriz Hessiana em (3.19) por sua esperança. Como $E\left[\boldsymbol{H}_{\beta \theta}\right]=0$ (pois $E\left[\varepsilon_{o j}\right]=0$ em $(3.13)$ ), valores para $\boldsymbol{\beta}^{(w+1)}$ e $\boldsymbol{\theta}^{(w+1)}$ podem ser obtidos por equações separadas. Então

$$
\beta^{(w+1)}=\left(\sum_{j=1}^{N} X_{o j}^{t} \Sigma_{j}^{-1}\left(\theta^{(w)}\right) X_{o j}\right)^{-1}\left(\sum_{j=1}^{N} X_{o j}^{t} \Sigma_{j}^{-1}\left(\theta^{(w)}\right) y_{o j}\right)
$$

e novas estimativas $\theta^{(w+1)}$ são calculadas através de

$$
\theta^{(w+1)}=\theta^{(w)}-\left[E H_{\theta \theta}\left(\beta^{(w)}, \theta^{(w)}\right)\right]^{-1} s_{\theta}\left(\beta^{(w+1)}, \theta^{(w)}\right)
$$


onde

$$
E\left[H_{\theta \theta}\left(\beta^{(w)}, \theta^{(w)}\right)\right]=\left[\left\langle-\frac{1}{2} \sum_{j=1}^{N} \operatorname{tr}\left(\Sigma_{j}^{-1} \dot{\Sigma}_{j m} \Sigma_{j}^{-1} \dot{\Sigma}_{j k}\right)\right\rangle_{m k}\right],
$$

$m, k=1, \ldots, h, \operatorname{com} \Sigma_{j}=\Sigma_{j}\left(\theta^{(w)}\right)$

\section{Algoritmo EM}

Os dados observados $y_{0}$ podem ser considerados como parte de um conjunto maior de dados $\boldsymbol{y}=\left(\boldsymbol{y}_{o}^{t}, \boldsymbol{y}_{m}^{t}\right)^{t}$, onde $y_{m}$ são os dados não-observados. Cada iteração do algoritmo EM consiste de dois passos, denominados passo $\mathrm{E}$ (esperança) e passo M (maximização). Assim, a $(w+1)$ ésima iteração do processo é composta por

passo E: calcula-se $E\left\{l(y ; \beta, \theta) \mid y_{o}, \beta^{(w)}, \theta^{(w)}\right\}$;

passo M: encontra-se $\left(\beta^{(w+1)}, \theta^{(w+1)}\right)$ que maximiza $E\left\{l(y ; \beta, \theta) \mid y_{o}, \beta^{(w)}, \theta^{(w)}\right\}$.

A idéia básica seria de se encontrar $\left(\beta^{*}, \theta^{*}\right)$ que maximizasse $l(y ; \beta, \theta)$, mas como $l(y ; \beta, \theta)$ não é conhecido, maximiza-se a sua esperança condicionalmente a $y_{o}$ e aos valores correntes de $\beta$ e $\boldsymbol{\theta}$. No caso especial em que a distribuição de $y$ pertence à família exponencial regular (que é justamente o nosso caso, pois y segue uma distribuição Normal), o procedimento é bem mais simples, pois a densidade de $y$ pode ser escrita na forma

$$
f(y \mid \beta, \theta)=b(y) \exp \left\{(\beta, \theta) t(y)^{t}\right\} / a(\beta, \theta),
$$

onde $t(y)$ é um vetor $(1 \times(p+h))$ de estatísticas suficientes (veja Bickel e Doksum (1977, cap.2), por exemplo), $b(y)$ é uma função de $y$ e $a(\beta, \theta)$ é uma função dos parâmetros contidos em $\beta$ e $\theta$. Assim,

$$
\begin{aligned}
E\left\{l(y ; \beta, \theta) \mid y_{o}, \beta^{(w)}, \theta^{(w)}\right\}= & -\ln a(\beta, \theta)+E\left\{b(y) \mid y_{o}, \beta^{(w)}, \theta^{(w)}\right\}+ \\
& +(\beta, \theta) E\left\{t(y) \mid y_{o}, \beta^{(w)}, \theta^{(w)}\right\}^{t},
\end{aligned}
$$


de forma que maximizar (3.22) equivale a maximizar $-\ln a(\beta, \theta)+(\beta, \theta) E\left\{t(y) \mid y_{o}, \beta^{(w)}\right.$, $\left.\theta^{(w)}\right\}^{t}$, sendo necessário o cálculo somente das esperanças das estatísticas suficientes. No caso geral, o passo $\mathrm{M}$ pode ainda requerer a utilização de um processo iterativo adicional que geralmente é o algoritmo Scoring de Fisher, como sugerido por Jennrich e Schluchter (1986). Detalhes sobre o algoritmo EM podem ser encontrados em Dempster et al. (1977).

O algoritmo de Newton-Raphson geralmente converge em um pequeno número de iterações, mas com um custo computacional muito alto por iteração; no outro extremo, o algoritmo EM possui um custo baixo por iteração, mas às vezes requer um grande número de iterações até convergir. $\mathrm{O}$ algoritmo Scoring de Fisher é intermediário em termos de custo e número de iterações. Devido ao fato de o algoritmo Scoring de Fisher ser frequentemente mais robusto para valores iniciais pobres do que o de Newton-Raphson, uma boa sugestão é começar o processo de convergência com o algoritmo Scoring de Fisher e então mudar para o de Newton-Raphson após alguns passos.

Quando o número de parâmetros em $\theta$ é pequeno (como no caso de simetria composta), qualquer um dos algoritmos fornece resultados satisfatórios. Quando esse número é grande (como no caso de $\boldsymbol{\Sigma}$ não-estruturada), somente o algoritmo EM é viável, devido ao alto custo dos demais.

Somente os algoritmos de Newton-Raphson e Scoring de Fisher fornecem desvios-padrão para as estimativas dos parâmetros de $\theta$. Como o algoritmo EM não os fornece, uma possível alternativa seria a de, após a convergência, utilizar um único passo de outro algoritmo para se obterem tais desvios-padrão.

A matriz de covariância de $\hat{\boldsymbol{\beta}}_{M V}$ e $\hat{\boldsymbol{\theta}}_{M V}$ é igual à inversa da matriz de informação de Fisher (ver Searle (1970), por exemplo), que por sua vez é igual a esperança da matriz Hessiana com relação aos $p+q$ parâmetros de $\boldsymbol{\beta}$ e $\theta$ com sinal trocado (ou seja, $\left.\operatorname{Var}\left(\hat{\boldsymbol{\beta}}_{M V}, \hat{\boldsymbol{\theta}}_{M V}\right)=(-E[\boldsymbol{H}(\boldsymbol{\beta}, \boldsymbol{\theta})])^{-1}\right)$. Quando os dados são MCAR, um estimador assintótico para a matriz de covariância de $\hat{\beta}_{M V}$ e $\hat{\boldsymbol{\theta}}_{M V}$ pode ser baseado na matriz de informação de Fisher observada, $\left(-E\left[\boldsymbol{H}\left(\hat{\boldsymbol{\beta}}_{M V}, \hat{\boldsymbol{\theta}}_{M V}\right]\right.\right.$, de forma que 


$$
\begin{aligned}
& \widehat{\operatorname{Var}}_{a}\left(\hat{\beta}_{M V}\right)=\left(\sum_{j=1}^{N} X_{o j}^{t} \hat{\Sigma}_{j}^{-1}\left(\hat{\theta}_{M V}\right) X_{o j}\right)^{-1} \\
& \widehat{\operatorname{Var}}_{a}\left(\hat{\theta}_{M V}\right)=2\left[\left\langle\sum_{j=1}^{N} \operatorname{tr}\left(\hat{\Sigma}_{j}^{-1}\left(\hat{\theta}_{M V}\right) \dot{\Sigma}_{j k} \hat{\Sigma}_{j}^{-1}\left(\hat{\theta}_{M V}\right) \dot{\Sigma}_{j h}\right)\right\rangle_{k h}\right]^{-1} \mathrm{e} \\
& \widehat{\operatorname{Cov}}_{a}\left(\hat{\beta}_{M V}, \hat{\theta}_{M V}\right)=0
\end{aligned}
$$

No caso de mecanismo de não-resposta ignorável, mas não MCAR (ou seja, quando o mecanismo de não-resposta não depende dos dados não-observados, mas depende dos dados observados), os estimadores (3.23) não são consistentes (ver Schluchter (1988)). Uma alternativa para esses casos sugerida por Schluchter (1988) é a obtenção de estimadores de variância e covariância para $\hat{\beta}_{M V}$ e $\hat{\theta}_{M V}$ a partir da matriz de informação empírica $-H\left(\hat{\beta}_{M V}, \hat{\theta}_{M V}\right)$. Infelizmente, tais cálculos são bem mais complicados do que (3.23).

O estimador $\hat{\beta}_{M V}$, coincide com o estimador de mínimos quadrados generalizados (2.14). Porém, o estimador de MV de $\theta$ geralmente é viciado (subestimando o valor de $\theta$ ), por não levar em consideração a perda de graus de liberdade resultante da estimação de $\beta$ (veja Harville (1977), por exemplo). Uma possível solução para a eliminação desse vício está no método de máxima verossimilhança restrita (MVR). Esse método se baseia na maximização da função de verossimilhança associada aos resíduos dos efeitos fixos em vez da função de verossimilhança usual (3.9) e por meio disso, leva em consideração os graus de liberdade perdidos na estimação de $\beta$. No método de MVR, a função de verossimilhança não envolve $\beta$; então, uma vez encontrado o estimador de MVR de $\theta, \hat{\theta}_{M V R}, \beta$ pode ser estimado através de mínimos quadrados generalizados, substituindo-se $\hat{\Sigma}_{j}\left(\hat{\boldsymbol{\theta}}_{M V}\right)$ por $\hat{\boldsymbol{\Sigma}}_{j}\left(\hat{\boldsymbol{\theta}}_{M V R}\right)$ em (3.16). Entretanto, para se obter $\hat{\boldsymbol{\theta}}_{M V R}$, frequentemente são necessários processos iterativos. Jennrich e Schluchter (1986) sugerem a utilização do algoritmo EM Generalizado para MVR. A obtenção dos estimadores de MVR pode ser vista em Andreoni (1989, Capítulo 3).

Tanto para MV quanto para MVR, testes de hipóteses sobre combinações lineares do tipo $H_{o}: C \boldsymbol{\beta}=0$, onde $C(c \times p)$ é uma matriz de contrastes conhecida e posto $c(c \leq p)$, podem ser 
realizados através da estatistica de Wald

$$
Q_{c}=\hat{\beta}^{t} C^{t}\left[C\left(\sum_{j=1}^{N} X_{o j}^{t} \hat{\Sigma}_{j}^{-1}(\hat{\theta}) X_{o j}\right)^{-1} C^{t}\right]^{-1} C \hat{\beta} .
$$

Sob $H_{o}, Q_{c}$ tem distribuição assintótica $\chi_{c}^{2}$.

Para tamanhos amostrais pequenos, Berk (1987) sugere a utilização de um teste $F$ aproximado, cuja estatística é dada por $Q_{c} / c$ e que deve ser comparada com o valor tabelado de uma distribuição $F \operatorname{com} c$ e $g l_{2}$ graus de liberdade, onde $g l_{2}$ é igual ao número de graus de liberdade do denominador para um teste exato para dados completos. Esse procedimento é mais rigoroso para $N$ pequeno, na medida em que $F_{\left[c, g l_{2}\right]}>F_{[c, \infty]}$, onde $F_{[c, \infty]}$ seria uma variável com distribuição $\chi_{(c)}^{2}$. Quando há poucos indivíduos com dados incompletos, é razoável considerar somente o número de indivíduos com dados completos ao se determinar $g l_{2}$. Por exemplo, se há $n$ indivíduos com dados completos, $G$ tratamentos e $T$ ocasiões de avaliação (tempos), então $g l_{2}=n-G$ para testar o efeito de Tratamento e $g l_{2}=(n-G)(T-1)$ para testar o efeito de Tempo e da sua interação com Tratamento (exatamente como na ANOVA da Seção 2.1).

Para avaliar a adequabilidade do modelo podemos utilizar testes que comparam modelos mais simples com modelos mais gerais (sendo que essas estruturas precisam ser encaixadas (nested)). No caso do método de MV, uma estatística utilizada para testar a hipótese $H_{0}$ de que o modelo mais simples é adequado, é a da razão de verossimilhança generalizada, dada por

$$
Q_{1}=2\left[l\left(\hat{\beta}_{M V}^{G}, \hat{\theta}_{M V}^{G}\right)-l\left(\hat{\beta}_{M V}^{S}, \hat{\theta}_{M V}^{S}\right)\right]
$$

onde $\hat{\beta}_{M V}^{G}$ e $\hat{\theta}_{M V}^{G}$ são os valores de $\beta$ e $\theta$ que maximizam a verossimilhança sob o modelo mais geral e $\hat{\boldsymbol{\beta}}_{M V}^{S}$ e $\hat{\boldsymbol{\theta}}_{M V}^{S}$ sob o modelo mais simples. Sob $H_{o}, Q_{1}$ tem distribuição assintótica $\chi^{2}$ com $\left(p^{G}+k^{G}-p^{S}-k^{S}\right)$ graus de liberdade, onde $\left(p^{G}\right.$ e $\left.k^{G}\right)$ e $\left(p^{S}\right.$ e $\left.k^{S}\right)$ correspondem ao número de parâmetros de $\beta$ e $\theta$ sob os modelos mais geral e mais simples, respectivamente.

Quanto à MVR, a hipótese $H_{0}$ de que a estrutura de covariância mais simples é mais adequada aos dados do que a estrutura mais geral (sendo elas encaixadas), pode ser testada através da 
estatística da razão de verossimilhança generalizada

$$
Q_{2}=2\left[l_{R}\left(\hat{\theta}_{M V R}^{G}\right)-l_{R}\left(\hat{\theta}_{M V R}^{S}\right)\right]
$$

onde $l_{R}$ denota o logaritmo da função de verossimilhança restrita, $\hat{\theta}_{M V R}^{G}$ é o valor que maximiza a verossimilhança restrita sob o modelo mais geral e $\hat{\theta}_{M V R}^{S}$ sob o modelo mais simples. Sob $H_{o}, Q_{2}$ tem distribuição assintótica $\chi^{2} \operatorname{com}\left(k^{G}-k^{S}\right)$ graus de liberdade.

Considerando a estrutura de simetria composta para $\Sigma$ que foi abordada no Capítulo 2 sob o enfoque de mínimos quadrados, podemos escrever a matriz de covariância associada ao $j$-ésimo indivíduo como

$$
\Sigma_{j}(\theta)=\sigma_{\pi}^{2} 1_{T,} \mathbf{1}_{T,}^{t}+\sigma^{2} I_{T,}=\sum_{k=1}^{2} \theta_{k} G_{j k} .
$$

onde $\theta_{1}=\sigma_{\pi}^{2}, \theta_{2}=\sigma^{2}, G_{j 1}=1_{T j} 1_{T,}^{t}$ e $G_{j 2}=I_{T j}$. Nesse caso, $\dot{\Sigma}_{j k}=G_{j k}, \ddot{\Sigma}_{j k h}=0$ e

$$
\Sigma_{j}^{-1}(\theta)=\frac{1}{\sigma^{2}} I_{T_{j}}-\frac{\sigma_{\pi}^{2}}{\sigma^{2}\left(\sigma^{2}+T_{j} \sigma_{\pi}^{2}\right)} 1_{T_{j}} 1_{T_{j}}^{t}=\Delta_{j} .
$$

Os termos da função escore e da matriz Hessiana que são utilizadas na derivação dos estimadores de máxima verossimilhança para $\beta$ e $\theta$ ficam reduzidos a

$$
\begin{aligned}
\underset{(p \times 1)}{s_{\beta}} & =\sum_{j=1}^{N} X_{o j}^{t} \Delta_{j} \varepsilon_{o j}, \\
\underset{(2 \times 1)}{s_{\theta}} & =\left[\left\langle\frac{1}{2} \sum_{j=1}^{N} \operatorname{tr}\left(\Delta_{j}\left(\varepsilon_{o j} \varepsilon_{o j}^{t}-\Sigma_{j}(\theta)\right) \Delta_{j} G_{j k}\right)\right\rangle_{k}\right] \\
\underset{(p \times p)}{H_{\beta \beta}} & =-\sum_{j=1}^{N} X_{o j}^{t} \Delta_{j} X_{o j}, \\
\underset{(p \times 2)}{H_{\beta \theta}} & =H_{\theta \beta}^{t}=\left[\left\langle-\sum_{j=1}^{N} \mathbf{x}_{j l}^{t} \Delta_{j} G_{j k} \Delta_{j} \varepsilon_{o j}\right\rangle_{l k}\right] \\
H_{\theta \theta} & =\left[\left\langle-\frac{1}{2} \sum_{j=1}^{N} \operatorname{tr}\left(\Delta_{j} G_{j m} \Delta_{j}\left(2 \varepsilon_{o j} \varepsilon_{o j}^{t}-\Sigma_{j}(\theta)\right) \Delta_{j} G_{j k}\right)\right\rangle_{m k}\right],
\end{aligned}
$$


onde $\varepsilon_{o j}=y_{o j}-X_{o j} \beta$ e $x_{j l}$ é a $l$-ésima coluna de $X_{o j}, l=1, \ldots, p, m, k=1,2$. Andrade e Helms (1984) apresentam os resultados acima para estruturas de covariância do tipo (3.27) com $k=1, \ldots, s(s \geq 2)$. 


\section{Capítulo 4}

\section{Implementação Computacional e}

\section{Exemplos}

Na Seção 4.1 utilizaremos um exemplo real para comparar o método de Bartlett apresentado na Seção 2.3 com o procedimento usual de mínimos quadrados em que os dados correspondentes aos indivíduos com dados incompletos são eliminados (usualmente adotado pela maioria dos pacotes estatísticos). Na Seção 4.2 apresentaremos algumas alternativas de utilização de pacotes estatísticos com o método de Bartlett. Na Seção 4.3 mostraremos a utilização de pacotes estatísticos com procedimentos de MV.

Os programas computacionais e as correspondentes saídas encontram-se no Apêndice B. 


\subsection{Comparação entre o método de Bartlett e o procedimento usual que descarta os indivíduos com dados incompletos}

\section{Exemplo 4.1:}

Um estudo foi realizado com 20 mulheres saudáveis com idades entre 17 e 35 anos, sendo que 12 preferencialmente mastigam do lado direito da boca e 8 do lado esquerdo. Um dos objetivos do estudo era o de verificar se há diferenças entre mulheres com mastigação preferencial direita ou esquerda com relação aos fluxos de saliva dos dois lados da boca. De cada mulher foram coletadas amostras de saliva dos dois lados da boca, simultaneamente, em 5 momentos consecutivos, utilizando coletores adaptados nas saídas das glândulas parótidas esquerda e direita. A primeira e a quinta coletas foram feitas sem estímulo, enquanto que nas três coletas intermediárias a salivação foi estimulada pela aplicação de $15 \mathrm{ml}$ de uma solução de ácido cítrico a $5 \%$ na ponta da língua. Vamos considerar como variável resposta a diferença entre os fluxos de saliva dos lados esquerdo e direito da boca (em $\mathrm{ml} / \mathrm{min})$, que denotaremos por diferencial de fluxo.

Este estudo faz parte de um projeto de pesquisa realizado por Estela Maris Losso no Instituto de Química da USP. Nosso único objetivo neste trabalho é utilizá-lo para ilustração das técnicas estatísticas apresentadas nos capítulos anteriores; para maiores detalhes sobre as conclusões do projeto, ver Losso (1994).

Os dados a serem analisados encontram-se na Tabela 4.1, enquanto que os dados originais encontram-se na Tabela B.1 do Apêndice B.

O fator que define as ocasiões de avaliação é COLETA, com $T=5$ níveis, e o fator que define os tratamentos é GRUPO, com $G=2$ níveis. Denotaremos por grupo direito (D) e grupo esquerdo (E) os grupos em que as mulheres mastigam predominantemente do lado direito e esquerdo, respectivamente. 
Tabela 4.1: Diferencial de fluxo $(\mathrm{ml} / \mathrm{min})$.

\begin{tabular}{ccrrrrr}
\hline Grupo & Indivíduo & Coleta 1 & Coleta 2 & Coleta 3 & Coleta 4 & Coleta 5 \\
\hline D & 1 & 0.000 & -0.164 & -0.078 & -0.035 & -0.071 \\
D & 2 & -0.004 & 0.034 & 0.000 & -0.067 & -0.003 \\
D & 3 & 0.000 & -0.100 & -0.100 & -0.166 & 0.016 \\
D & 4 & - & - & 0.020 & 0.020 & -0.007 \\
D & 5 & -0.003 & 0.070 & 0.030 & 0.170 & 0.033 \\
D & 6 & - & 0.115 & 0.134 & 0.023 & 0.012 \\
D & 7 & - & -0.170 & -0.104 & -0.067 & -0.018 \\
D & 8 & 0.008 & -0.066 & -0.033 & -0.100 & -0.020 \\
D & 9 & - & 0.000 & 0.000 & 0.066 & 0.000 \\
D & 10 & -0.004 & -0.063 & -0.063 & -0.117 & 0.000 \\
D & 11 & -0.007 & -0.063 & -0.050 & -0.100 & -0.056 \\
D & 12 & 0.006 & -0.050 & 0.000 & 0.000 & -0.020 \\
E & 1 & 0.005 & 0.117 & 0.163 & 0.100 & 0.000 \\
E & 2 & 0.043 & 0.267 & 0.234 & 0.200 & 0.123 \\
E & 3 & 0.005 & 0.034 & 0.077 & 0.078 & 0.050 \\
E & 4 & 0.000 & 0.033 & 0.033 & 0.007 & -0.050 \\
E & 5 & 0.003 & 0.030 & 0.070 & 0.054 & 0.020 \\
E & 6 & 0.017 & 0.066 & 0.033 & 0.067 & 0.014 \\
E & 7 & -0.001 & -0.010 & 0.000 & 0.000 & -0.001 \\
E & 8 & -0.005 & 0.166 & 0.184 & 0.150 & 0.016 \\
\hline
\end{tabular}

(-): dados não-observados

Temos $N=20$ indivíduos e $m=5$ dados não observados. Para efeito da aplicação do método de Bartlett esses dados foram inicialmente substituidos por zeros. O teste de Mauchly (2.49) indica alguma evidência contra a hipótese de esfericidade de $\Sigma(p=0.0774)$, de forma que é conveniente considerar o fator de correção para os graus de liberdade associados aos testes que envolvem o fator Coleta. Utilizando a correção de Huynh e Feldt $(\tilde{\varepsilon}=0.8968)$, verificamos que há evidências de interação COLETA $\times$ GRUPO $(p=0.0001)$. Esse fato fica patente nos perfis médios de resposta dos dois grupos apresentados na Figura 4.1.

Eliminando os quatro indivíduos com dados incompletos (todos pertencentes ao grupo direito) teremos $N=16$. Aqui, a hipótese de esfericidade de $\Sigma$ é menos plausível como indica o teste de Mauchly $(p=0.0086)$, e utilizando a correção de Huynh e Feldt $(\tilde{\varepsilon}=0.7485)$ também concluímos que há evidências de interação COLETA $\times$ GRUPO $(p=0.0003)$. Observe os perfis médios de resposta dos dois grupos apresentados na Figura 4.2. 
Figura 4.1: Perfis médios dos grupos com relação ao diferencial de fluxo (considerando todos os dados da Tabela 4.1).

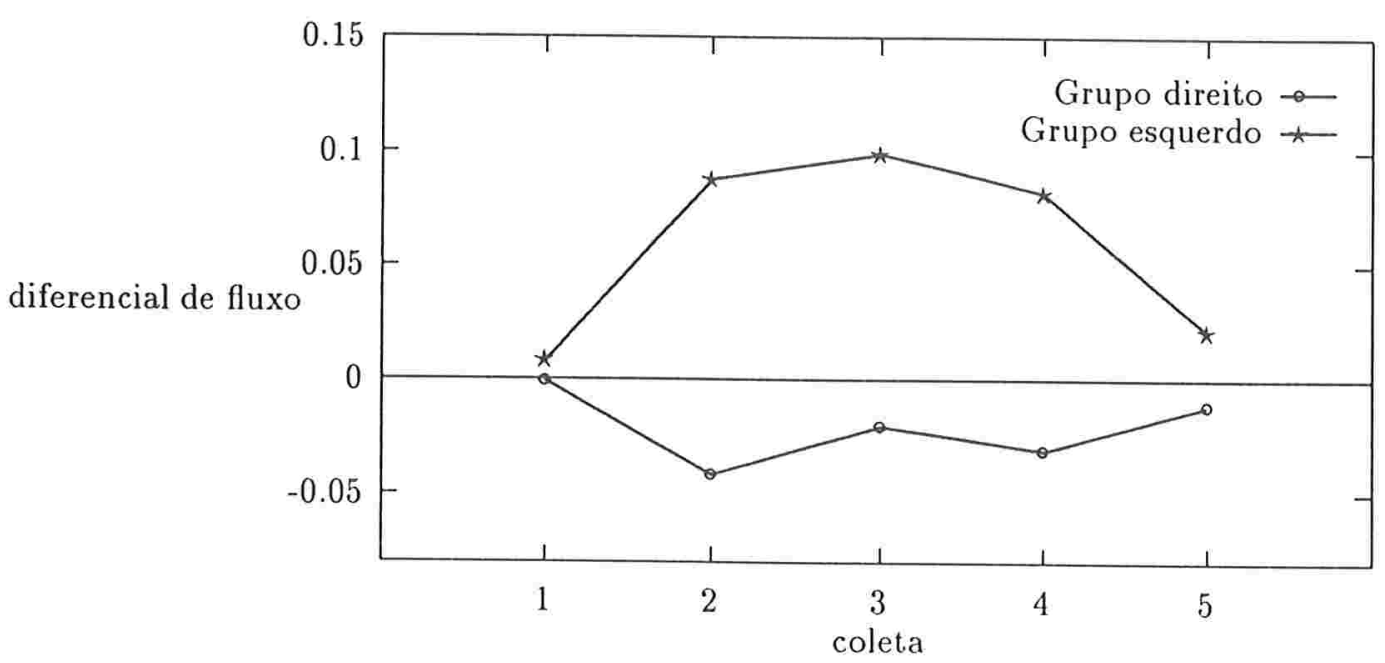

Figura 4.2: Perfis médios dos grupos com relação ao diferencial de fluxo (considerando apenas os indivíduos com dados completos).

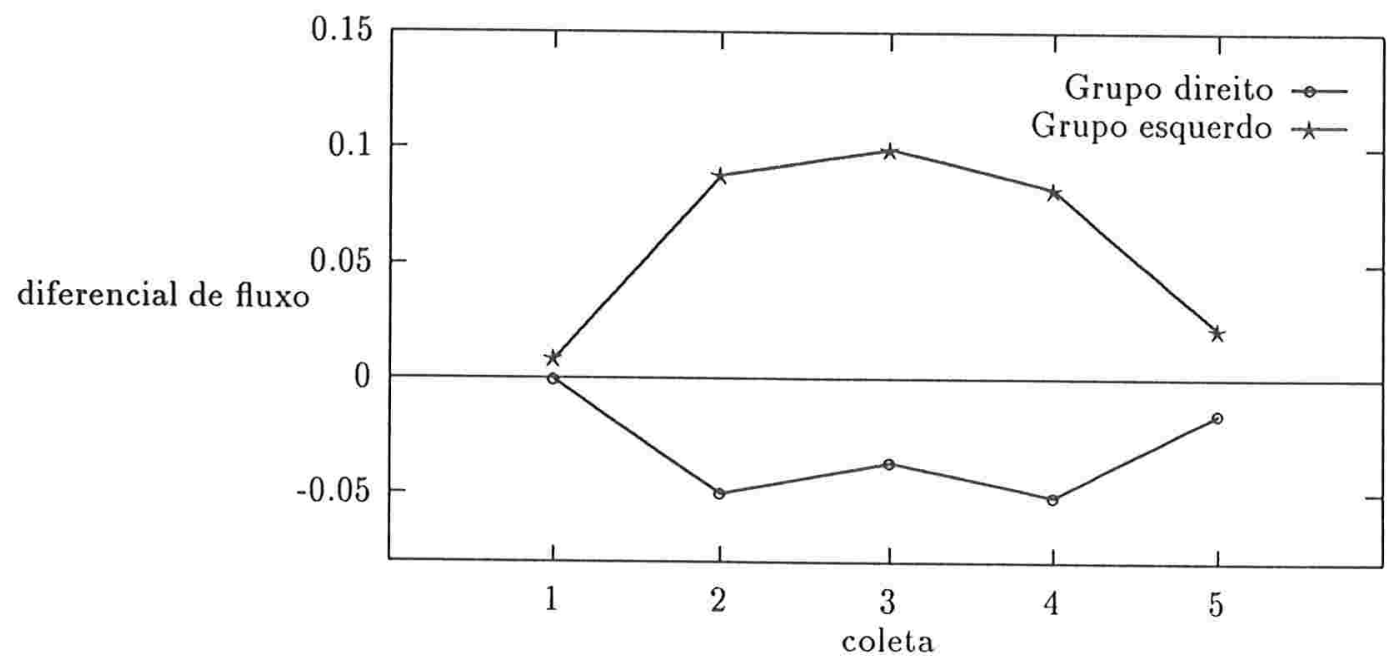


Comparando as Figuras 4.1 e 4.2 notamos que não há muitas diferenças entre elas, uma vez que o único perfil que se alterou com a eliminação dos quatro indivíduos (e não muito) foi o associado ao grupo direito. Portanto, não esperamos conclusões muito diferentes para os dois enfoques.

Possíveis comparações de interesse são:

(1) Comparação dos dois grupos com relação à diferença entre a resposta média das 3 coletas estimuladas (coletas 2,3 e 4 ) e a resposta média das 2 coletas não-estimuladas (coletas 1 e 5 ), que corresponde ao teste da hipótese

$$
H_{\circ}: \frac{\mu_{12}+\mu_{13}+\mu_{14}}{3}-\frac{\mu_{11}+\mu_{15}}{2}=\frac{\mu_{22}+\mu_{23}+\mu_{24}}{3}-\frac{\mu_{21}+\mu_{25}}{2},
$$

onde $\mu_{i j}$ representa a resposta média da $j$-ésima coleta do $i$-ésimo grupo. Denotaremos o contraste acima por DIF.

(2) Comparação dos dois grupos com relação à resposta média das 3 coletas estimuladas, que corresponde ao teste da hipótese

$$
H_{o}: \frac{\mu_{12}+\mu_{13}+\mu_{14}}{3}=\frac{\mu_{22}+\mu_{23}+\mu_{24}}{3} .
$$

O contraste correspondente será denotado por EST.

(3) Comparação dos dois grupos com relação à resposta média das 2 coletas não-estimuladas, o que corresponde a se testar a hipótese

$$
H_{o}: \frac{\mu_{11}+\mu_{15}}{2}=\frac{\mu_{21}+\mu_{25}}{2} .
$$

Denotaremos o contraste correspondente por ÑEST.

No caso do método de Bartlett, para efetuar os testes associados aos contrastes é necessário completar os dados com suas estimativas $\left(\hat{y}_{1}=0.0446, \hat{y}_{2}=-0.0068, \hat{y}_{3}=0.1090, \hat{y}_{4}=-0.0518\right.$ e $\hat{y}_{5}=$ 0.0545) obtidas através do ajuste do modelo de ANCOVA, e então realizar uma ANOva com dados 
completos para cada um dos contrastes de interesse. Na Tabela 4.2 encontram-se os níveis descritivos associados aos testes, obtidos segundo o método de Bartlett e o procedimento usual, e na Tabela 4.3 encontram-se as estimativas dos contrastes para ambos os enfoques.

Tabela 4.2: Níveis descritivos associados aos testes obtidos com os dois procedimentos aplicados aos dados da Tabela 4.1.

\begin{tabular}{lcc}
\hline Hipótese & $\begin{array}{c}\text { Método de Bartlett } \\
(N=20)\end{array}$ & $\begin{array}{c}\text { Procedimento Usual } \\
(N=16)\end{array}$ \\
\hline Esfericidade & 0.0774 & 0.0086 \\
GRUPO X COLETA & 0.0001 & 0.0003 \\
COLETA & 0.1811 & 0.3687 \\
GRUPO & 0.0061 & 0.0031 \\
DIFXGRUPO & 0.0008 & 0.0023 \\
ESTXGRUPO & 0.0028 & 0.0023 \\
$\tilde{N}$ ESTXGRUPO & 0.3054 & 0.0952 \\
$\tilde{N}$ EST & 0.2560 & 0.5840 \\
\hline
\end{tabular}

Tabela 4.3: Estimativas das médias ( \pm erros-padrão) associadas aos contrastes, obtidas com os dois procedimentos aplicados aos dados da Tabela 4.1.

\begin{tabular}{llcc}
\hline Contraste & Grupo & $\begin{array}{c}\text { Método de Bartlett } \\
(N=20)\end{array}$ & $\begin{array}{c}\text { Procedimento Usual } \\
(N=16)\end{array}$ \\
\hline \multirow{2}{*}{ DIF } & direito & $-0.031 \pm 0.018$ & $-0.039 \pm 0.024$ \\
& esquerdo & $0.075 \pm 0.022$ & $0.075 \pm 0.024$ \\
\multirow{2}{*}{ EST } & direito & $-0.030 \pm 0.038$ & $-0.046 \pm 0.045$ \\
& esquerdo & $0.090 \pm 0.046$ & $0.090 \pm 0.045$ \\
\multirow{2}{*}{ NEST } & & $0.006 \pm 0.009$ & $0.004 \pm 0.009$ \\
\hline
\end{tabular}


Observando os resultados obtidos com o método de Bartlett concluimos que:

(1) A diferença entre a resposta média das coletas estimuladas e a resposta média das coletas não-estimuladas não apresenta o mesmo comportamento para os dois grupos $(p=0.0008)$. A estimativa ( \pm erro- padrão) dessa diferença para o grupo direito é igual a $-0.031 \pm 0.018$, enquanto que para o grupo esquerdo é igual a $0.075 \pm 0.022$. Ou seja, para o grupo direito o diferencial de fluxo é em média menor nas coletas estimuladas do que nas coletas nãoestimuladas; já para o grupo esquerdo observa-se que o diferencial de fluxo é em média maior nas coletas estimuladas.

(2) A resposta média das coletas estimuladas varia de um grupo para outro ( $p=0.0028)$, cuja estimativa ( \pm erro-padrão) para o grupo direito é igual a $-0.030 \pm 0.038$, e para o grupo esquerdo é igual a $0.090 \pm 0.046$. Observe que com relação às coletas estimuladas, o diferencial de fluxo médio é negativo para o grupo direito e positivo para o grupo esquerdo, o que significa que para o grupo direito o fluxo direito é maior do que o fluxo esquerdo e para o grupo esquerdo o fluxo esquerdo é maior do que o fluxo direito.

(3) Não foram detectadas diferenças significantes entre as respostas médias das coletas nãoestimuladas para os dois grupos ( $p=0.3054$ para o teste de interação entre ÑEST e GRUPO) e não há evidências de que ela seja significantemente diferente de zero $(p=0.2560)$. Isso quer dizer que com relação às coletas não-estimuladas não há, em média, diferença entre fluxo esquerdo e fluxo direito para os dois grupos. A estimativa ( \pm erro- padrão) dessa diferença é igual a $0.006 \pm 0.009$.

Embora a estimação dos parâmetros do modelo não seja relevante nesse tipo de análise, vamos estimá-los utilizando a teoria descrita no Capítulo 2. Sob o modelo definido por (1.20) e (2.1), $\beta=\left(\beta_{1}^{t}, \beta_{2}^{t}\right)$, com

$$
\beta_{1}^{t}=\left(\mu, \alpha_{1}\right)
$$




$$
\boldsymbol{\beta}_{2}^{t}=\left(\gamma_{1}, \gamma_{2}, \gamma_{3}, \gamma_{4}, \alpha \gamma_{11}, \alpha \gamma_{12}, \alpha \gamma_{13}, \alpha \gamma_{14}\right)
$$

Utilizando (2.15) para o procedimento usual e (2.52) (ou (2.32)) e (2.33) para o método de Bartlett, obtemos estimativas dos parâmetros que compoem $\beta$. Para obter as correspondentes estimativas dos erros-padrão basta utilizar (2.16) para o procedimento usual e (2.54) (ou (2.36)) e (2.39) para o método de Bartlett. A partir de (2.17) e (2.18) para o procedimento usual e (2.36) e (2.37) para o método de Bartlett, obtemos estimativas de $\sigma^{2}$ e $\sigma_{\pi}^{2}$ que compoem $\Sigma$. Os resultados encontram-se na Tabela 4.4.

Tabela 4.4: Estimativas dos parâmetros que compoem $\beta$ e $\Sigma$.

\begin{tabular}{lcc}
\hline Parâmetro & $\begin{array}{c}\text { Método de Bartlett } \\
(N=20)\end{array}$ & $\begin{array}{c}\text { Procedimento Usual } \\
(N=16)\end{array}$ \\
\hline$\mu$ & $0.0176 \pm 0.0124$ & $0.0145 \pm 0.0138$ \\
$\alpha_{1}$ & $-0.0422 \pm 0.0124$ & $-0.0454 \pm 0.0138$ \\
$\gamma_{1}$ & $-0.0105 \pm 0.0102$ & $-0.0105 \pm 0.0100$ \\
$\gamma_{2}$ & $0.0036 \pm 0.0096$ & $0.0044 \pm 0.0100$ \\
$\gamma_{3}$ & $0.0184 \pm 0.0094$ & $0.0168 \pm 0.0100$ \\
$\gamma_{4}$ & $0.0044 \pm 0.0094$ & $0.0006 \pm 0.0100$ \\
$\alpha \gamma_{11}$ & $0.0409 \pm 0.0102$ & $0.0409 \pm 0.0100$ \\
$\alpha \gamma_{12}$ & $-0.0245 \pm 0.0096$ & $-0.0237 \pm 0.0100$ \\
$\alpha \gamma_{13}$ & $-0.0210 \pm 0.0094$ & $-0.0227 \pm 0.0100$ \\
$\alpha \gamma_{14}$ & $-0.0178 \pm 0.0094$ & $-0.0216 \pm 0.0100$ \\
$\sigma^{2}$ & 0.0021 & 0.0020 \\
$\sigma_{\pi}^{2}$ & 0.0025 & 0.0027 \\
\hline
\end{tabular}


A maioria dos pacotes estatísticos não fornece estimativas dos parâmetros do modelo; os valores da Tabela 4.4 foram obtidos com o auxílio do Lotus 123 e do soc/CM. (O soc é um programa estatístico desenvolvido pela EMBRAPA, cujo módulo CM é destinado a cálculos matriciais. Para maiores detalhes consulte Soc (1989)).

No exemplo que acabamos de analisar, os dois procedimentos adotados não produziram resultados suficientemente diferentes para que as conclusões fossem divergentes, embora tenham sido observadas diferenças nos níveis descritivos. Por exemplo, o nível descritivo obtido para o teste da inexistência de interação ÑESTXGRUPO com o procedimento usual pode sugerir uma certa dúvida quanto a sua significância, enquanto que com o método de Bartlett o resultado é claramente nãosignificante (veja Tabela 4.2).

Para essas análises empregamos o módulo $2 \mathrm{~V}$ do pacote estatístico BMDP. Para efeito de ilustração, os comandos e saída do programa utilizado na análise com o método de Bartlett encontramse nas Figuras B.1 e B.2, respectivamente.

Suponha agora que o mesmo estudo descrito no Exemplo 4.1 tenha originado um outro conjunto de dados (hipotético), apresentado na Tabela 4.5, onde há quatro observações incompletas. Assim como foi feito anteriormente, vamos analisar esses dados através do método de Bartlett e do procedimento usual e então, comparar os resultados. Considere os perfis médios de resposta incluindo os dados dos 20 indivíduos (Figura 4.3) e incluindo somente os 16 indivíduos com dados completos (Figura 4.4). Observando as Figuras 4.3 e 4.4 vemos claramente que a eliminação dos 4 indivíduos fez com que houvesse uma mudança considerável nos perfis médios de respostas, principalmente no associado ao grupo esquerdo. As alterações nos níveis descritivos dos testes (veja Tabela 4.6) são mais aparentes, como no teste para a interação EST XGRUPO cujo nível descritivo é de 0.0029 com o método de Bartlett e de 0.0522 com o procedimento usual, o que implica conclusões divergentes se utilizarmos um nível de significância de $5 \%$. As estimativas das médias também mostram 
que a eliminação dos 4 indivíduos alteram bastante os resultados (veja Tabela 4.7). A eliminação dos indivíduos com dados incompletos pode ter grande influência nas conclusões, de modo que o método de Bartlett pode ser uma opção satisfatória para a análise de dados longitudinais com dados incompletos.

Tabela 4.5: Diferencial de fluxo ( $\mathrm{ml} / \mathrm{min})$ (dados hipotéticos baseados na Tabela 4.1).

\begin{tabular}{ccrrrrr}
\hline Grupo & Indivíduo & Coleta 1 & Coleta 2 & Coleta 3 & Coleta 4 & Coleta 5 \\
\hline D & 1 & 0.000 & -0.164 & -0.078 & -0.035 & -0.071 \\
D & 2 & -0.004 & 0.034 & 0.000 & -0.067 & -0.003 \\
D & 3 & - & -0.100 & -0.100 & -0.166 & 0.016 \\
D & 4 & 0.045 & -0.007 & 0.020 & 0.020 & -0.007 \\
D & 5 & -0.003 & 0.070 & 0.030 & 0.170 & 0.033 \\
D & 6 & 0.109 & 0.115 & 0.134 & 0.023 & 0.012 \\
D & 7 & -0.052 & -0.170 & -0.104 & - & -0.018 \\
D & 8 & 0.008 & -0.066 & -0.033 & -0.100 & -0.020 \\
D & 9 & 0.055 & 0.000 & 0.000 & 0.066 & 0.000 \\
D & 10 & -0.004 & -0.063 & -0.063 & -0.117 & 0.000 \\
D & 11 & -0.007 & -0.063 & -0.050 & -0.100 & -0.056 \\
D & 12 & 0.006 & -0.050 & 0.000 & 0.000 & -0.020 \\
E & 1 & 0.005 & 0.117 & 0.163 & 0.100 & 0.000 \\
E & 2 & 0.043 & 0.267 & 0.234 & & - \\
E & 3 & 0.005 & 0.034 & 0.077 & 0.078 & 0.123 \\
E & 4 & 0.000 & 0.033 & 0.033 & 0.007 & -0.050 \\
E & 5 & 0.003 & 0.030 & 0.070 & 0.054 & 0.020 \\
E & 6 & 0.017 & 0.066 & 0.033 & 0.067 & 0.014 \\
E & 7 & -0.001 & -0.010 & 0.000 & 0.000 & -0.001 \\
E & 8 & -0.005 & - & 0.184 & 0.150 & 0.016 \\
\hline
\end{tabular}

(-): dados não-observados 
Figura 4.3: Perfis médios dos grupos com relação ao diferencial de fluxo (considerando todos os dados da Tabela 4.4).

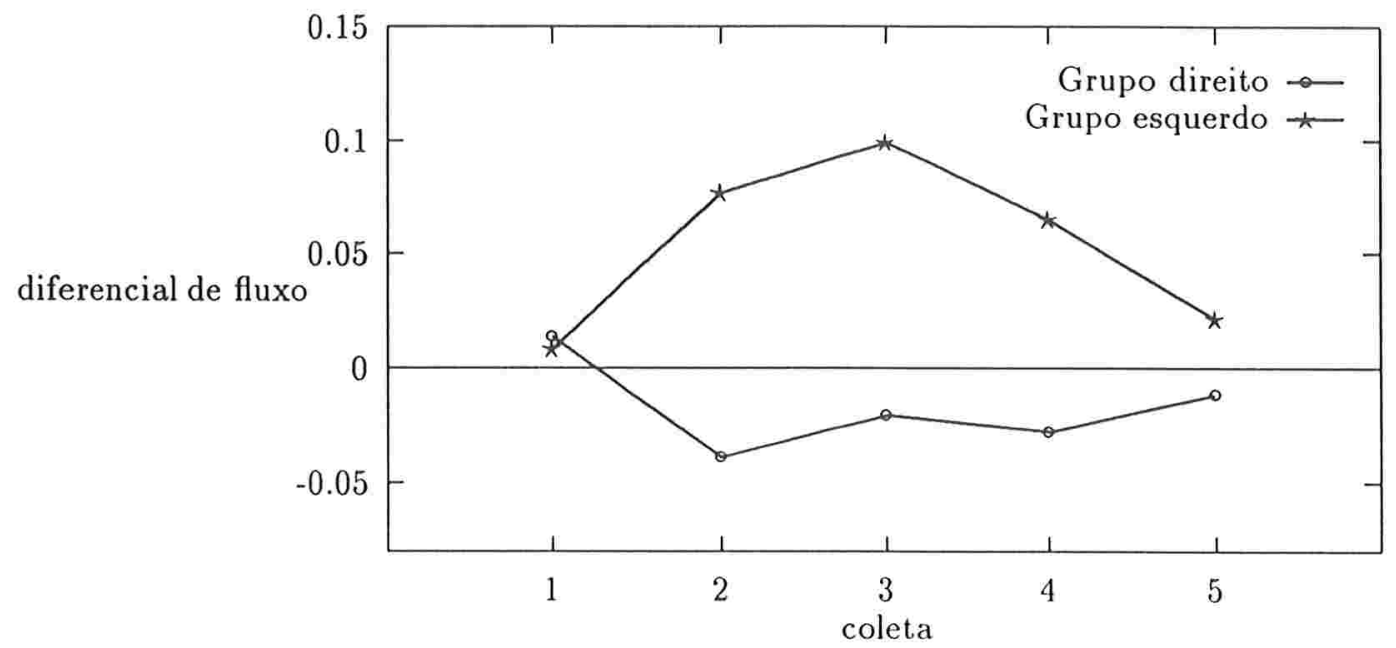

Figura 4.4: Perfis médios dos grupos com relação ao diferencial de fluxo (considerando apenas os indivíduos com dados completos da Tabela 4.4).

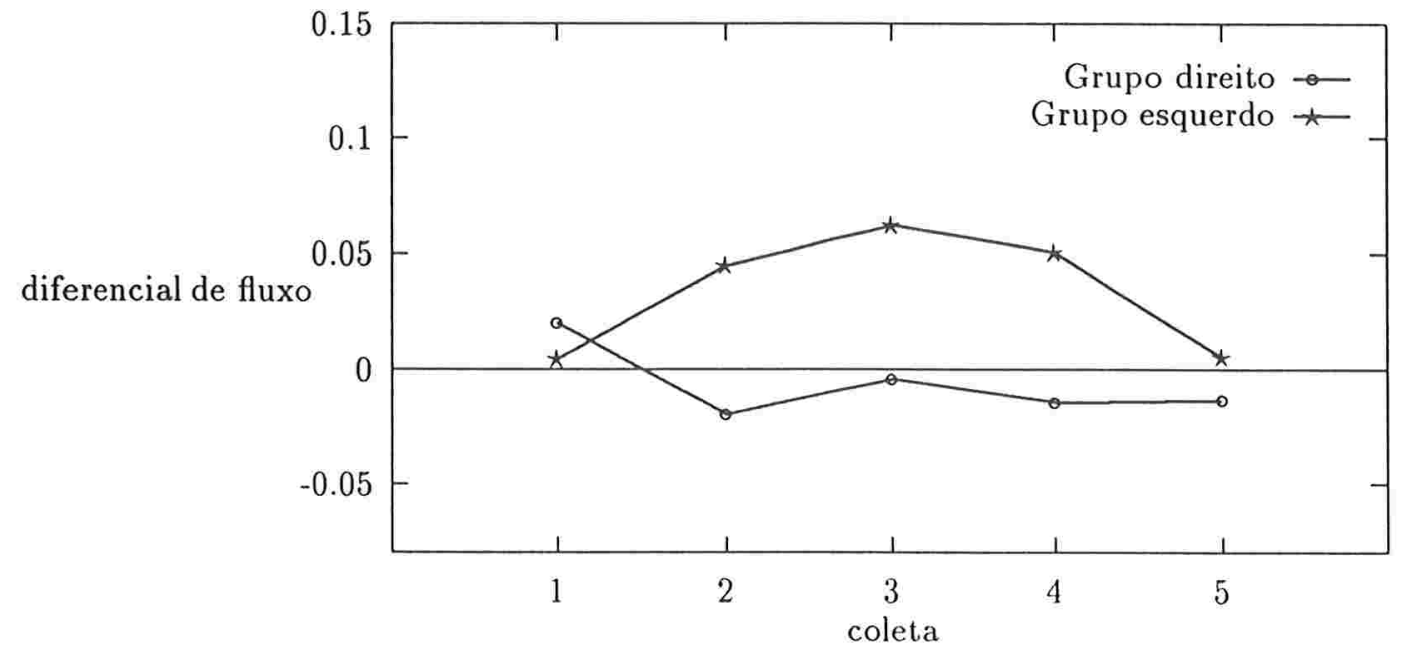


Tabela 4.6: Níveis descritivos associados aos testes obtidos com os dois procedimentos aplicados aos dados da Tabela 4.4.

\begin{tabular}{lcc}
\hline Hipótese & $\begin{array}{c}\text { Método de Bartlett } \\
(N=20)\end{array}$ & $\begin{array}{c}\text { Procedimento Usual } \\
(N=16)\end{array}$ \\
\hline Esfericidade & 0.2159 & 0.1136 \\
GRUPO X COLETA & 0.0001 & 0.0173 \\
COLETA & 0.1453 & 0.2515 \\
GRUPO & 0.0065 & 0.1000 \\
DIFXGRUPO & 0.0007 & 0.0144 \\
ESTXGRUPO & 0.0029 & 0.0522 \\
$\tilde{N}$ ESTXGRUPO & 0.2421 & 0.9085 \\
$\tilde{N}$ EST & 0.3306 & 0.5075 \\
\hline
\end{tabular}

Tabela 4.7: Estimativas das médias ( \pm erros-padrão) associadas aos contrastes, obtidas com os dois procedimentos aplicados aos dados da Tabela 4.4 .

\begin{tabular}{llcc}
\hline Contraste & Grupo & $\begin{array}{c}\text { Método de Bartlett } \\
(N=20)\end{array}$ & $\begin{array}{c}\text { Procedimento Usual } \\
(N=16)\end{array}$ \\
\hline \multirow{2}{*}{ DIF } & direito & $-0.030 \pm 0.017$ & $-0.016 \pm 0.015$ \\
& esquerdo & $0.072 \pm 0.021$ & $0.048 \pm 0.020$ \\
\multirow{2}{*}{ EST } & direito & $-0.031 \pm 0.035$ & $-0.012 \pm 0.033$ \\
& esquerdo & $0.087 \pm 0.046$ & $0.053 \pm 0.042$ \\
\multirow{2}{*}{ NEST } & & $0.005 \pm 0.009$ & $0.004 \pm 0.009$ \\
\hline
\end{tabular}




\subsection{Alternativas de implementação computacional para análise utilizando o método de Bartlett}

\subsubsection{BMDP $/ 2 \mathrm{~V}$}

$\mathrm{O}$ módulo $2 \mathrm{~V}$ do programa estatístico BMDP é especialmente destinado à análise de variância e covariância com medidas repetidas. Esse foi o programa utilizado nas análises que acabamos de apresentar e dentre os programas avaliados nesse trabalho, parece ser o mais conveniente, pois ele permite a análise de dados longitudinais sob o enfoque split-plot com covariáveis que variam no tempo. O BMDP/2v fornece como saída básica:

- Tabela com médias e desvios-padrão associados às variáveis dependentes e covariáveis;

- O nível de significância aproximado do teste de Mauchly (utilizando a aproximação de Anderson (1984), dada por (2.10));

- As estimativas para o fator de correção $\varepsilon$ (Greenhouse-Geisser e Huynh-Feldt);

- A ANCOVA, incluindo os testes associados a comparações intra-indivíduos corrigidos pelas estimativas de $\varepsilon$;

- Estimativas para os coeficientes das covariáveis (a partir dos quais calculam-se as estimativas para os dados não-observados através de (2.58));

- anovas para cada contraste.

O programa não fornece estimativas para os parâmetros do modelo. Um exemplo de análise efetuada com о BмDP / $2 \mathrm{~V}$ pode ser encontrado nas Figuras B.1 e B.2 (parte da análise dos dados da Tabela 4.1 associada ao Exemplo 4.1). Para maiores detalhes sobre o programa veja Dixon (1990).

É importante notar que о вмDP/2V utiliza um modelo diferente do apresentado em (2.41), mas que produz os mesmos resultados quando se trata de comparações intra-indivíduos sob o método 
de Bartlett. O modelo utilizado possui dois coeficientes associados a cada covariável e pode ser escrito como

$$
Y_{i j k}=\mu+\alpha_{i}+\gamma_{k}+\alpha \gamma_{i k}+\sum_{l=1}^{m}\left\{\psi_{l 1}\left(\bar{z}_{i j . l}-\bar{z}_{\ldots l}\right)+\psi_{l 2}\left(z_{i j k l}-\bar{z}_{i j . l}\right)\right\}+\pi_{j(i)}+e_{i j k}
$$

onde $\bar{z}_{i j . l}$ é a média dos valores da l-ésima covariável associados à todas as obsrvações do $j$-ésimo indivíduo do $i$-ésimo tratamento, $\bar{z}_{\text {..l }}$ é a média de todos os valores da $l$-ésima covariável, $\psi_{l 1}$ e $\psi_{l 2}$ são os dois coeficientes associados à $l$-ésima covariável.

Para um teste que envolva uma comparação intra-indivíduos, o termo $\left(\bar{z}_{i j . l}-\bar{z}_{\ldots l . l}\right)$ em (4.1) é constante e o termo $\left(z_{i j k l}-\bar{z}_{i j . l}\right)$ corresponde a $z_{i j k l}$ no modelo (2.41).

\subsubsection{SAS/GLM}

A subrotina SAS/GLM/REPEATED é especialmente dirigida à análise através de modelos de dados longitudinais split-plot, porém ela não aceita covariáveis que variem no tempo. Assim, a análise baseada no método de Bartlet requer duas rotinas:

(a) uma ANCOVA utilizando o modelo linear geral (2.40) através do módulo GLM;

(b) uma ANOVA para os dados completados, ou seja, substituindo-se os dados não-observados por suas estimativas, utilizando a subrotina REPEATED. Aqui, podem ser inseridos contrastes associados a comparações intra-indivíduos, caso sejam de interesse.

Para exemplificar, considere a análise dos dados da Tabela 4.1, cujos programas e saídas utilizando o SAS/GLM encontram-se nas Figuras B.3 a B.6:

(i) Com a AnCova obtém-se os testes de interesse associados a comparações intra-indivíduos (no exemplo, Coleta e GruPo × COleta) (veja Figuras B.3 e B.4). Porém essa rotina não fornece o teste de esfericidade nem estimativas para $\varepsilon$; 
(ii) Ainda na rotina (a) obtêm-se estimativas para os coeficientes das covariáveis, a partir das quais calculam-se as estimativas para os dados não-observados utilizando (2.58) (veja Figura B.4);

(iii) Para se rodar a rotina (b), os dados não-observados devem ser substituídos pelas suas estimativas (veja Figura B.5);

(iv) A rotina (b) fornece o teste de Mauchly (o teste que apresentamos em (2.7) é o aplicado a componentes ortogonais) e também estimativas para $\varepsilon$ (veja Figura B.6). Utilizamos essas informações para testar se $\Sigma$ é esférica: se for, então devemos considerar os testes obtidos com a rotina (a); se não for, os testes de (a) devem ser corrigidos pelas estimativas de $\varepsilon$ obtidas com a rotina (b);

(v) Se for conveniente considerar testes para os efeitos dos fatores entre individuos (no exemplo, fator GRUPO), os testes fornecidos pela rotina (b) são os adequados (veja Figura B.6).

Para maiores esclarecimentos sobre o programa, veja SAS Institute, Inc. (1987).

\subsubsection{SPSS/MANOVA}

O programa SPSS (versão 2.0 para PC) possui em seu módulo MANOVA comandos específicos para a análise de dados longitudinais sob o modelo do tipo split-plot; entretanto, não permite a inserção de covariáveis que variem no tempo. Além disso, o sPSS não possui um módulo destinado à construção de um modelo com fatores aleatórios a partir do modelo linear geral. Assim sendo, não é possível utilizar o sPSS na análise de dados longitudinais através do método de Bartlett. Para maiores detalhes, veja SPSS, Inc. (1988).

$\mathrm{Na}$ ausência de um programa estatístico adequado, é possível a construção de um algoritmo que reproduza a metodologia descrita no Capítulo 2 através de um programa que faça cálculos matriciais, como por exemplo o SOC/CM e o SAS/ıML. 


\subsection{Implementação computacional para Máxima Verossimilhan- ça - BMDP $/ 5 \mathrm{~V}$}

O módulo $5 \mathrm{~V}$ do programa estatístico BMDP é dirigido para a análise de medidas repetidas sob o enfoque de máxima verossimilhança ou máxima verossimilhança restrita. Podem ser consideradas diferentes estruturas de covariância para $\Sigma$ e situações de dados incompletos são automaticamente incorporadas ao modelo.

Para a estimação dos parâmetros de $\beta$ e $\theta$, o programa oferece vários algoritmos iterativos, como o de Newton-Raphson, Scoring de Fisher, o algoritmo EM Generalizado híbrido com o Scoring de Fisher (apresentado por Jenrich e Schluchter (1986)) e o algoritmo EM aplicado à máxima verossimilhança restrita.

Como saída básica, o BMDP/5V fornece:

- O $\log$ da verossimilhança para cada passo do processo iterativo (até atingir o valor máximo);

- Estimativas dos componentes de $\boldsymbol{\Sigma}(\boldsymbol{\theta})$;

- Testes de Wald associados aos fatores fixos do modelo;

- Estimativas dos parâmetros de $\beta$ e a matriz de covariância estimada de $\hat{\beta}_{M V}$.

Utilizamos O BMDP/5V para analisar os dados da Tabela 4.1 do Exemplo 4.1 sob o enfoque de máxima verossimilhança. Foram consideradas diferentes estruturas de covariância para $\Sigma$ e os resultados associados aos vários ajustes encontram-se na Tabela 4.8 
Tabela 4.8: Ajuste de vários modelos de estrutura de covariância aos dados da Tabela 4.1.

\begin{tabular}{cccccc}
\hline $\begin{array}{c}\text { Estrutura de } \\
\text { covariância }\end{array}$ & $\begin{array}{c}\text { Número de } \\
\text { parâmetros }\end{array}$ & $\begin{array}{c}\text { Valor máximo do } \\
\log \text { da verossim. }\end{array}$ & $\begin{array}{c}2 \times \log \\
\text { da verossim. }\end{array}$ & $\begin{array}{c}\text { Diferença para } \\
\text { não-estruturada }\end{array}$ & AIC \\
\hline simetria composta & 2 & 144.086 & 288.172 & 91.264 & 142.086 \\
AR (1) & 2 & 144.942 & 289.884 & 89.552 & 142.942 \\
autorregressiva geral & 5 & 148.039 & 296.078 & 83.358 & 143.039 \\
não-estruturada & 15 & 189.718 & 379.436 & & 174.718 \\
\hline
\end{tabular}

Utilizando o teste da razão de verossimilhança generalizada apresentado em (3.25), podemos verificar se há alguma estrutura que se adeque melhor aos dados do que a não-estruturada. Assim, concluimos que a estrutura de covariância mais adequada para $\Sigma$ dentre as aqui consideradas é a não-estruturada (compare os valores da quinta coluna da Tabela $4.8 \mathrm{com}$ os valores tabelados $\chi_{(13 ; 0.01)}^{2}=27.7$ e $\left.\chi_{(10 ; 0.01)}^{2}=23.2\right)$. Considerando o critério de informação de Akaike (AIC) (veja Akaike (1973), por exemplo) cujos valores também se encontram na Tabela 4.8 chegamos à mesma conclusão. A Tabela 4.9 apresenta os níveis descritivos dos testes de Wald obtidos sob as várias estruturas de covariância:

Tabela 4.9: Níveis descritivos dos testes de Wald obtidos para os modelos ajustados com as várias estruturas de covariância.

\begin{tabular}{cccc}
\hline $\begin{array}{c}\text { Estrutura de } \\
\text { covariância }\end{array}$ & GRUPO & COLETA & GRUPO $\times$ COLETA \\
\hline simetria composta & 0.001 & 0.115 & 0.000 \\
AR (1) & 0.000 & 0.182 & 0.000 \\
autorregressiva geral & 0.000 & 0.084 & 0.000 \\
não-estruturada & 0.000 & 0.029 & 0.007 \\
\hline
\end{tabular}

Em todos os casos o teste associado à interação GRUPO X COLETA é altamente significante $(p<$ 
0.01). Entretanto, vale notar que resultados diferentes podem ser obtidos sob diferentes estruturas de covariância, o que mostra a importância da escolha de uma estrutura que seja adequada aos dados.

Para essa análise efetuada com o BMDP / 5V foi rodado um programa para cada uma das estruturas de covariância. Para efeito de ilustração, os comandos e a saída do programa com a estrutura de simetria composta encontram-se, respectivamente, nas Figuras B.7 e B.8. Maiores detalhes sobre o BMDP/5V podem ser encontrados em Dixon (1990).

Quanto aos contrastes que inserimos na análise apresentada na Seção 4.1, não foi possível reproduzi-los com о BMDP/5V. 


\section{Apêndice A}

\section{Demonstrações associadas à Seção}

\section{3}

Considere o modelo (2.43). Para efeito de demonstração de (2.45), (2.46) e (2.53), suponha que para $s$ dos $N$ indivíduos $(s \leq N)$ pelo menos uma das $T$ observações esteja fallando. Dessa forma podemos representar o vetor $(T \times 1)$ de dados do $j$-ésimo indivíduo com dados incompletos na forma $\boldsymbol{y}_{j}=\left(\boldsymbol{y}_{j m}^{t}, \boldsymbol{y}_{j l}^{t}\right)^{t}, j=1, \ldots, s$, onde $\boldsymbol{y}_{j m}$ corresponde ao vetor $\left(m_{j} \times 1\right)$ dos dados nãoobservados (substituídos por valores quaisquer) e $y_{j l}$ corresponde ao vetor $\left(l_{j} \times 1\right)$ dos dados observados $\left(m_{j}+l_{j}=T, j=1, \ldots, s\right)$. As observações dos outros $r(=N-s)$ indivíduos com dados completos serão representadas pelo vetor $(r T \times 1) y_{r}$, ou seja, $y_{r}=\left(y_{s+1}^{t}, \ldots, y_{N}^{t}\right)^{t}$. Sem perda de generalidade, estamos admitindo que os $s$ primeiros indivíduos têm dados incompletos. O número total de dados não-observados é $\sum_{j=1}^{s} m_{j}=m$ e o número total de dados observados é $\sum_{j=1}^{s} l_{j}+r T=T ;$ portanto, $T .+m=N T$, o número total de observações. 
Podemos, então, escrever as componentes de (2.43) da seguinte maneira:

$$
y=\left(\begin{array}{c}
y_{1 m} \\
y_{1 l} \\
y_{2 m} \\
y_{2 l} \\
\vdots \\
y_{s m} \\
y_{s l} \\
y_{r}
\end{array}\right), A^{*}=\left(\begin{array}{ccccc}
X_{1 m}^{*} & I_{m_{1}} & 0 & \ldots & 0 \\
X_{1 l}^{*} & 0 & 0 & \ldots & 0 \\
X_{2 m}^{*} & 0 & I_{m_{2}} & \ldots & 0 \\
X_{2 l}^{*} & 0 & 0 & \ldots & 0 \\
\vdots & \vdots & \vdots & \ddots & \vdots \\
X_{s m}^{*} & 0 & 0 & \ldots & I_{m s} \\
X_{s l}^{*} & 0 & 0 & \ldots & 0 \\
X_{r}^{*} & 0 & 0 & \ldots & 0
\end{array}\right) \text { e } \eta^{*}=\left(\begin{array}{c}
\beta^{*} \\
\Psi_{1} \\
\Psi_{2} \\
\vdots \\
\Psi_{s}
\end{array}\right)
$$

onde $X_{j m}^{*}, X_{j l}^{*}$ e $X_{r}^{*}$ são submatrizes da matriz de especificação global $X^{*}$ associadas a $y_{j m}$, $y_{j l}, j=1, \ldots, s$, e $y_{r}$, respectivamente, $\boldsymbol{I}_{m_{j}}$ é a matriz identidade de ordem $m_{j}$ e $\Psi_{j}$ é o vetor de $m_{j}$ parâmetros desconhecidos associado à matriz $Z_{j}$ de covariáveis correspondentes ao $j$-ésimo indivíduo, $j=1, \ldots, s$.

1. Demonstração de (2.45) e (2.46)

Para encontrar $S Q H_{A N C}$, vamos expandir (2.45):

$$
\begin{aligned}
\boldsymbol{A}^{* t} \boldsymbol{A}^{*}= & \left(\begin{array}{ccccc}
\left(\sum_{j=1}^{s} X_{j m}^{* t} X_{j m}^{*}+\sum_{j=1}^{s} X_{j l}^{* t} X_{j l}^{*}+X_{r}^{* t} X_{r}^{*}\right) & X_{1 m}^{* t} & X_{2 m}^{* t} & \ldots & X_{s m}^{* t} \\
X_{1 m}^{*} & I_{m_{1}} & 0 & \ldots & 0 \\
X_{2 m}^{*} & 0 & I_{m_{2}} & \ldots & 0 \\
\vdots & \vdots & \vdots & \ddots & \vdots \\
X_{s m}^{*} & 0 & 0 & \ldots & I_{m_{s}}
\end{array}\right)= \\
& =\left(\begin{array}{cc}
\left(X_{m}^{* t} X_{m}^{*}+X_{o}^{* t} X_{o}^{*}\right) & X_{m}^{* t} \\
X_{m}^{*} & \boldsymbol{I}_{m}
\end{array}\right),
\end{aligned}
$$


onde $X_{m}^{*}=\left(X_{1 m}^{* t}, X_{2 m}^{* t}, \ldots, X_{s m}^{* t}\right)^{t}$ e $X_{o}^{*}=\left(X_{l}^{* t}, X_{r}^{* t}\right)^{t} \operatorname{com} X_{l}^{*}=\left(X_{1 l}^{* t}, X_{2 l}^{* t}, \ldots, X_{s l}^{* t}\right)^{t}$. Utilizando a técnica usual para obtenção da inversa de uma matriz particionada, temos:

$$
\left(A^{* t} A^{*}\right)^{-1}=\left(\begin{array}{ll}
B_{11} & B_{12} \\
B_{12}^{t} & B_{22}
\end{array}\right)
$$

onde

$$
\begin{aligned}
& B_{11}=\left(X_{o}^{* t} X_{o}^{*}\right)^{-1}, \\
& B_{12}=-\left(X_{o}^{* t} X_{o}^{*}\right)^{-1} X_{m}^{* t}, \quad \mathrm{e} \\
& B_{22}=I_{m}+X_{m}^{*}\left(X_{o}^{* t} X_{o}^{*}\right)^{-1} X_{m}^{* t} .
\end{aligned}
$$

Utilizando (A.3) temos que

$$
\left(D\left(A^{* t} A^{*}\right)^{-1} D^{t}\right)=\left(\begin{array}{ll}
C & 0
\end{array}\right)\left(\begin{array}{cc}
B_{11} & B_{12} \\
B_{12}^{t} & B_{22}
\end{array}\right)\left(\begin{array}{c}
C^{t} \\
0^{t}
\end{array}\right)=C B_{11} C^{t}=C\left(X_{o}^{* t} X_{o}^{*}\right)^{-1} C^{t} .
$$

Logo, de (2.45),

$$
\begin{aligned}
S Q H_{A N C} & =\left(\begin{array}{ll}
\hat{\beta}^{* t} & \hat{\Psi}^{t}
\end{array}\right)\left(\begin{array}{c}
C^{t} \\
0^{t}
\end{array}\right)\left(C\left(X_{o}^{* t} X_{o}^{*}\right)^{-1} C^{t}\right)^{-1}\left(\begin{array}{ll}
C & 0
\end{array}\right)\left(\begin{array}{c}
\hat{\beta}^{*} \\
\hat{\Psi}
\end{array}\right)= \\
& =\hat{\boldsymbol{\beta}}^{*} C^{t}\left(C\left(X_{o}^{* t} X_{o}^{*}\right)^{-1} C^{t}\right)^{-1} C \hat{\beta}^{*}
\end{aligned}
$$

De maneira análoga, desenvolvemos (2.46) para obter $S Q E_{2}$ :

$$
S Q E_{2 A N C}=y^{t} y-y^{t} A^{*}\left(A^{* t} A^{*}\right)^{-1} A^{* t} y
$$

Mas,

$$
y^{t} y=y_{m}^{t} y_{m}+y_{o}^{t} y_{o}
$$




$$
\boldsymbol{A}^{* t} \boldsymbol{y}=\left(\begin{array}{c}
\left(\sum_{i=1}^{s} X_{i m}^{* t} y_{i m}+\sum_{i=1}^{s} X_{i l}^{* t} y_{i l}+X_{r}^{* t} y_{r}\right) \\
y_{1 m} \\
y_{2 m} \\
\vdots \\
y_{s m}
\end{array}\right)=\left(\begin{array}{c}
\left(X_{m}^{* t} y_{m}+X_{o}^{* t} y_{o}\right) \\
y_{m}
\end{array}\right)
$$

onde $y_{m}=\left(y_{1 m}^{t}, y_{2 m}^{t}, \ldots, y_{s m}^{t}\right)^{t}$. Assim, de (A.3) e (A.8),

$$
\begin{aligned}
& y^{t} A^{*}\left(A^{* t} A^{*}\right)^{-1} A^{* t} y=\left(y_{m}^{t} X_{m}^{*}+y_{o}^{t} X_{o}^{*} y_{m}^{t}\right)\left(\begin{array}{cc}
B_{11} & B_{12} \\
B_{12}^{t} & B_{22}
\end{array}\right)\left(\begin{array}{c}
X_{m}^{* t} y_{m}+X_{o}^{* t} y_{o} \\
y_{m}
\end{array}\right)= \\
& =y_{o}^{t} X_{o}^{*}\left(X_{o}^{* t} X_{o}^{*}\right)^{-1} X_{o}^{* t} y_{o}+y_{m}^{t} y_{m} \text {. }
\end{aligned}
$$

Assim, substituindo (A.7) e (A.9) em (A.6) chegamos em

$$
S Q E_{2 A N C}=y_{o}^{t}\left(I_{T .}-X_{o}\left(X_{o}^{* t} X_{o}^{*}\right)^{-1} X_{o}^{* t}\right) y_{o}
$$

\section{Demonstração de (2.53)}

De (A.3) e (A.8) temos que

$$
\hat{\eta}^{*}=\left(\begin{array}{c}
\hat{\beta}^{*} \\
\hat{\Psi}
\end{array}\right)=\left(A^{* t} A^{*}\right)^{-1} A^{* t} y=\left(\begin{array}{c}
\left(X_{o}^{* t} X_{o}^{*}\right)^{-1} X_{o}^{* t} y_{o} \\
y_{m}-X_{m}^{*}\left(X_{o}^{* t} X_{o}^{*}\right)^{-1} X_{o}^{* t} y_{o}
\end{array}\right)
$$

e portanto, $\hat{\boldsymbol{\beta}}^{*}$ é igual a (2.53).

Com essas demonstrações fica claro que os valores imputados ao conjunto de dados original para substituir os dados não-observados não interferem no cálculo das somas de quadrados que definem as estatísticas usadas nos testes $F$ e nem na obtenção da estimativa de $\beta$. 
Apêndice B

Tabelas e programas associados ao

Capítulo 4 
Tabela B.1: Dados originais do Exemplo 4.1.

\begin{tabular}{|c|c|c|c|c|c|c|c|c|c|c|c|}
\hline \multirow[t]{2}{*}{ Indiv } & \multirow[t]{2}{*}{ Grupo } & \multicolumn{2}{|c|}{ Coleta 1} & \multicolumn{2}{|c|}{ Coleta 2} & \multicolumn{2}{|c|}{ Coleta 3} & \multicolumn{2}{|c|}{ Coleta 4} & \multicolumn{2}{|c|}{ Coleta 5} \\
\hline & & Esq. & Dir. & Esq. & Dir. & Esq. & Dir. & Esq. & Dir. & Esq. & Dir. \\
\hline 1 & D & 0.046 & 0.046 & 0.635 & 0.799 & 0.670 & 0.749 & 0.515 & 0.550 & 0.245 & 0.316 \\
\hline 2 & D & 0.026 & 0.030 & 0.267 & 0.233 & 0.167 & 0.167 & 0.100 & 0.167 & 0.070 & 0.073 \\
\hline 3 & $\mathrm{D}$ & 0.050 & 0.050 & 0.267 & 0.367 & 0.300 & 0.400 & 0.267 & 0.433 & 0.116 & 0.100 \\
\hline 4 & D & - & 0.018 & - & 0.055 & 0.100 & 0.080 & 0.100 & 0.080 & 0.043 & 0.050 \\
\hline 5 & D & 0.053 & 0.056 & 0.300 & 0.230 & 0.230 & 0.200 & 0.400 & 0.230 & 0.200 & 0.167 \\
\hline 6 & D & - & 0.010 & 0.315 & 0.200 & 0.334 & 0.200 & 0.184 & 0.161 & 0.075 & 0.064 \\
\hline 7 & D & - & 0.008 & 0.063 & 0.233 & 0.063 & 0.167 & 0.083 & 0.150 & 0.019 & 0.037 \\
\hline 8 & D & 0.013 & 0.005 & 0.167 & 0.233 & 0.167 & 0.200 & 0.167 & 0.267 & 0.026 & 0.046 \\
\hline 9 & $\mathrm{D}$ & - & 0.030 & 0.200 & 0.200 & 0.233 & 0.233 & 0.233 & 0.167 & 0.073 & 0.073 \\
\hline 10 & D & 0.038 & 0.042 & 0.267 & 0.330 & 0.267 & 0.330 & 0.200 & 0.317 & 0.067 & 0.067 \\
\hline 11 & D & 0.023 & 0.030 & 0.267 & 0.330 & 0.233 & 0.283 & 0.233 & 0.333 & 0.110 & 0.166 \\
\hline 12 & D & 0.018 & 0.012 & 0.350 & 0.400 & 0.200 & 0.200 & 0.233 & 0.233 & 0.090 & 0.110 \\
\hline 13 & $\mathrm{E}$ & 0.048 & 0.043 & 0.533 & 0.416 & 0.630 & 0.467 & 0.533 & 0.433 & 0.200 & 0.200 \\
\hline 14 & $\mathrm{E}$ & 0.093 & 0.050 & 0.467 & 0.200 & 0.367 & 0.133 & 0.333 & 0.133 & 0.200 & 0.077 \\
\hline 15 & $\mathrm{E}$ & 0.018 & 0.013 & 0.137 & 0.103 & 0.200 & 0.123 & 0.183 & 0.105 & 0.083 & 0.033 \\
\hline 16 & $\mathrm{E}$ & 0.050 & 0.050 & 0.300 & 0.267 & 0.233 & 0.200 & 0.150 & 0.143 & 0.083 & 0.133 \\
\hline 17 & $\mathrm{E}$ & 0.020 & 0.017 & 0.130 & 0.100 & 0.143 & 0.073 & 0.137 & 0.083 & 0.037 & 0.017 \\
\hline 18 & $\mathrm{E}$ & 0.087 & 0.070 & 0.333 & 0.267 & 0.233 & 0.200 & 0.267 & 0.200 & 0.107 & 0.093 \\
\hline 19 & $\mathrm{E}$ & 0.037 & 0.038 & 0.233 & 0.243 & 0.233 & 0.233 & 0.233 & 0.233 & 0.050 & 0.051 \\
\hline 20 & $\mathrm{E}$ & 0.008 & 0.013 & 0.333 & 0.167 & 0.367 & 0.183 & 0.267 & 0.117 & 0.073 & 0.057 \\
\hline
\end{tabular}

(-): dados não-observados 
Figura B.1: Análise dos dados da Tabela 4.1 utilizando o Método de Bartlett ( Programa BMDP 2V)

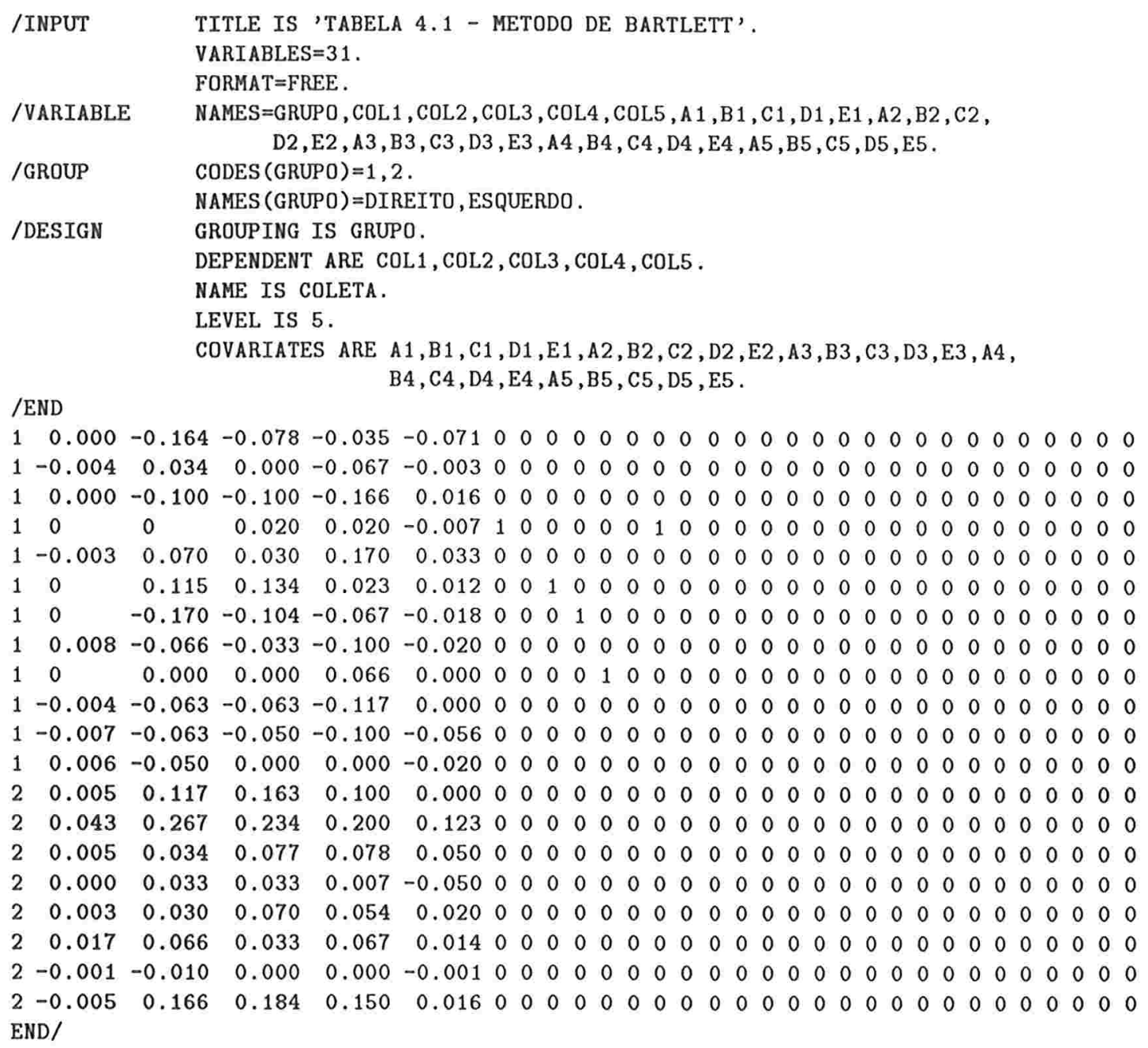

Obs: A covariável $A$ corresponde ao primeiro dado não-observado do quarto indivíduo; a covariável $B$ ao segundo dado não-observado do quarto indivíduo; a covariável $C$ ao dado não-observado do sexto indivíduo; $D$ do sétimo indivíduo e $E$ do nono. 
Figura B.2: Análise dos dados da Tabela 4.1 utilizando o Método de Bartlett

(Saída do programa da Figura B.1)

BMDP2V - AIALYSIS OF VARIAICE AHD COVARIAHCE WITH REPEATED MEASURES.

Version: PC90 (1990 IBH PC/MS-DOS)

Site: $169-2520$

Date: $08 / 16 / 94$ at $16: 08: 58$

UIIV DE SAO PAULO

DESIGI SPECIFICATIONS

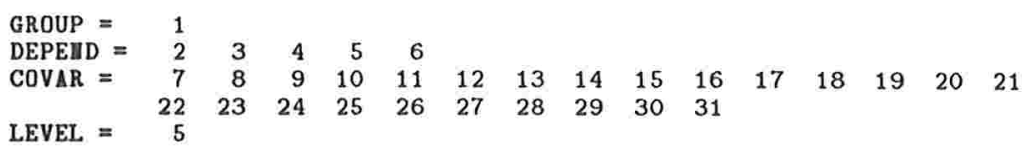

HUMBER OF CASES READ. . . . . . . . . . . . . . 20

GROUP STRUCTURE

GRUPO COUHT

DIREIT0 12

SUMS OF SQUARES AND CORRELATION MATRIX OF THE

ORTHOGOIAL COMPOHEUTS POOLED FOR ERROR 2 IN ANOVA TABLE BELOH.

$\begin{array}{lrrrr}0.02124 & 1.000 & & & \\ 0.06514 & -0.053 & 1.000 & & \\ 0.03415 & -0.406 & 0.073 & 1.000 & \\ 0.02115 & 0.445 & 0.522 & -0.285 & 1.000\end{array}$

SPHERICITY TEST APPLIED TO ORTHOGOHAL COMPONENTS - TAIL PROBABILITY 0.0774

- Ha' evidencias de violacao da hipotese de esfericidade *

CELL MEAIS FOR 1-ST COVARIATE

$\begin{array}{lcccc} & \text { GRUPO }= & \text { DIREITO } & \text { ESQUERDO } & \text { MARGIHAL } \\ & \text { COLETA } & & & \\ \text { A1 } & 1 & 0.08333 & 0.00000 & 0.05000 \\ \text { A2 } & 2 & 0.00000 & 0.00000 & 0.00000 \\ \text { A3 } & 3 & 0.00000 & 0.00000 & 0.00000 \\ \text { A4 } & 4 & 0.00000 & 0.00000 & 0.00000 \\ \text { A5 } & 5 & 0.00000 & 0.00000 & 0.00000 \\ & & & & \\ & \text { MARGIHAL } & 0.01667 & 0.00000 & 0.01000 \\ & \text { COUNT } & 12 & 8 & 20\end{array}$

STAIDARD DEVIATIONS FOR 1-ST COVARIATE

\begin{tabular}{lccc} 
& GRUPO & DIREITO & ESQUERDO \\
A1 & COLETA & DIT & \\
A2 & 1 & 0.28868 & 0.00000 \\
A3 & 2 & 0.00000 & 0.00000 \\
A4 & 3 & 0.00000 & 0.00000 \\
A5 & 4 & 0.00000 & 0.00000 \\
CELL MEAIS & 5 & 0.00000 & 0.00000 \\
\hline
\end{tabular}




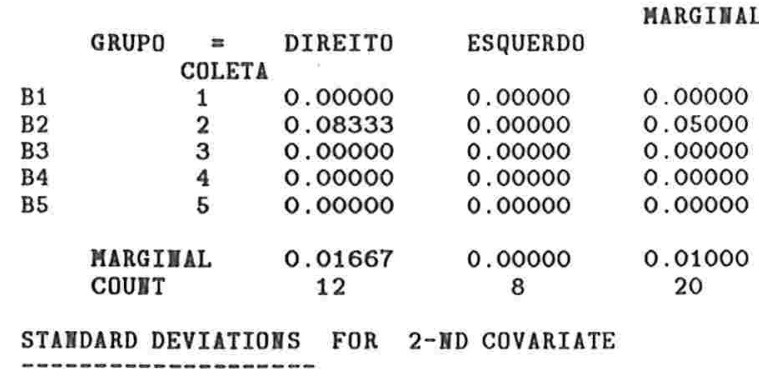

$\begin{array}{lccl} & \text { GRUPO } & \text { DIREITO } & \text { ESQUERDO } \\ \text { B1 } & \text { COLETA } & & \\ \text { B2 } & 1 & 0.00000 & 0.00000 \\ \text { B3 } & 2 & 0.28868 & 0.00000 \\ \text { B4 } & 3 & 0.00000 & 0.00000 \\ \text { B5 } & 4 & 0.00000 & 0.00000 \\ & 5 & 0.00000 & 0.00000\end{array}$

CELL MEARS FOR 3-RD COVARIATE

\begin{tabular}{|c|c|c|c|c|}
\hline & GRUPO $\stackrel{=}{=}$ & DIREITO & ESQUERDO & HAKGINAL \\
\hline $\mathrm{C} 1$ & 1 & 0.08333 & 0.00000 & 0.05000 \\
\hline $\mathrm{C} 2$ & 2 & 0.00000 & 0.00000 & 0.00000 \\
\hline C3 & 3 & 0.00000 & 0.00000 & 0.00000 \\
\hline $\mathrm{C} 4$ & 4 & 0.00000 & 0.00000 & 0.00000 \\
\hline C5 & 5 & 0.00000 & 0.00000 & 0.00000 \\
\hline & $\begin{array}{l}\text { MARGIMIIL } \\
\text { COUIIT }\end{array}$ & $\begin{array}{l}0.01667 \\
12\end{array}$ & $\begin{array}{c}0.00000 \\
8\end{array}$ & $\begin{array}{l}0.01000 \\
20\end{array}$ \\
\hline
\end{tabular}

$\begin{array}{lccc} & \text { GRUPO } & & \\ & & \text { DIREITO } & \text { ESQUERDO } \\ \text { C1 } & \text { COLETA } & & \\ \text { C2 } & 1 & 0.28868 & 0.00000 \\ \text { C3 } & 2 & 0.00000 & 0.00000 \\ \text { C4 } & 3 & 0.00000 & 0.00000 \\ \text { C5 } & 4 & 0.00000 & 0.00000 \\ & 5 & 0.00000 & 0.00000\end{array}$

\section{CELL MEAISS FOR 4-TH COVARIATE}

\begin{tabular}{|c|c|c|c|c|c|}
\hline \multirow{2}{*}{\multicolumn{2}{|c|}{ GRUPO }} & \multirow[b]{2}{*}{$\begin{array}{c}= \\
\text { COLETA }\end{array}$} & & \multirow[b]{2}{*}{ ESQUERDO } & \multirow[t]{2}{*}{ MARGIHAL } \\
\hline & & & DIREITO & & \\
\hline D1 & & 1 & 0.08333 & 0.00000 & 0.05000 \\
\hline D2 & & 2 & 0.00000 & 0.00000 & 0.00000 \\
\hline D3 & & 3 & 0.00000 & 0.00000 & 0.00000 \\
\hline D4 & & 4 & 0.00000 & 0.00000 & 0.00000 \\
\hline \multirow[t]{2}{*}{ D5 } & & 5 & 0.00000 & 0.00000 & 0.00000 \\
\hline & $\begin{array}{l}\text { MARGI } \\
\text { COUIT }\end{array}$ & $\mathrm{AL}$ & $\begin{array}{c}0.01667 \\
12\end{array}$ & $\begin{array}{c}0.00000 \\
8\end{array}$ & $\begin{array}{c}0.01000 \\
20\end{array}$ \\
\hline
\end{tabular}

GRUPO $\underset{\text { COLETA }}{=}$ DIREITO ESQUERDO 


$\begin{array}{llll}\text { D1 } & 1 & 0.28868 & 0.00000 \\ \text { D2 } & 2 & 0.00000 & 0.00000 \\ \text { D3 } & 3 & 0.00000 & 0.00000 \\ \text { D4 } & 4 & 0.00000 & 0.00000 \\ \text { D5 } & 5 & 0.00000 & 0.00000\end{array}$
FOR 5-TH COVARIATE

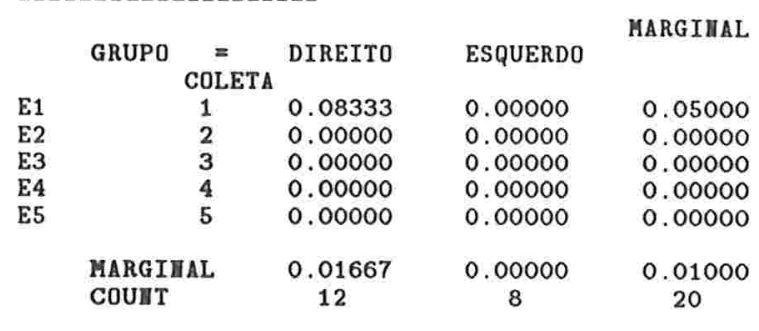

STAIDARD DEVIATIOIS FOR 5-TH COVARIATE

\begin{tabular}{|c|c|c|c|c|}
\hline & GRUPO & $\begin{array}{c}= \\
\text { COLETA }\end{array}$ & DIREITO & ESQUERDO \\
\hline E1 & & 1 & 0.28868 & 0.00000 \\
\hline E2 & & 2 & 0.00000 & 0.00000 \\
\hline E3 & & 3 & 0.00000 & 0.00000 \\
\hline E4 & & 4 & 0.00000 & 0.00000 \\
\hline E5 & & 5 & 0.00000 & 0.00000 \\
\hline
\end{tabular}

CELL MEAHS

FOR 1-ST DEPENDENT VARIABLE

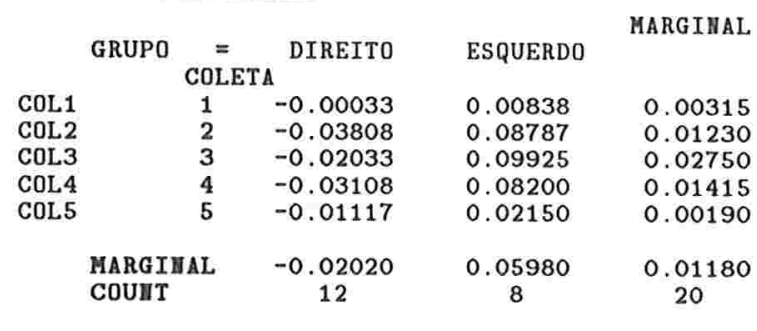

STAEDARD DEVIATIOHS FOR 1-ST DEPENDENT VARIABLE

$\begin{array}{lccc} & \text { GRUPO } & \text { DIREITO } & \text { ESQUERDO } \\ \text { COL1 } & \text { COLETA } & & \\ \text { COL2 } & 1 & 0.00414 & 0.01541 \\ \text { COL3 } & 2 & 0.08659 & 0.09131 \\ \text { COL4 } & 3 & 0.06657 & 0.08399 \\ \text { COL5 } & 4 & 0.09246 & 0.06787 \\ & 5 & 0.02916 & 0.04969\end{array}$

AIIALYSIS OF VARIAICE FOR 1-ST DEPENDENT VARIABLE $\begin{array}{lllll}\text { COL1 COL2 COL3 } & \text { COL4 COL5 }\end{array}$

\begin{tabular}{lrrrrl} 
SOURCE & SUM OF & D.F. & \multicolumn{1}{c}{ MEAI } & \multicolumn{1}{l}{ F } & \multicolumn{1}{l}{ TAIL } \\
SQUARES & & \multicolumn{1}{l}{ SQUARE } & & \multicolumn{1}{l}{ PROB. } \\
GRUPO & 0.16453 & 1 & 0.16453 & 12.71 & 0.0031 \\
1-ST COVAR & 0.00625 & 1 & 0.00625 & 0.48 & 0.4985 \\
2-HD COVAR & 0.00000 & 0 & 0.00000 & 0.00 & 1.0000 \\
3-RD COVAR & 0.03418 & 1 & 0.03418 & 2.64 & 0.1265 \\
4-TH COVAR & 0.00743 & 1 & 0.00743 & 0.57 & 0.4611
\end{tabular}




$\begin{array}{lrrrrr}\text { 5-TH COVAR } & 0.00864 & 1 & 0.00864 & 0.67 & 0.4276 \\ \text { ALL COVARIATES } & 0.05671 & 4 & 0.01418 & 1.10 & 0.3969 \\ 1 \text { ERROR } & 0.18124 & 14 & 0.01295 & & \\ \text { COLETA } & 0.01365 & 4 & 0.00341 & 1.61 & 0.1811 \\ \text { CG } & 0.06102 & 4 & 0.01525 & 7.21 & 0.0001 \\ \text { 1-ST COVAR } & 0.00133 & 1 & 0.00133 & 0.63 & 0.4313 \\ \text { 2-ID COVAR } & 0.00003 & 1 & 0.00003 & 0.01 & 0.9030 \\ \text { 3-RD COVAR } & 0.00845 & 1 & 0.00845 & 4.00 & 0.0497 \\ \text { 4-TH COVAR } & 0.00190 & 1 & 0.00190 & 0.90 & 0.3460 \\ \text { 5-TH COVAR } & 0.00211 & 1 & 0.00211 & 1.00 & 0.3212 \\ \text { ALL COVARIATES } & 0.01410 & 5 & 0.00282 & 1.33 & 0.2608 \\ 2 \text { ERROR } & 0.14168 & 67 & 0.00211 & & \end{array}$

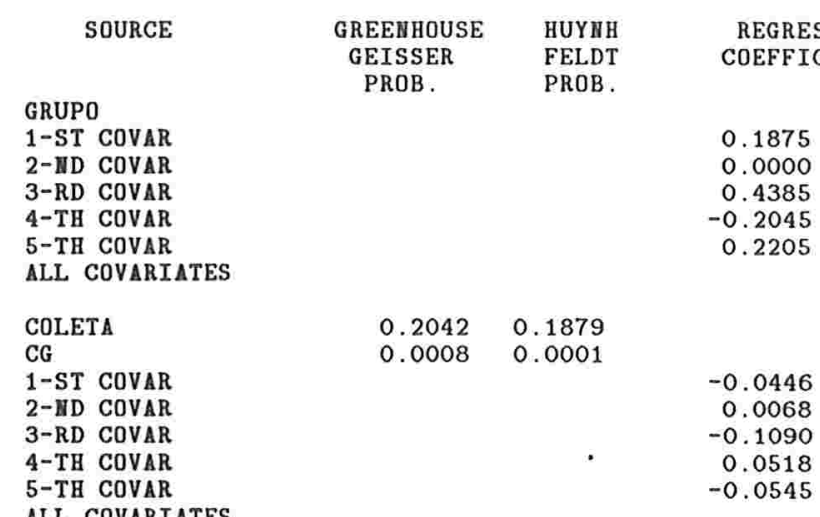
EPSILOH FACTORS FOR DEGREES OF FREEDOM ADJUSTMENT
GREENHOUSE-GEISSER HUYNH-FELDT
$\begin{array}{lr}0.6581 & 0.8968\end{array}$

2

* zero degreEs of freEdom indicate that the covariate did hot pass THE TOLERANCE CHECK DUE TO MULTICOLLINEARITY

* Essa observacao diz respeito 'a primeira parte da ANOVA.

- Informacao nao utilizada na analise.

$\begin{array}{lr}\text { 1-ST COVARIATE } & -0.03400 \\ \text { 2-ID COVARIATE } & 0.01532 \\ \text { 3-RD COVARIATE } & -0.08752 \\ \text { 4-TH COVARIATE } & 0.04170 \\ \text { 5-TH COVARIATE } & -0.04371\end{array}$

ADJUSTED CELL MEANS FOR 1-ST DEPENDENT VARIABLE

\begin{tabular}{lcrl} 
& GRUPO & \multicolumn{1}{c}{ DIREITO } & ESQUERDO \\
& COLETA & & \\
COL1 & 1 & 0.00888 & 0.00729 \\
COL2 & 2 & -0.04044 & 0.08679 \\
COL3 & 3 & -0.02142 & 0.09817 \\
COL4 & 4 & -0.03217 & 0.08092 \\
COL5 & 5 & -0.01225 & 0.02042
\end{tabular}

HUMBER OF INTEGER YORDS USED IN PRECEDIHG

PROBLEH 3608
* Utilizar os testes corrigidos por "epsilon" (interacao altamente significante). "

* Estimativas dos dados nao-observados sao dadas por essas estimativas dos coeficientes de regressao com sinais trocados. 
Figura B.3: Análise dos dados da Tabela 4.1 utilizando o Método de Bartlett (Programa SAS GLM

- Primeira rotina)

DATA ESTELA;

INPUT GRUPO INDIV COLETA DIFFLUXO A B C D E QQ;

CARDS;

$\begin{array}{llllllllllllllllllllllllllllll}1 & 1 & 1 & 0.000 & 0 & 0 & 0 & 0 & 0 & 1 & 1 & 2 & -0.164 & 0 & 0 & 0 & 0 & 0 & 1 & 1 & 3 & -0.078 & 0 & 0 & 0 & 0 & 0\end{array}$

$\begin{array}{lllllllllllllllllllllllllllllllllll}1 & 1 & 4 & -0.035 & 0 & 0 & 0 & 0 & 0 & 1 & 1 & 5 & -0.071 & 0 & 0 & 0 & 0 & 0 & 1 & 2 & 1 & -0.004 & 0 & 0 & 0 & 0 & 0\end{array}$

$\begin{array}{llllllllllllllllllllllllllllllllllll}1 & 2 & 2 & 0.034 & 0 & 0 & 0 & 0 & 0 & 1 & 2 & 3 & 0.000 & 0 & 0 & 0 & 0 & 0 & 1 & 2 & 4 & -0.067 & 0 & 0 & 0 & 0 & 0\end{array}$

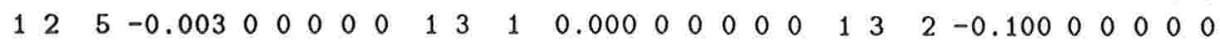

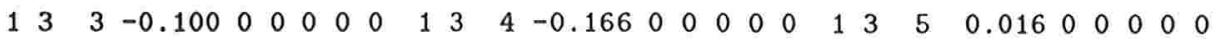

$\begin{array}{lllllllllllllllllllllllllllllllll}14 & 1 & 0 & & 1 & 0 & 0 & 0 & 0 & 1 & 4 & 2 & 0 & 0 & 1 & 0 & 0 & 0 & 1 & 4 & 3 & 0.020 & 0 & 0 & 0 & 0 & 0\end{array}$

$144 \begin{array}{llllllllllllllllllllllllllllllll}14 & 4 & 0.020 & 0 & 0 & 0 & 0 & 0 & 1 & 4 & 5 & -0.007 & 0 & 0 & 0 & 0 & 0 & 1 & 5 & 1 & -0.003 & 0 & 0 & 0 & 0 & 0\end{array}$

$\begin{array}{lllllllllllllllllllllllllllllllllll}15 & 2 & 0.070 & 0 & 0 & 0 & 0 & 0 & 1 & 5 & 3 & 0.030 & 0 & 0 & 0 & 0 & 0 & 1 & 5 & 4 & 0.170 & 0 & 0 & 0 & 0 & 0\end{array}$

$\begin{array}{lllllllllllllllllllllllllll}15 & 5 & 0.033 & 0 & 0 & 0 & 0 & 0 & 1 & 6 & 1 & 0 & 0 & 0 & 1 & 0 & 0 & 1 & 6 & 2 & 0.115 & 0 & 0 & 0 & 0 & 0\end{array}$

$\begin{array}{lllllllllllllllllllllllllllll}16 & 3 & 0.134 & 0 & 0 & 0 & 0 & 0 & 1 & 6 & 4 & 0.023 & 0 & 0 & 0 & 0 & 0 & 1 & 6 & 5 & 0.012 & 0 & 0 & 0 & 0 & 0\end{array}$

$\begin{array}{lllllllllllllllllllllllllllllllllll}17 & 1 & 0 & & 0 & 0 & 0 & 1 & 0 & 1 & 7 & 2 & -0.170 & 0 & 0 & 0 & 0 & 0 & 1 & 7 & 3 & -0.104 & 0 & 0 & 0 & 0 & 0\end{array}$

$\begin{array}{lllllllllllllllllllllllllllllllllll}17 & 4 & -0.067 & 0 & 0 & 0 & 0 & 0 & 1 & 7 & 5 & -0.018 & 0 & 0 & 0 & 0 & 0 & 1 & 8 & 1 & 0.008 & 0 & 0 & 0 & 0 & 0\end{array}$

$\begin{array}{lllllllllllllllllllllllllllllllll}18 & 2 & -0.066 & 0 & 0 & 0 & 0 & 0 & 1 & 8 & 3 & -0.033 & 0 & 0 & 0 & 0 & 0 & 1 & 8 & 4 & -0.100 & 0 & 0 & 0 & 0 & 0\end{array}$

$\begin{array}{llllllllllllllllllllllllllll}1 & 8 & 5 & -0.020 & 0 & 0 & 0 & 0 & 0 & 1 & 9 & 1 & 0 & 0 & 0 & 0 & 0 & 1 & 1 & 9 & 2 & 0.000 & 0 & 0 & 0 & 0 & 0\end{array}$

$\begin{array}{lllllllllllllllllllllllllllllll}19 & 3 & 0.000 & 0 & 0 & 0 & 0 & 0 & 1 & 9 & 4 & 0.066 & 0 & 0 & 0 & 0 & 0 & 1 & 9 & 5 & 0.000 & 0 & 0 & 0 & 0 & 0\end{array}$

$\begin{array}{llllllllllllllllllllllllllllllll}1 & 10 & 1 & -0.004 & 0 & 0 & 0 & 0 & 0 & 1 & 10 & 2 & -0.063 & 0 & 0 & 0 & 0 & 0 & 1 & 10 & 3 & -0.063 & 0 & 0 & 0 & 0 & 0\end{array}$

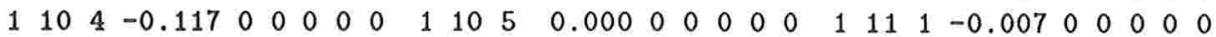

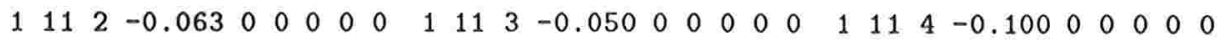

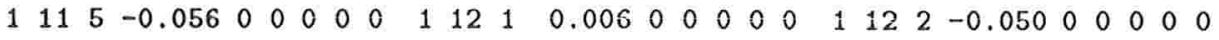

$\begin{array}{llllllllllllllllllllllllllllllllll}1 & 12 & 3 & 0.000 & 0 & 0 & 0 & 0 & 0 & 1 & 12 & 4 & 0.000 & 0 & 0 & 0 & 0 & 0 & 1 & 12 & 5 & -0.020 & 0 & 0 & 0 & 0 & 0\end{array}$

$\begin{array}{lllllllllllllllllllllllllllllllll}2 & 1 & 1 & 0.005 & 0 & 0 & 0 & 0 & 0 & 2 & 1 & 2 & 0.117 & 0 & 0 & 0 & 0 & 0 & 2 & 1 & 3 & 0.163 & 0 & 0 & 0 & 0 & 0\end{array}$

$\begin{array}{llllllllllllllllllllllllllllllllllll}2 & 1 & 4 & 0.100 & 0 & 0 & 0 & 0 & 0 & 2 & 1 & 5 & 0.000 & 0 & 0 & 0 & 0 & 0 & 2 & 2 & 1 & 0.043 & 0 & 0 & 0 & 0 & 0\end{array}$

$\begin{array}{lllllllllllllllllllllllllllllllll}2 & 2 & 2 & 0.267 & 0 & 0 & 0 & 0 & 0 & 2 & 2 & 3 & 0.234 & 0 & 0 & 0 & 0 & 0 & 2 & 2 & 4 & 0.200 & 0 & 0 & 0 & 0 & 0\end{array}$

$\begin{array}{lllllllllllllllllllllllllllll}2 & 2 & 5 & 0.123 & 0 & 0 & 0 & 0 & 0 & 2 & 3 & 1 & 0.005 & 0 & 0 & 0 & 0 & 0 & 2 & 3 & 2 & 0.034 & 0 & 0 & 0 & 0 & 0\end{array}$

$\begin{array}{lllllllllllllllllllllllllllllll}2 & 3 & 3 & 0.077 & 0 & 0 & 0 & 0 & 0 & 2 & 3 & 4 & 0.078 & 0 & 0 & 0 & 0 & 0 & 2 & 3 & 5 & 0.050 & 0 & 0 & 0 & 0 & 0\end{array}$

$\begin{array}{lllllllllllllllllllllllllllllllll}2 & 4 & 1 & 0.000 & 0 & 0 & 0 & 0 & 0 & 2 & 4 & 2 & 0.033 & 0 & 0 & 0 & 0 & 0 & 2 & 4 & 3 & 0.033 & 0 & 0 & 0 & 0 & 0\end{array}$

$\begin{array}{lllllllllllllllllllllllllllllllll}24 & 4 & 0.007 & 0 & 0 & 0 & 0 & 0 & 2 & 4 & 5 & -0.050 & 0 & 0 & 0 & 0 & 0 & 2 & 5 & 1 & 0.003 & 0 & 0 & 0 & 0 & 0\end{array}$

$\begin{array}{llllllllllllllllllllllllllllll}2 & 5 & 2 & 0.030 & 0 & 0 & 0 & 0 & 0 & 2 & 5 & 3 & 0.070 & 0 & 0 & 0 & 0 & 0 & 2 & 5 & 4 & 0.054 & 0 & 0 & 0 & 0 & 0\end{array}$

$\begin{array}{lllllllllllllllllllllllllllllll}25 & 5 & 0.020 & 0 & 0 & 0 & 0 & 0 & 2 & 6 & 1 & 0.017 & 0 & 0 & 0 & 0 & 0 & 2 & 6 & 2 & 0.066 & 0 & 0 & 0 & 0 & 0\end{array}$

$\begin{array}{lllllllllllllllllllllllllllll}26 & 3 & 0.033 & 0 & 0 & 0 & 0 & 0 & 2 & 6 & 4 & 0.067 & 0 & 0 & 0 & 0 & 0 & 2 & 6 & 5 & 0.014 & 0 & 0 & 0 & 0 & 0\end{array}$

$\begin{array}{lllllllllllllllllllllllllllllll}27 & 1 & -0.001 & 0 & 0 & 0 & 0 & 0 & 2 & 7 & 2 & -0.010 & 0 & 0 & 0 & 0 & 0 & 2 & 7 & 3 & 0.000 & 0 & 0 & 0 & 0 & 0\end{array}$

$\begin{array}{lllllllllllllllllllllllllllll}27 & 4 & 0.000 & 0 & 0 & 0 & 0 & 0 & 27 & 5 & 5 & -0.001 & 0 & 0 & 0 & 0 & 0 & 2 & 8 & 1 & -0.005 & 0 & 0 & 0 & 0 & 0\end{array}$

$\begin{array}{lllllllllllllllllllllllllllll}28 & 2 & 0.166 & 0 & 0 & 0 & 0 & 0 & 2 & 8 & 3 & 0.184 & 0 & 0 & 0 & 0 & 0 & 2 & 8 & 4 & 0.150 & 0 & 0 & 0 & 0 & 0\end{array}$

$\begin{array}{lllllllllll}2 & 8 & 5 & 0.016 & 0 & 0 & 0 & 0 & 0\end{array}$

;

PROC GLM;

CLASS GRUPO INDIV COLETA;

MODEL DIFFLUXO=GRUPO INDIV(GRUPO) COLETA COLETA*GRUPO A B C D E /

SS3 SOLUTION;

RANDOM INDIV(GRUPO);

RUN ; 
Figura B.4: Análise dos dados da Tabela 4.1 utilizando o Método de Bartlett (Saída do programa da Figura B.3)

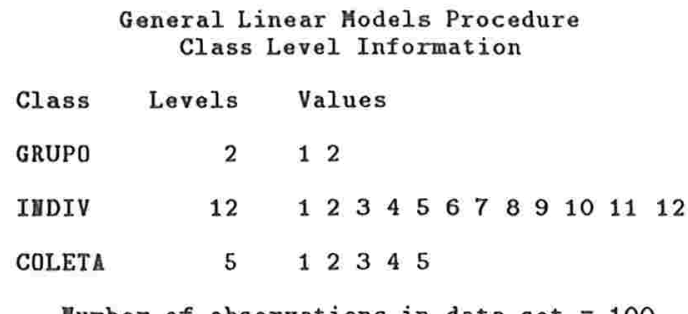

General Linear Models Procedure

Dependent Variable: DIFFLUXO

$\begin{array}{lrrrrr}\text { Source } & \text { DF } & \begin{array}{r}\text { Sum of } \\ \text { Squares }\end{array} & \begin{array}{r}\text { Mean } \\ \text { Square }\end{array} & \text { F Value } & \text { Pr }>\text { F } \\ \text { Model } & 32 & 0.47221703 & 0.01475678 & 6.98 & 0.0001 \\ \text { Error } & 67 & 0.14168097 & 0.00211464 & & \\ \text { Corrected Total } & 99 & 0.61389800 & & \\ & \text { R-Square } & \text { C.V. } & \text { Root HSE } & \text { DIFFLUXO Hean } \\ & 0.769211 & 389.7053 & 0.045985 & 0.01180000\end{array}$

General Linear Models Procedure

Dependent Variable: DIFFLUXO

\begin{tabular}{|c|c|c|c|c|c|c|}
\hline Source & DF & Type III SS & Mean Square & F Value & $\operatorname{Pr}>\mathrm{F}$ & \\
\hline GRUPO & 1 & 0.13536108 & 0.13536108 & 64.01 & 0.0001 & \\
\hline IHDIV (GRUPO) & 18 & 0.25046925 & 0.01391496 & 6.58 & 0.0001 & \\
\hline COLETA & 4 & 0.01364752 & 0.00341188 & 1.61 & 0.1811 & * Considerar somente os testes \\
\hline GRUP0 * COLETA & 4 & 0.06101543 & 0.01525386 & 7.21 & 0.00011 & associados aos efeitos intra- \\
\hline A & 1 & 0.00132583 & 0.00132583 & 0.63 & 0.4313 & individuos. \\
\hline B & 1 & 0.00003168 & 0.00003168 & 0.01 & 0.9030 & \\
\hline C & 1 & 0.00844871 & 0.00844871 & 4.00 & 0.0497 & \\
\hline D & 1 & 0.00190440 & 0.00190440 & 0.90 & 0.3460 & \\
\hline E & 1 & 0.00211218 & 0.00211218 & 1.00 & 0.3212 & \\
\hline
\end{tabular}

General Linear Models Procedure

Dependent Variable: DIFFLUXO

\begin{tabular}{|c|c|c|c|c|c|}
\hline \multicolumn{2}{|l|}{ Parameter } & Estimate & $\begin{array}{l}\mathrm{T} \text { for } \mathrm{HO}: \\
\text { Parameter }=0\end{array}$ & $\operatorname{Pr}>|\mathrm{T}|$ & $\begin{array}{c}\text { Std Error of } \\
\text { Estimate }\end{array}$ \\
\hline \multicolumn{2}{|l|}{ IHTERCEPT } & $0.0639000000 \mathrm{~B}$ & 2.54 & 0.0135 & 0.02518715 \\
\hline \multirow[t]{2}{*}{ GRUPO } & 1 & $-.0701585859 \mathrm{~B}$ & -2.02 & 0.0472 & 0.03469924 \\
\hline & 2 & $0.0000000000 \mathrm{~B}$ & & & \\
\hline \multirow[t]{4}{*}{ INDIV (GRUPO) } & 11 & $-.0568000000 \mathrm{~B}$ & -1.95 & 0.0550 & 0.02908361 \\
\hline & 21 & $0.0048000000 \mathrm{~B}$ & 0.17 & 0.8694 & 0.02908361 \\
\hline & 31 & $-.0572000000 \mathrm{~B}$ & -1.97 & 0.0534 & 0.02908361 \\
\hline & 41 & $0.0269530303 \mathrm{~B}$ & 0.79 & 0.4309 & 0.03401537 \\
\hline
\end{tabular}




\begin{tabular}{|c|c|c|c|c|c|}
\hline & 51 & $0.0728000000 \mathrm{~B}$ & 2.50 & 0.0148 & 0.02908361 \\
\hline & 61 & $0.0914000000 \mathrm{~B}$ & 2.94 & 0.0045 & 0.03106131 \\
\hline & 71 & $-.0693500000 \mathrm{~B}$ & -2.23 & 0.0289 & 0.03106131 \\
\hline & 81 & $-.0294000000 \mathrm{~B}$ & -1.01 & 0.3157 & 0.02908361 \\
\hline & 91 & $0.0369000000 \mathrm{~B}$ & 1.19 & 0.2390 & 0.03106131 \\
\hline & 101 & $-.0366000000 \mathrm{~B}$ & -1.26 & 0.2126 & 0.02908361 \\
\hline & 111 & $-.0424000000 \mathrm{~B}$ & -1.46 & 0.1495 & 0.02908361 \\
\hline & 121 & $0.0000000000 \mathrm{~B}$ & & & \\
\hline & 12 & $-.0252000000 \mathrm{~B}$ & -0.87 & 0.3893 & 0.02908361 \\
\hline & 22 & $0.0712000000 \mathrm{~B}$ & 2.45 & 0.0170 & 0.02908361 \\
\hline & 32 & $-.0534000000 \mathrm{~B}$ & -1.84 & 0.0708 & 0.02908361 \\
\hline & 42 & $-.0976000000 \mathrm{~B}$ & -3.36 & 0.0013 & 0.02908361 \\
\hline & 52 & $-.0668000000 \mathrm{~B}$ & -2.30 & 0.0248 & 0.02908361 \\
\hline & 62 & $-.0628000000 \mathrm{~B}$ & -2.16 & 0.0344 & 0.02908361 \\
\hline & 72 & $-.1046000000 \mathrm{~B}$ & -3.60 & 0.0006 & 0.02908361 \\
\hline & 82 & $0.0000000000 \mathrm{~B}$ & & & \\
\hline COLETA & 1 & $-.0131250000 \mathrm{~B}$ & -0.57 & 0.5700 & 0.02299262 \\
\hline & 2 & $0.0663750000 \mathrm{~B}$ & 2.89 & 0.0052 & 0.02299262 \\
\hline & 3 & $0.0777500000 \mathrm{~B}$ & 3.38 & 0.0012 & 0.02299262 \\
\hline & 4 & $0.0605000000 \mathrm{~B}$ & 2.63 & 0.0105 & 0.02299262 \\
\hline & 5 & $0.0000000000 \mathrm{~B}$ & . & & \\
\hline GRUPO*COLETA & 11 & $0.0369835859 \mathrm{~B}$ & 1.17 & 0.2446 & 0.03150513 \\
\hline & 12 & $-.0938573232 \mathrm{~B}$ & -3.12 & 0.0026 & 0.03004098 \\
\hline & 13 & $-.0869166667 \mathrm{~B}$ & -2.93 & 0.0047 & 0.02968334 \\
\hline & 14 & $-.0804166667 \mathrm{~B}$ & -2.71 & 0.0086 & 0.02968334 \\
\hline & 15 & $0.0000000000 \mathrm{~B}$ & . & . & . \\
\hline & 21 & $0.0000000000 \mathrm{~B}$ & . & . & 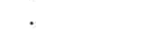 \\
\hline & 22 & $0.0000000000 \mathrm{~B}$ & . & . & . \\
\hline & 23 & $0.0000000000 \mathrm{~B}$ & . & . & . \\
\hline & & $0.0000000000 \mathrm{~B}$ & : & . & r. \\
\hline & 25 & $0.0000000000 \mathrm{~B}$ & & & \\
\hline A & & $\mid-.0445530303$ & -0.79 & 0.4313 & 0.05626682 \\
\hline B & & 0.0067878788 & 0.12 & 0.9030 & 0.05546027 \\
\hline c & & -.1090000000 & -2.00 & 0.0497 & 0.05453177 \\
\hline D & & 0.0517500000 & 0.95 & 0.3460 & 0.05453177 \\
\hline E & & -.0545000000 & -1.00 & 0.3212 & 0.05453177 \\
\hline $\begin{array}{c}\text { OTE: The } X ' X \\
\text { was use } \\
\text { letter }\end{array}$ & & $\begin{array}{l}\text { is been found } t \\
\text { the normal } \\
\text { ased, and are }\end{array}$ & $\begin{array}{l}\text { ingular } \\
\text { s. Es } \\
\text { ique es }\end{array}$ & $\begin{array}{l}\text { a gener } \\
\text { tes foll } \\
\text { tors of }\end{array}$ & $\begin{array}{l}\text { zed inverse } \\
\text { d by the } \\
\text { parameters }\end{array}$ \\
\hline & & General Linear & s Proced & & \\
\hline Source & Typ & I Expected Mean & & & \\
\hline GRUPO & Var & (or) $+4.6942 \mathrm{Var}$ & $V($ GRUPO) & Q(GRUPD & UPO $*$ COLETA) \\
\hline IIIDIV(GRUPO) & Var & (or) $+4.7222 \mathrm{Var}$ & $V$ (GRUPO) & & \\
\hline COLETA & Var & or $)+Q($ COLETA,$C$ & COLETA) & & \\
\hline GRUPO *COLETA & Var & or $)+Q($ GRUP $0 * C D$ & & & \\
\hline A & Var & or $)+Q(A)$ & & & \\
\hline B & Var & or $)+Q(B)$ & & & \\
\hline $\mathrm{c}$ & Var & $o x)+Q(C)$ & & & \\
\hline D & Var & or $)+Q(D)$ & & & \\
\hline E & Var & r) $+Q(E)$ & & & \\
\hline
\end{tabular}

* Essas estimativas nao estao compativeis com o modelo que adotamos, portanto nao possuem nenhuma interpretacao plausivel no nosso caso.

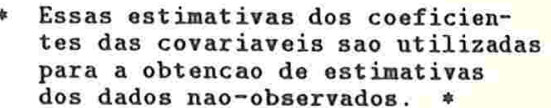


Figura B.5: Análise dos dados da Tabela 4.1 utilizando o Método de Bartlett (Programa SAS GLM - Segunda rotina)

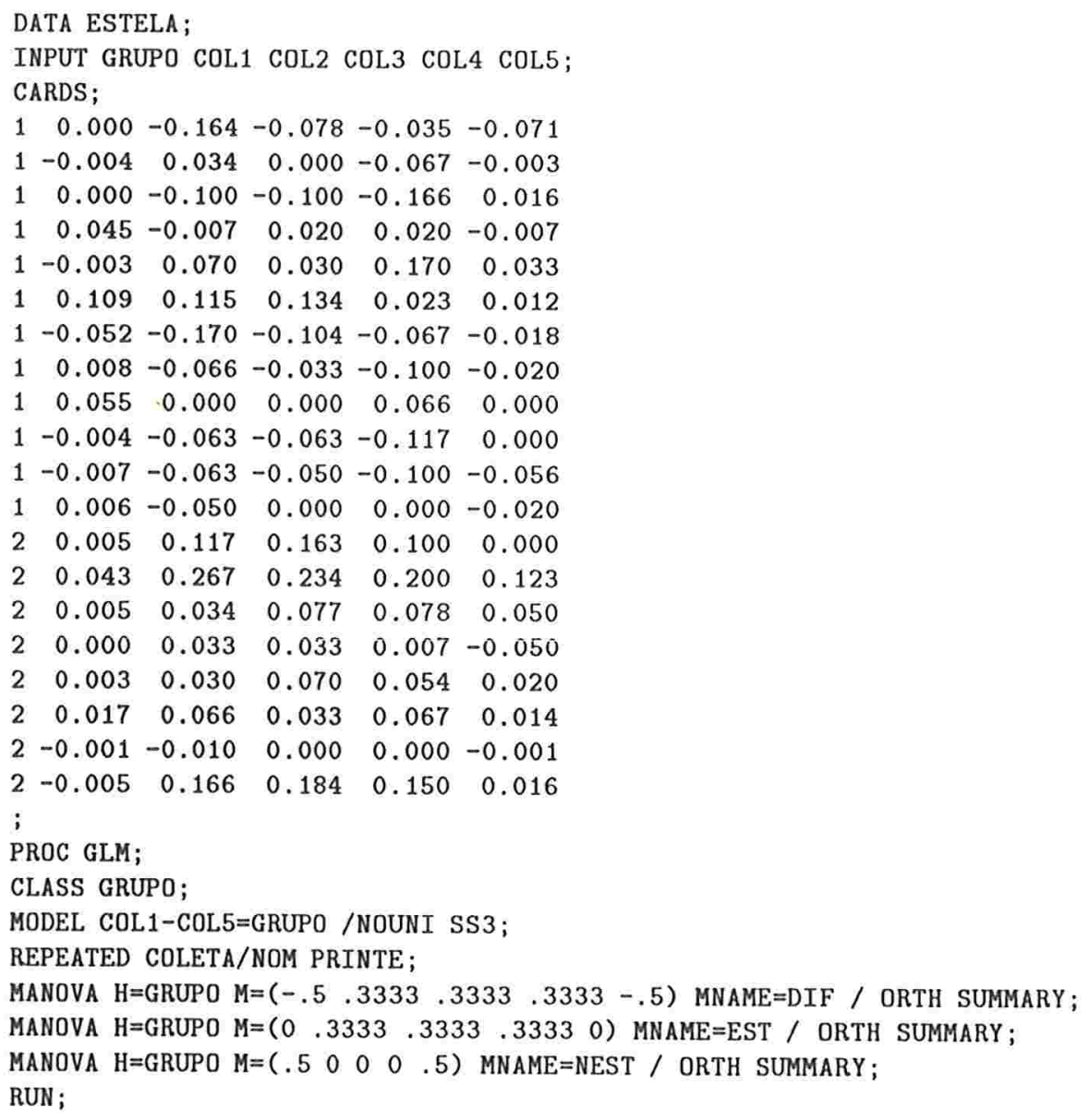


Figura B.6: Análise dos dados da Tabela 4.1 utilizando o Método de Bartlett (Saída do programa da Figura B.5)

General Linear Hodels Procedure
Class Level Information
$\begin{array}{rrrr}\text { Class } & \text { Levels } & \text { Values } \\ \text { GRUPO } & 2 & 12\end{array}$

Number of observations in data set $=20$

General Linear Models Procedure

Repeated Heasures Analysis of Variance

Repeated Measures Level Information

$\begin{array}{rrrrrr}\text { Dependent Variable } & \text { COL1 } & \text { COL2 } & \text { COL3 } & \text { COL4 } & \text { COL5 } \\ \text { Level of COLETA } & 1 & 2 & 3 & 4 & 5\end{array}$

General Linear Models Procedure

Repeated Measures Analysis of Variance

Partial Correlation Coefficients from the Error Ss\&CP Matrix / Prob > |r|

$\begin{array}{lrrrrr}\text { DF }=17 & \text { COL1 } & \text { COL2 } & \text { COL3 } & \text { COL4 } & \text { COL5 } \\ \text { COL1 } & 1.000000 & 0.634738 & 0.656291 & 0.401645 & 0.349826 \\ & 0.0 & 0.0035 & 0.0023 & 0.0883 & 0.1421 \\ \text { COL2 } & 0.634738 & 1.000000 & 0.920367 & 0.698469 & 0.644010 \\ & 0.0035 & 0.0 & 0.0001 & 0.0009 & 0.0029 \\ \text { COL3 } & 0.656291 & 0.920367 & 1.000000 & 0.725687 & 0.542191 \\ & 0.0023 & 0.0001 & 0.0 & 0.0004 & 0.0165 \\ \text { COL4 } & 0.401645 & 0.698469 & 0.725687 & 1.000000 & 0.497969 \\ & 0.0883 & 0.0009 & 0.0004 & 0.0 & 0.0300 \\ \text { COL5 } & 0.349826 & 0.644010 & 0.542191 & 0.497969 & 1.000000 \\ & 0.1421 & 0.0029 & 0.0165 & 0.0300 & 0.0\end{array}$

General Linear Models Procedure

Repeated Measures Analysis of Variance

$E=$ Error SS\&CP Matrix

COLETA.I represents the contrast between the nth level of COLETA and the last

COLETA. 1

COLETA. 2

COLETA. 3

COLETA. 4

COLETA . 1

0.0302117917

0.0125168750

0.0196715833

0.0097245833

25168750

0.0882248750

0.0675507500

0.0513650000

0.0196715833

0.0675507500
0.0513650000

0.0693311667

0.0508211667

COLETA. 4

0.0097245833

0.0508211667

0.0951589167

* Informacao nao utilizada.

General Linear Models Procedure

Repeated Measures Analysis of Variance

Partial Correlation Coefficients from the Error SS\&CP Matrix 
of the Variables Defined by the Specified Transformation / Prob > |r|

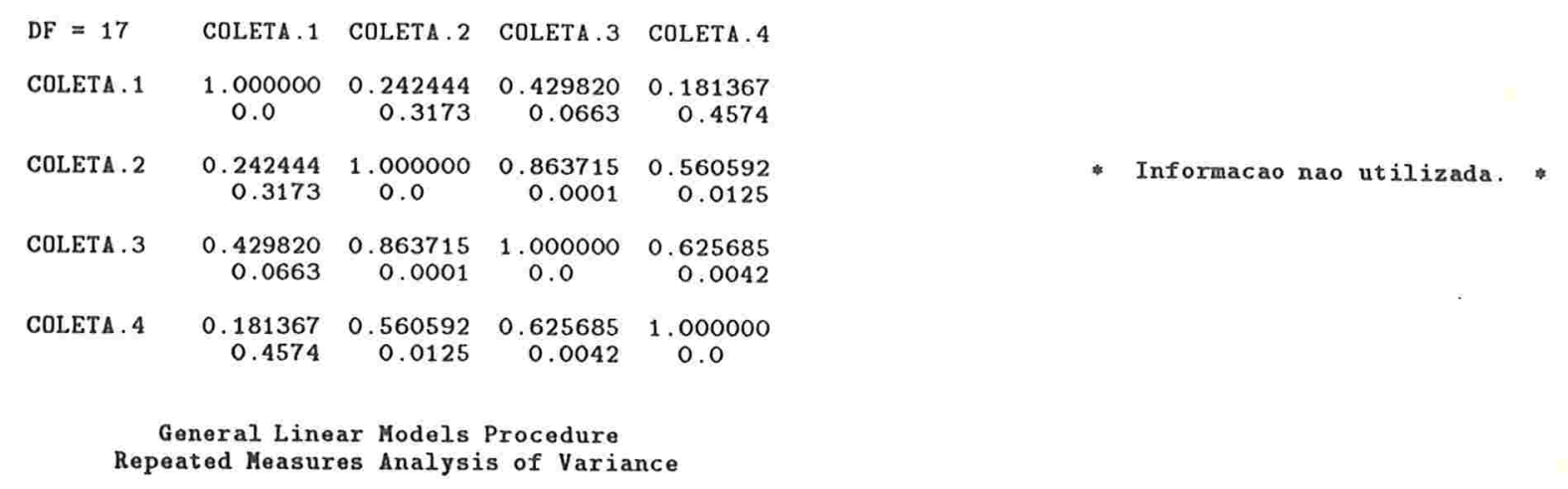

Test for Sphericity: Mauchly's Criterion $=0.0801549$

Chisquare Approximation $=41.432298$ with 9 df Prob $>$ Chisquare $=0.0000$

Applied to Orthogonal Components:
Test for Sphericity: Mauchly's Criterion $=0.2549202$

Test for Sphericity: Mauchly's Criterion $=0.2549202$
Chisquare Approximation $=22.438375$ vith 9 df Prob $>$ Chisquare $=0.0076$

* Considerar o teste de esfericidade aplicado a componentes ortogonais.

General Linear Models Procedure

Repeated Measures Analysis of Variance

Tests of Hypotheses for Betreen Subjects Effects

$\begin{array}{lrrrrrr}\text { Source } & \text { DF } & \text { Type III SS } & \text { Mean Square } & \text { F Value } & \text { Pr }>F \\ \text { GRUP0 } & 1 & 0.14415000 & 0.14415000 & 9.64 & 0.0061 \% \text { Considerar esse teste } \\ \text { Error } & 18 & 0.26924900 & 0.01495828 & & \text { para GRUP0. * * }\end{array}$

General Linear Models Procedure

Repeated Measures Analysis of Variance

Univariate Tests of Hypotheses for Uithin Subject Effects

Source: COLETA

$\begin{array}{rrrrrrr}\text { DF } & \text { Type III SS } & \text { Mean Square } & \text { F Value } & \text { Pr }>F & \text { Gdj }-\mathrm{Pr}>F \\ 4 & 0.01407744 & 0.00351936 & 1.79 & 0.1405 & 0.1681 & 0.1542\end{array}$

Source : COLETA*GRUPO

$\begin{array}{rrrrrrr}\text { DF } & \text { Type III SS } & \text { Kean Square } & \text { F Value } & \text { Pr }>F & \text { G G }-\mathrm{Gr} & \mathrm{Pr} F \\ 4 & 0.06794788 & 0.01698697 & 8.63 & 0.0001 & 0.0002 & 0.0001\end{array}$

considerar esses testes associados a comparacoes intra-individuos. *

Source: Error (COLETA)

$\begin{array}{lrr}\text { DF } & \text { Type III SS } & \text { Mean Square } \\ 72 & 0.14168142 & 0.00196780\end{array}$

Greenhouse-Geisser Epsilon $=0.6586$ Huynh-Feldt Epsilon $=0.8246$

General Linear Models Procedure

Multivariate Analysis of Variance

* Essas estimativas devem ser utilizadas para corrigir os testes associados a comparacoes intra-individuos obtidos na Figura B.4.

H Matrix Describing Transformed Variables 
General Linear Models Procedure

Multivariate Analysis of Variance

Characteristic Roots and Vectors of: E Inverse * H, there

$\mathrm{H}=$ Type III SS\&CP Matrix for GRUPO E = Error SS\&CP Matrix

Variables have been transformed by the M Matrix

Characteristic Percent Characteristic Vector V'EV $=1$
Root

0.9012657864

100.00

3.74647766

General Linear Models Procedure Multivariate Analysis of Variance

Manova Test Criteria and Exact F Statistics for the Hypothesis of no Overall GRUPO Effect

on the variables defined by the M Hatrix Transformation

H = Type III SSaCP Matrix for GRUPO E = Error SS\&CP Matrix

$$
\mathrm{S}=1 \quad \mathrm{H}=-0.5 \quad \mathrm{H}=8
$$

Statistic

Value

F

Ium DF Den DF $\mathrm{Pr}>\mathrm{F}$

Hilks' Lambda

Pillai's Trace

Hotelling-Larley Trace

0.52596539

0.47403461

16. 2228

0.90126579

16. 2228

0.90126579

16.2228

16. 2228

General Linear Models Procedure

Multivariate Analysis of Variance

Dependent Variable: DIF

$\begin{array}{lrrrrr}\text { Source } & \text { DF } & \text { Type III SS } & \text { Mean Square } & \text { F Value } & \text { Pr }>\text { F } \\ \text { GRUPO } & 1 & 0.06421058 & 0.06421058 & 16.22 & 0.0008 \\ \text { Error } & 18 & 0.07124489 & 0.00395805 & & \end{array}$

* Informacoes relacionadas a testes multivariados (nao abordados nesse trabalho).

* Informacao nao utilizada.

General Linear Models Procedure Multivariate Analysis of Variance

M Matrix Describing Transformed Variables COL1

COL2

COL3

$\operatorname{COL} 4$

COL5

EST

0

0.5773502692

0.5773502692

0.5773502692

General Linear Models Procedure Multivariate Analysis of Variance

Characteristic Roots and Vectors of: E Inverse * H, phere H = Type III SS\&CP Matrix for GRUPO E = Error SS\&CP Hatrix Variables have been transformed by the $\mathrm{N}$ Matrix 


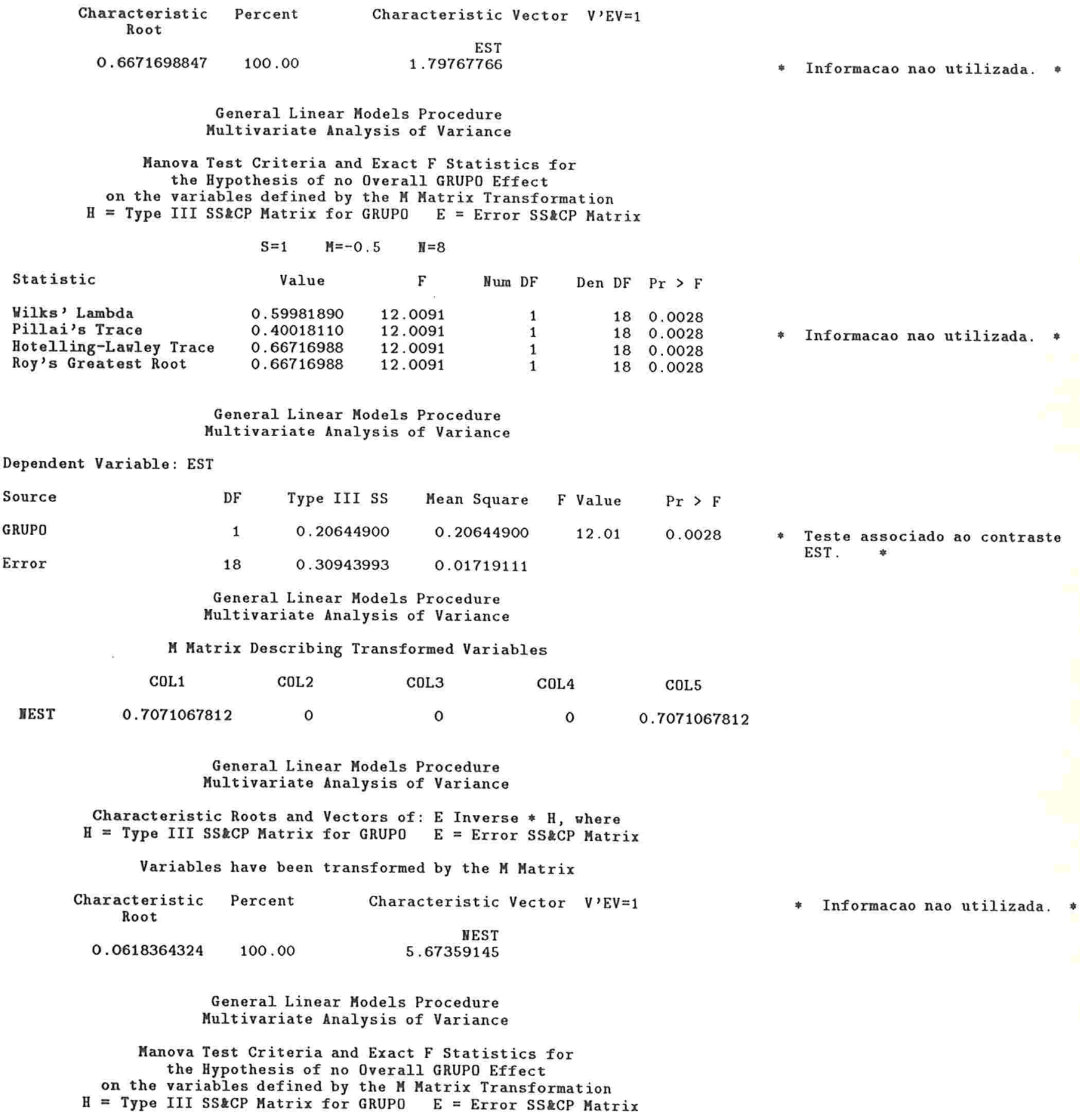




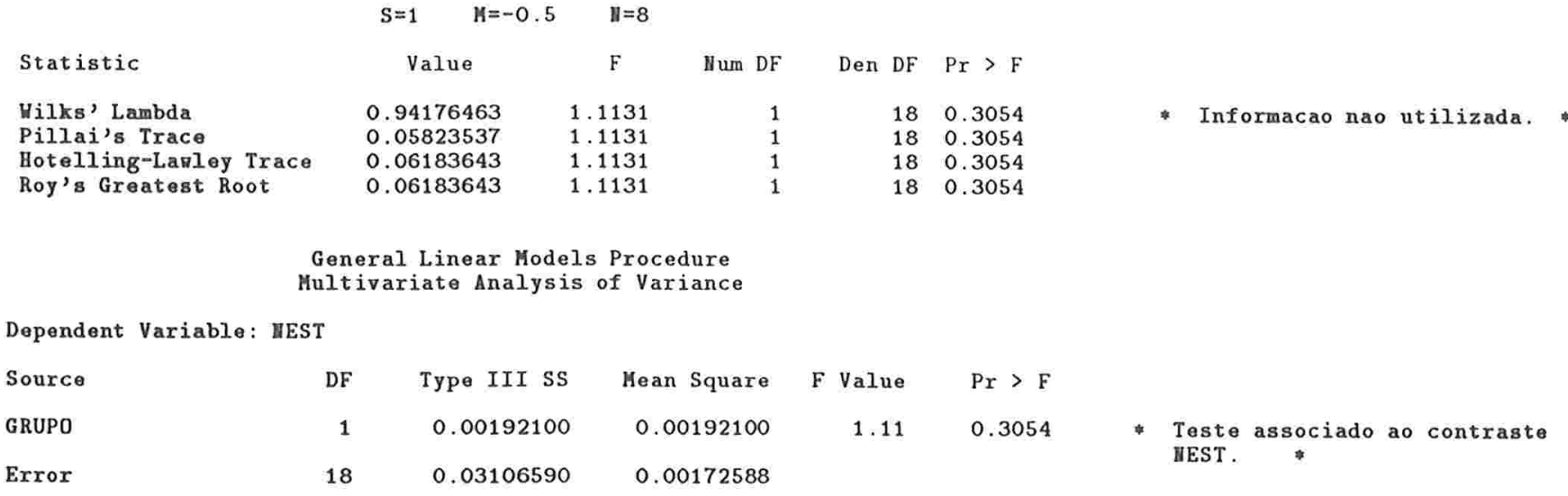


Figura B.7: Análise dos dados da Tabela 4.1 sob o enfoque de máxima verossimilhança (Programa BMDP /5V - estrutura de covariância: simetria composta)

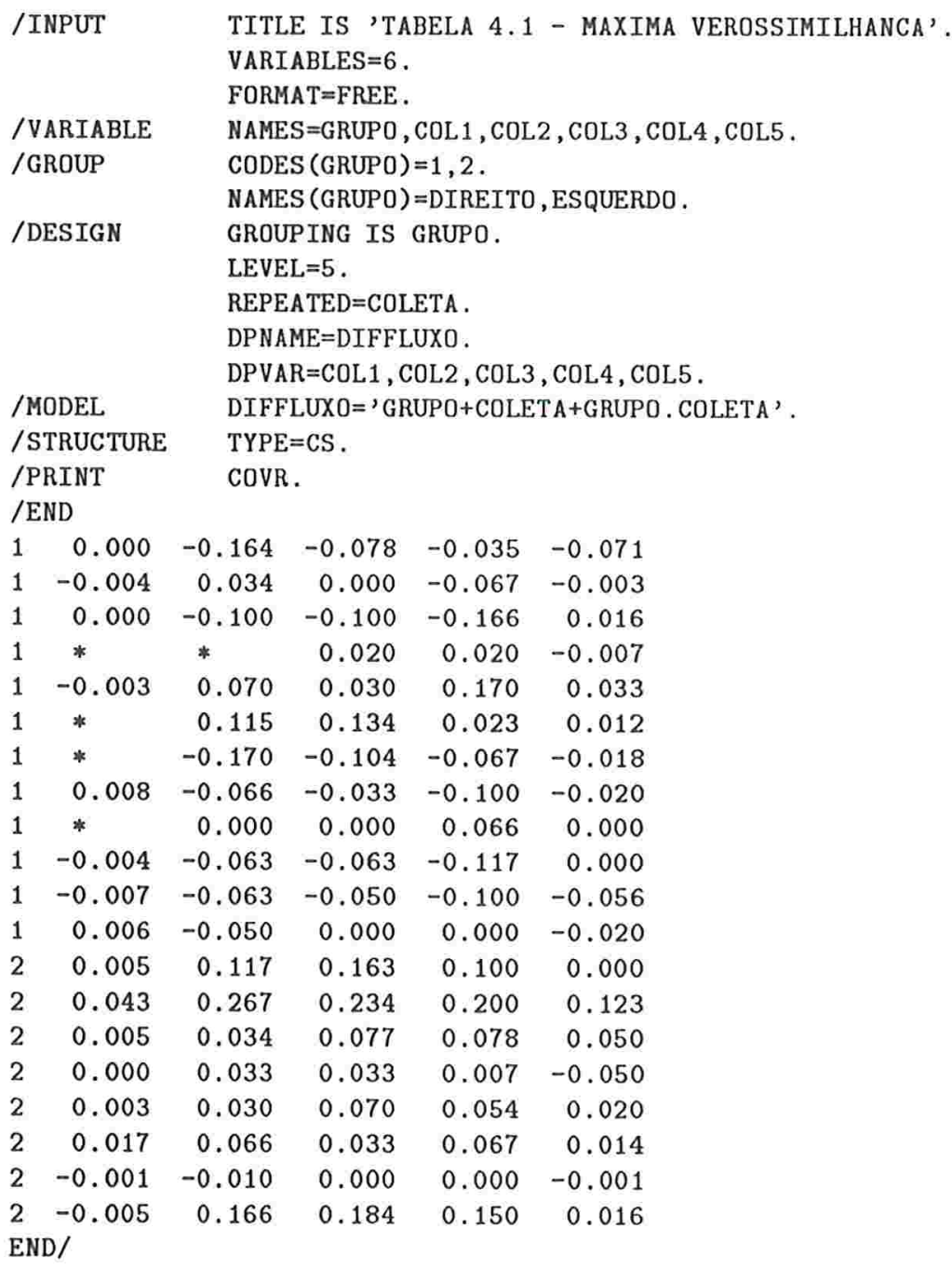

Obs: Esse programa foi rodado para cada uma das estruturas de covariância consideradas, alterando-se o parágrafo /STRUCTURE (TYPE $=\langle$ CS, AR 1 , UNSTRUC, BANDED $\rangle)$. 
Figura B.8: Análise dos dados da Tabela 4.1 sob o enfoque de máxima verossimilhança (Saídas dos programas da Figura B.7)

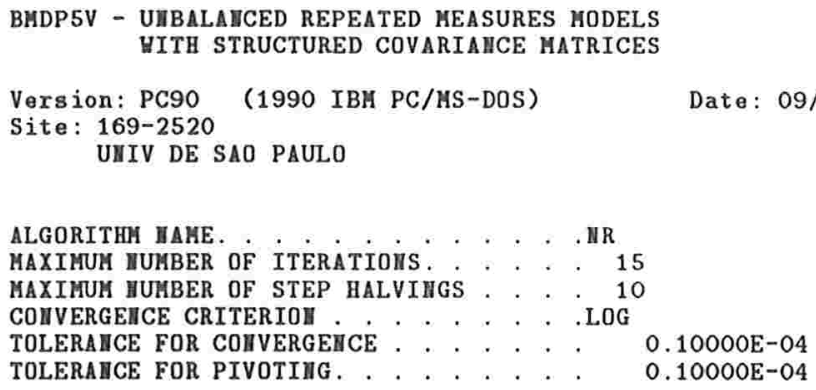


STRUCTURES AED SELECTIIG THE ONE WITH MAXIMUM AIC VALUE.

AIC

142.086

ESTIMATES OF COVARIAHCE PARAMETERS:

WITHII-SUBJECT COVARIANCE MATRIX IS A FUHCTIOH

OF COVARIAICE PARAMETERS. 5V PROVIDES SEVERAL

BUILT-II STRUCTURES YOU CAI CHOOSE FROM BY

SPECIFYING THE TYPE II THE STRUCTURE PARAGRAPH

COV. STRUCTURE TYPE=COMPOUND SYMMETRY

UIDER THIS MODEL, THE RESPONSES HAVE A

VARIAICE $=$ COV PAR $1+$ COV PAR 2

COMMOII COVARIANCE $=$ COV PAR 2

\begin{tabular}{cccc} 
COV PAR & ESTIMATE & ASYMPTOTIC SE & Z-SCORE \\
\hline 1 & .001890 & $3087 \mathrm{E}-7$ & 6.124 \\
2 & .002274 & $8490 \mathrm{E}-7$ & 2.678
\end{tabular}

MODEL: VITHIE-SUBJECT COVARIAHCE MATRIX
10.0041641
2
5
$2 \quad 0.0022738 \quad 0.0041641$
$\begin{array}{llll}3 & 0.0022738 & 0.0022738 & 0.0041641\end{array}$
$\begin{array}{lllll}4 & 0.0022738 & 0.0022738 & 0.0022738 & 0.0041641\end{array}$
$\begin{array}{llllll}5 & 0.0022738 & 0.0022738 & 0.0022738 & 0.0022738 & 0.0041641\end{array}$

ALL-PAIRS WITHIN-SUBJECT COVARIANCE MATRIX

$\begin{array}{rrrrrr} & 1 & 2 & 3 & 4 & 5 \\ 1 & 0.0001738 & & & & \\ 2 & 0.0004379 & 0.0073316 & & & \\ 3 & 0.0003738 & 0.0056162 & 0.0049068 & & \\ 4 & 0.0003913 & 0.0048071 & 0.0040393 & 0.0063142 & \\ 5 & 0.0002890 & 0.0020652 & 0.0013860 & 0.0014440 & 0.0013318\end{array}$

MODEL : HITHIN-SUBJECT CORRELATION MATRIX

$\begin{array}{rrrrrr} & 1 & 2 & 3 & 4 & 5 \\ 1 & 1.0000000 & & & & \\ 2 & 0.5460452 & 1.0000000 & & & \\ 3 & 0.5460452 & 0.5460452 & 1.0000000 & & \\ 4 & 0.5460452 & 0.5460452 & 0.5460452 & 1.0000000 & \\ 5 & 0.5460452 & 0.5460452 & 0.5460452 & 0.5460452 & 1.0000000\end{array}$

ALL-PAIRS UITHIH-SUBJECT CORRELATION MATRIX

$\begin{array}{rrrrrr} & 1 & 2 & 3 & 4 & 5 \\ 1 & 1.0000000 & & & & \\ 2 & 0.3878335 & 1.0000000 & & & \\ 3 & 0.4047716 & 0.9363618 & 1.0000000 & & \\ 4 & 0.3734608 & 0.7065228 & 0.7256871 & 1.0000000 & \\ 5 & 0.6005795 & 0.6609308 & 0.5421908 & 0.4979689 & 1.0000000\end{array}$

ESTIMATES OF REGRESSION PARAMETERS:

II THE TABLE BELOY EACH FIXED EFFECT PART OF THE MODEL IS DECOMPOSED IETO SIIGLE DEGREE OF FREEDOH REGRESSION TERHS AHD COVARIATES 


\begin{tabular}{rlrrrr} 
PARAMETER & ESTIMATE & ASYHPTOTIC SE & $\begin{array}{r}\text { Z- } \\
\text { SCORE }\end{array}$ & $\begin{array}{c}\text { TUO-SIDED } \\
\text { P-VALUE }\end{array}$ \\
\hline 1 & COIST. & 0.02074 & 0.01180 & 1.757 & 0.0789 \\
2 & GRUP01 & -0.03906 & 0.01180 & -3.309 & 0.0009 \\
3 & COLETA1 & -0.01141 & 0.00969 & -1.177 & 0.2392 \\
4 & COLETA2 & 0.00356 & 0.00907 & 0.392 & 0.6951 \\
5 & COLETA3 & 0.01872 & 0.00894 & 2.093 & 0.0364 \\
6 & COLETA4 & 0.00472 & 0.00894 & 0.527 & 0.5980 \\
7 & G1.C1 & 0.04001 & 0.00969 & 4.128 & 0.0000 \\
8 & G1.C2 & -0.02452 & 0.00907 & -2.703 & 0.0069 \\
9 & G1.C3 & -0.02073 & 0.00894 & -2.319 & 0.0204 \\
10 & G1.C4 & -0.01748 & 0.00894 & -1.955 & 0.0506
\end{tabular}

WALD TESTS OF SIGHIFICANCE OF

FIXED EFFECTS AID COVARIATES

\begin{tabular}{lcrc} 
TEST & DF & CHI-SQUARE & P-VALUE \\
\hline GRUPO & 1 & 10.95 & 0.001 \\
COLETA & 4 & 7.43 & 0.115 \\
G.C & 4 & 31.68 & 0.000
\end{tabular}

COVARIAICE KATRIX FOR ESTIMATES OF THE REGRESSION PARAMETERS (FROM IIIVERSE EXPECTED IHFORMATIOH MATRIX)

\begin{tabular}{|c|c|c|c|c|c|c|}
\hline 1 & $\begin{array}{c}1 \\
0.0001393\end{array}$ & 2 & 3 & 4 & 5 & 6 \\
\hline 2 & -0.0000264 & 0.0001393 & & & & \\
\hline 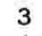 & 0.0000038 & 0.0000038 & 0.0000940 & & & \\
\hline 4 & -0.0000001 & -0.0000001 & -0.0000236 & 0.0000823 & & \\
\hline 5 & -0.0000012 & -0.0000012 & -0.0000235 & -0.0000196 & 0.0000800 & \\
\hline & -0.0000012 & -0.0000012 & -0.0000235 & -0.0000196 & -0.0000185 & 0.0000800 \\
\hline 7 & 0.0000038 & 0.0000038 & -0.0000005 & 0.0000000 & 0.0000002 & 0.0000002 \\
\hline 8 & -0.0000001 & -0.0000001 & 0.0000000 & -0.0000122 & 0.0000041 & 0.0000041 \\
\hline & -0.0000012 & -0.0000012 & 0.0000002 & 0.0000041 & -0.0000145 & 0.0000052 \\
\hline 10 & -0.0000012 & -0.0000012 & 0.0000002 & 0.0000041 & 0.0000052 & -0.0000145 \\
\hline 7 & $\begin{array}{c}{ }^{7} \\
0.00000940\end{array}$ & 8 & 9 & 10 & & \\
\hline 8 & -0.0000236 & 0.0000823 & & & & \\
\hline 9 & -0.0000235 & -0.0000196 & 0.0000800 & & & \\
\hline 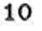 & -0.0000235 & -0.0000196 & 0.0000185 & .0000800 & & \\
\hline
\end{tabular}

MUMBER OF IIITEGER WORDS USED III PRECEDING

PROBLEM

5030 


\section{Bibliografia}

Agresti, A. (1990). Categorical data analysis. New York:John Wiley \& Sons.

Akaike, H. (1973). "Information theory and an extension of the maximum likelihood priciple". $2^{\text {nd }}$ International Symposium on Information Theory and Control, E.B.N. Petrov and F. Csaki, 267-281. Budapest:Akademia Kiado.

Anderson, T.W. (1984). An introduction to multivariate statistical analysis, $2^{\underline{a}}$ ed. New York:John Wiley \& Sons.

Andrade, D.F. e Helms, R.W. (1984). ML estimation and LR tests for the multivariate normal distribution with patterned mean and covariance matrix. Complete and incomplete-data cases. Department of Biostatistics-University of North Carolina at Chapel Hill. Institute of Statistics Mimeo Series n.1455.

Andreoni, S. (1989). Modelos de efeitos aleatórios para análise de dados longitudinais não balanceados em relação ao tempo. Dissertação de Mestrado, IME-USP, São Paulo.

Bartlett, M.S. (1937). "Some examples of statistical methods of research in agriculture and applied biology". Journal of the Royal Statistical Society, vol.4, 137-170.

Berk, K. (1987). "Computing for incomplete repeated measures". Biometrics, 43, 385-398. 
Bickel, P.J. e Doksum,, K.A. (1977). Mathematical statistics: Basic ideas and selected topics. San Francisco:Holden-Day,Inc.

Box, G.E.P. (1954). "Some theorems on quadratic forms applied in the study of analysis of variance problems, II. Effect of inequality of variance in the two-way classification". Annals of Mathematical Statistics, 25, 484-498.

Coons, I. (1957). "The analysis of covariance as a missing plot technique". Biometrics, 13, 387-405.

Crowder, M.J. e Hand, D.J. (1990). Analysis of repeated measures. London:Chapman and Hall.

Davis, A.W. (1971). "Percentile approximations for a class of likelihood radio criteria". Biometrika, $58,349-356$.

Dempster, A.P., Laird, N.M. e Rubin, D.B. (1977). "Maximum likelihood from incomplete data via the EM algorithm". Journal of the Royal Statistical Society, B39, 1-38.

Dixon, W.J., ed. (1990). BMDP Statistical Software Manual. University of California Press, Berkeley, California.

Domenech, C.H. (1989). Métodos exploratórios e uso de medidas resumo para análise de dados longitudinais. Dissertação de Mestrado, IME-USP, São Paulo.

Elandt-Johnson, R.C. e Johnson, N.L. (1980). Survival models and data analysis. New York:John Wiley \& Sons.

Geisser, S. e Greenhouse, A.W. (1958). "An extension of Box's results on the use of the $F$ distribution in multivariate analysis". Annals of Mathematical Statistics, 29, 885-891.

Goldstein, H. (1979). The design and analysis of longitudinal studies. New York:Academic Press.

Graybill, F.A. (1961). An introduction to linear statistical models, vol.1. New York:McGraw-Hill. 
raybill, F.A. (1976). Theory and application of the linear model. North Scituate:Duxbury Press.

reenhouse, S.W. e Geisser, S. (1959). "On methods in the analysis of profile data". Psychometrika, 24, $95-112$.

artley, H.O. e Hocking, R.R. (1971). "The analysis of incomplete data". Biometrics, 27, 783-808.

arville, D.A. (1977). "Maximum likelihood approaches to variance component estimation and to related problems". Journal of the American Statistical Association, 72, 320-340.

enderson, C.R. (1953). "Estimation of variance and covariance components". Biometrics, 9, 226-252. uynh, H. e Feldt, L.S. (1976). "Estimation of the Box correction for degrees of freedom from sample data in randomized block and split-plot designs". Journal of Educational Statistics, 1, 69-82.

uynh, H. e Mandeville, G.K. (1979). "Validity conditions in repeated measures designs". Psychological Bulletin, 86, 964-973.

:nnrich, R.I. e Schluchter, M.D. (1986). "Unbalanced repeated-measures models with structured covariance matrices". Biometrics, 42, 805-820.

albfleisch, J.D. e Prentice, R.L. (1980). The statistical analysis of failure time data. New York:John Wiley \& Sons.

enward, M.G. (1987). "A method for comparing profiles of repeated measurements". Applied Statistics, 36, no $3,296-308$.

res, H. (1983). Statistical tables for multivariate analysis. New York:Springer Verlag.

aird, N.M. (1988). "Missing data in longitudinal studies". Statistics in Medicine, 7, 305-315.

aird, N.M. e Ware, J.H. (1982). "Random-effects models for longitudinal data". Biometrics, 38, 963-974. 
Little, R.J.A. (1982). "Models for nonresponse in sample surveys". Journal of the American Statistical Association, 77, 237-250.

Little, R.J.A. e Rubin, D.B. (1987). Statistical analysis with missing data. New York:John Wiley \& Sons.

Losso, E.M. (1994). Avaliação do fluxo, proteina total e perfil proteico de saliva da glândula parótida direita e esquerda frente a um estímulo gustativo. Dissertação de Doutorado. Faculdade de Odontologia da Universidade de São Paulo.

Mauchly, J.W. (1940). "Significance test for sphericity of a normal n-variate distribution". Annals of Mathematical Statistics, 11, 204-209.

Morettin, P.A. e Toloi, C.M.C. (1985). Previsaio de séries temporais. São Paulo:Atual.

Morrison, D.F. (1976). Multivariate statistical methods, 2nd ed. New York:McGraw-Hill.

Muñoz, A.V.C., Schouten, J.P., Segal, M. e Rosner, B. (1992). "A parametric family of correlation structures for the analysis of longitudinal data". Biometrics, 48, 733- 742.

Nagarsenker, B.N. e Pillai, K.C.S. (1972). "The distribution of the sphericity test criterion" (ARL 720154). Wright Patterson Air Force Base, Ohio:Aerospace Research Laboratory, November (NTIS número AD-754232).

Rubin, D.B. (1972). "A non-iterative algorithm for least squares estimation of missing values in any analysis of variance design". Applied Statistics, 21, 136- 141.

Rubin, D.B. (1976). "Inference and missing data". Biometrika, 63, 581-592.

SAS Institute, Inc. (1987). SAS/STAT guide for personal computers, version 6. SAS Institute, Inc., North Carolina. 
Schluchter,M.D. (1988). "Analysis of incomplete multivariate data using linear models with structured covariance matrices". Statistics in Medicine, 7, 317-324.

Schwertman, N.C. (1978). "A note on the Geisser-Greenhouse correction for incomplete data split-plot analysis". Journal of the American Statistical Association, 73, 393-396.

Schwertman, N.C., Fridshal, D. e Magrey, J.M. (1981). "On the analysis of incomplete growth curve data: a Monte Carlo study of two nonparametric procedures". Communications in Statistics, B10, $51-66$.

Searle, S.R. (1970). "Large sample variances of maximum likelihood estimators of variance components using unbalanced data". Biometrics, 26, 505- 524.

Searle, S.R. (1987). Linear models for unbalanced data. New York:John Wiley \& Sons.

Shumway, R.H. (1988). Applied statistical time series analysis. New Jersey:Prentice Hall.

Singer, J.M. (1977). Análise de curvas de crescimento. Dissertação de Mestrado. IME-USP, São Paulo.

Singer, J.M. e Andrade, D.F. (1986). Análise de dados longitudinais. VII Simpósio Nacional de Probabilidade e Estatística, Campinas, São Paulo.

Singer, J.M. e Andrade, D.F. (1994). "On the choice of appropriate error terms in profile analysis". The Statistician, 43, 259-266.

Singer, J.M. e Mauro, E.S.R. (1987). Estudo de respostas eletrofisiológicas do nervo conectivo cérebrovisceral de Perna-Perna exposto a diferentes condições de stress osmótico. SEA RAE \#8708, IMEUSP, São Paulo.

SOC (1989). Manual do usuário (não-publicado). IME-USP. 
SPSS,Inc. (1988). SPSS/PC+ V2.0, SPSS,Inc., Chicago.

Szatrowski, T.H. (1980). "Necessary and sufficient conditions for explicit solutions in the multivariate normal estimation problem for patterned means and covariances". Annals of Statistics, 8, 802-810.

Winer, B.J. (1971). Statistical principles in experimental design, 2aㅡ ed. New York:McGraw-Hill. 